\title{
RELIABILITY ANALYSIS APPROACH FOR INTERSECTION SIGHT DISTANCE OF A SYMMETRICAL SINGLE-LANE ROUNDABOUT
}

\author{
by \\ Paria Sarshar \\ BASc, K.N.Toosi University of Technology, 2017 \\ Tehran, Iran
}

\author{
A Major Research Project \\ presented to Ryerson University \\ in partial fulfillment of the \\ requirements for the degree of \\ Master of Engineering \\ in the Program of \\ Civil Engineering
}

Toronto, Ontario, Canada, 2019

(c) Paria Sarshar, 2019 


\section{Author's Declaration for Electronic Submission of a MRP}

I hereby declare that I am the sole author of this MRP. This is a true copy of the MRP, including any required final revisions.

I authorize Ryerson University to lend this MRP to other institutions or individuals for the purpose of scholarly research.

I further authorize Ryerson University to reproduce this MRP by photocopying or by other means, in total or in part, at the request of other institutions or individuals for the purpose of scholarly research.

I understand that my MRP may be made electronically available to the public. 


\section{ABSTRACT}

Reliability Analysis Approach for Intersection Sight Distance of a Symmetrical Single-lane Roundabout

Master of Engineering, 2019

Paria Sarshar

Yeates School of Graduate Studies, Civil Engineering

Ryerson University

The current intersection sight distance values on a roundabout provided by ASSHTO and other worldwide guidelines are based on deterministic methods considering only single variables as the design inputs. However, most of the input design variables such as entering speed and the deceleration rate are random variables which are stochastic in nature. Therefore, this study proposes a reliability analysis approach to add uncertainty to the current deterministic models. Two different reliability approaches; the first order second moment and advanced first order second moment are presented in this paper. These approaches rely on the normal distribution of the random variables using the mean, variance and the covariance of the probability distribution of each variable rather than the single deterministic values. Results show that the AFOSM reliability methodology provides a more conservative outcome which ensures a greater safety margin comparing to FOSM which appears to be a more efficient and robust methodology. 


\section{AKNOWLEDGEMENTS}

I would like to first thank my supervisor Dr.Said Easa, for providing me with the topic of this major project, believing in my academic abilities, and for allowing my work to be done under his supervision and guidance while granting me the funding. I would also like to thank Dr. Sabbir for taking the time to review this major research project and providing me with beneficial feedback. Lastly, I would like to extend my appreciation to my family who supported me with an unending encouragement and love. 


\section{TABLE OF CONTENT}

Author's Declaration for Electronic Submission of a MRP .................................i

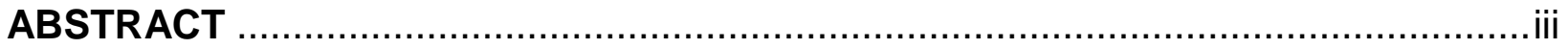

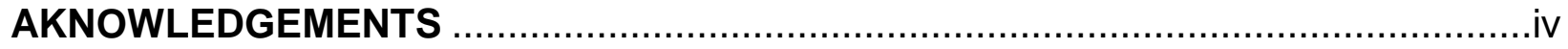

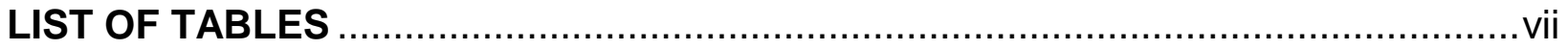

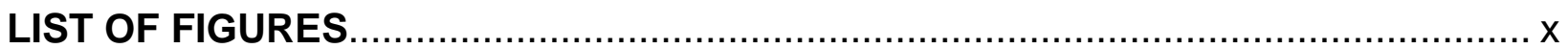

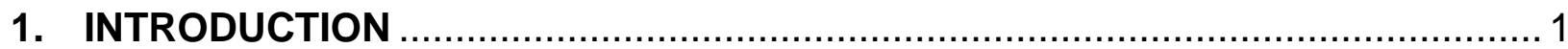

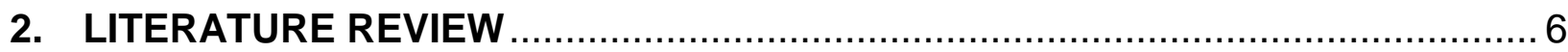

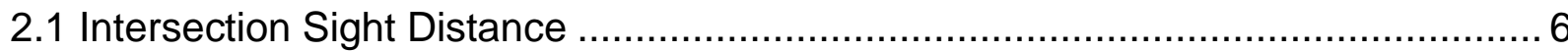

2.2 Application of Reliability Analysis in Transportation ......................................... 10

3. DETERMINISTIC INTERSECTION SIGHT DISTANCE ..................................... 12

3.1 Geometry of the Symmetrical Single-lane Roundabout ................................. 13

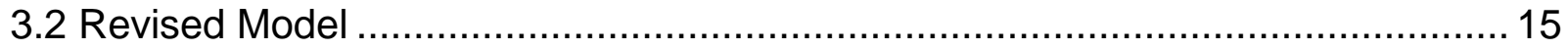

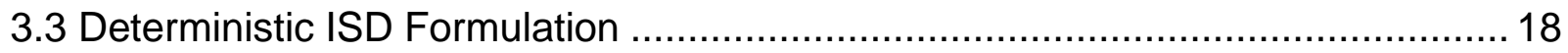

3.3.1 Case 1: Approach Vehicle at Yield Line ................................................... 18

3.3.2 Case 2: Approach Vehicle Ahead of the Yield Line ..................................... 23

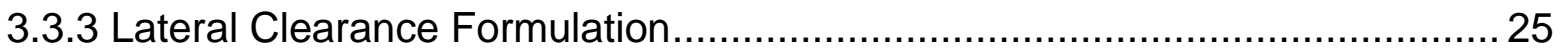

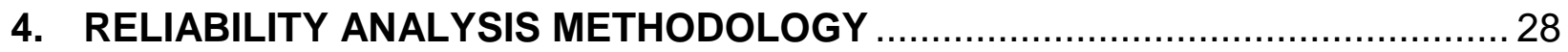


4.1 First Order Second Moment Method (FOSM) ................................................. 30

4.2 Advanced First Order Second Moment Method (AFOSM) .................................. 31

5. RELIABILITY ANALYSIS of INTERSECTION SIGHT DISTANCE ........................35

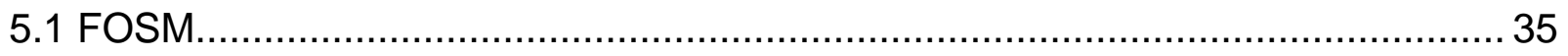

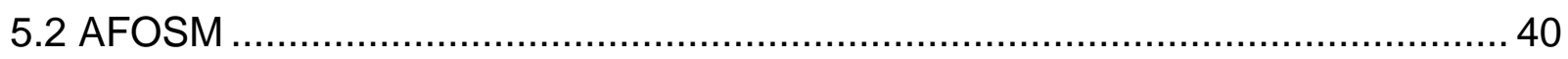

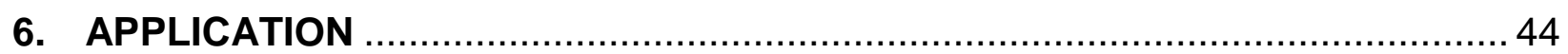

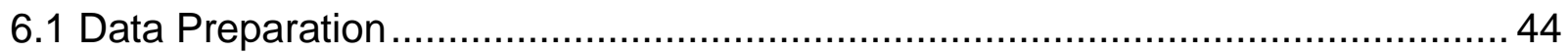

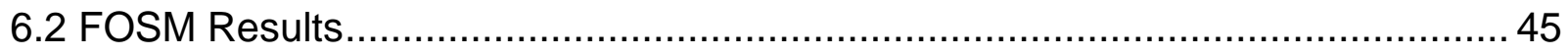

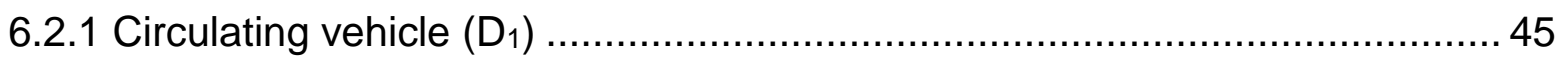

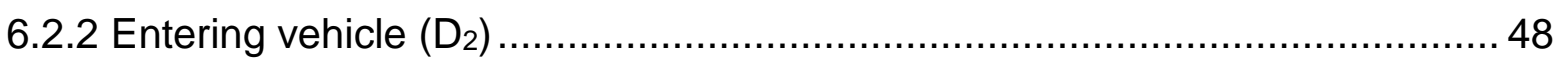

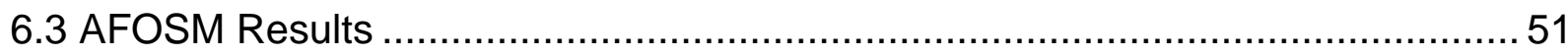

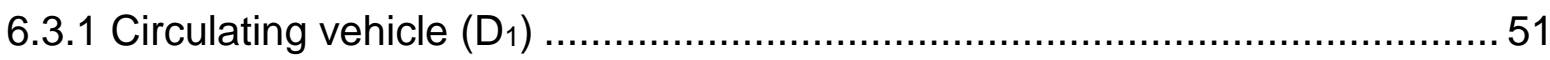

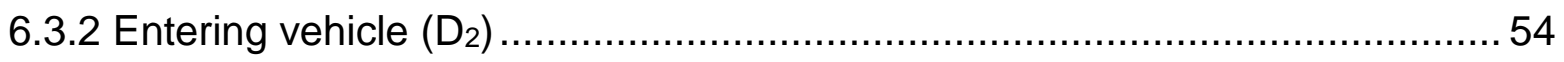

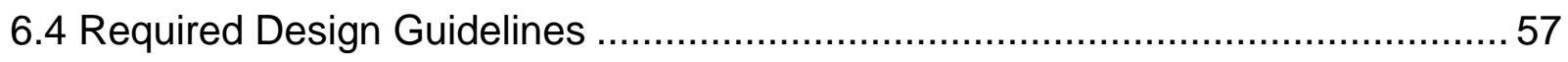

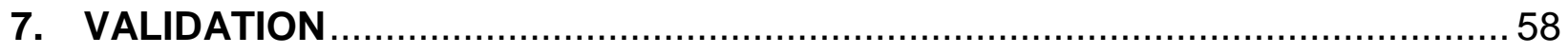

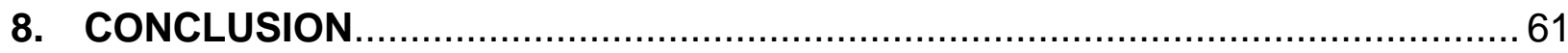

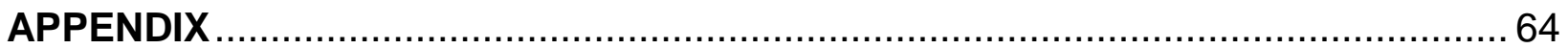

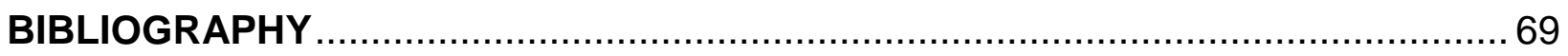




\section{LIST OF TABLES}

Table 1: ISD Requirements for Australian, United Kingdom, and USA Guidelines 9

Table 2: Length of the conflicting leg for both the circulating and entering streams in

metric and U.S. Customary scales (FHWA, 2000) 12 Table 3:The Maximum Lateral Clearance Requirements for ISD of a Circulating Vehicle (Easa, 2017) 27

Table 4: The Maximum Lateral Clearance Requirements for ISD of a Entering Vehicle (Easa, 2017) 27

Table 5: Corresponding $\beta$ values for respective probability of failure (Hussain et al., 2015)

Table 6: Literature Data, Extreme, and Mean values of Random Variables for the

Circulating Vehicle.

Table 7: Literature Data, Extreme, and Mean values of Random Variables for the Entering Vehicle

Table 8: FOSM results, Probabilistic Maximum Lateral Clearance for Circulating

Vehicle, $\mathrm{V}_{\text {cir }}=20 \mathrm{Km} / \mathrm{h}$

Table 9: FOSM results, Probabilistic Maximum Lateral Clearance for Circulating

Vehicle, $\mathrm{V}_{\text {cir }}=25 \mathrm{Km} / \mathrm{h}$

Table 10: FOSM results, Probabilistic Maximum Lateral Clearance for Circulating

Vehicle, $\mathrm{V}_{\text {cir }}=30 \mathrm{Km} / \mathrm{h}$ 46 
Table 11: FOSM results, Probabilistic Maximum Lateral Clearance for Circulating

Vehicle, $\mathrm{V}_{\text {cir }}=35 \mathrm{Km} / \mathrm{h}$

Table 12: FOSM results, Probabilistic Maximum Lateral Clearance for Circulating

Vehicle, $\mathrm{V}_{\text {cir }}=40 \mathrm{Km} / \mathrm{h}$ 47

Table 13: FOSM results, Probabilistic Maximum Lateral Clearance for Entering Vehicle,

$\mathrm{V}_{\text {cir }}=25 \mathrm{Km} / \mathrm{h}, \mathrm{V}_{\mathrm{Ent}}=30 \mathrm{Km} / \mathrm{h}$ 48

Table 14: FOSM results, Probabilistic Maximum Lateral Clearance for Entering Vehicle,

$\mathrm{V}_{\text {cir }}=25 \mathrm{Km} / \mathrm{h}, \mathrm{V}_{\text {Ent }}=35 \mathrm{Km} / \mathrm{h}$ 49

Table 15: FOSM results, Probabilistic Maximum Lateral Clearance for Entering Vehicle

$V_{\text {cir }}=25 \mathrm{Km} / \mathrm{h}, V_{\text {Ent }}=40 \mathrm{Km} / \mathrm{h}$

Table 16: FOSM results, Probabilistic Maximum Lateral Clearance for Entering Vehicle,

$\mathrm{V}_{\text {cir }}=25 \mathrm{Km} / \mathrm{h}, \mathrm{V}_{\text {Ent }}=45 \mathrm{Km} / \mathrm{h}$

Table 17: AFOSM Results, Probabilistic Maximum Lateral Clearance for Circulating

Vehicle, Vcir $=20 \mathrm{Km} / \mathrm{h}$

51

Table 18: AFOSM Results, Probabilistic Maximum Lateral Clearance for Circulating

Vehicle, $\mathrm{V}_{\text {cir }}=25 \mathrm{Km} / \mathrm{h}$.......

51

Table 19: AFOSM Results, Probabilistic Maximum Lateral Clearance for Circulating

Vehicle, $\mathrm{V}_{\text {cir }}=30 \mathrm{Km} / \mathrm{h}$

Table 20: AFOSM Results, Probabilistic Maximum Lateral Clearance for Circulating

Vehicle, $\mathrm{V}_{\text {cir }}=35 \mathrm{Km} / \mathrm{h}$

Table 21: AFOSM Results, Probabilistic Maximum Lateral Clearance for Circulating

Vehicle, $\mathrm{V}_{\text {cir }}=40 \mathrm{Km} / \mathrm{h}$ 
Table 22: AFOSM Results, Probabilistic Maximum Lateral Clearance for Entering

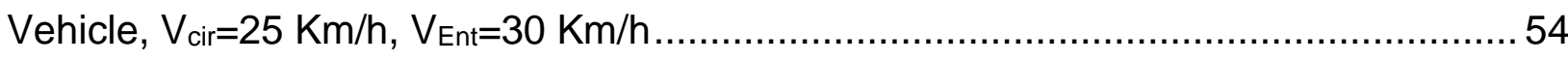

Table 23: AFOSM Results, Probabilistic Maximum Lateral Clearance for Entering

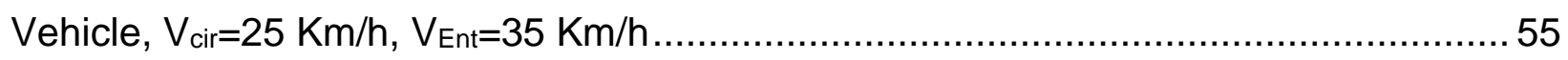

Table 24: AFOSM Results, Probabilistic Maximum Lateral Clearance for Entering

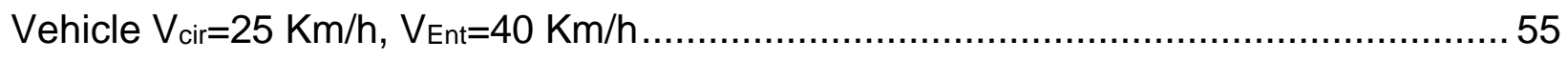

Table 25: AFOSM Results, Probabilistic Maximum Lateral Clearance for Entering

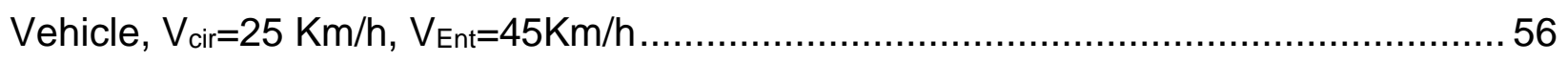

Table 26: Required Design Elements (Rodegerdts et al., 2010) …............................57

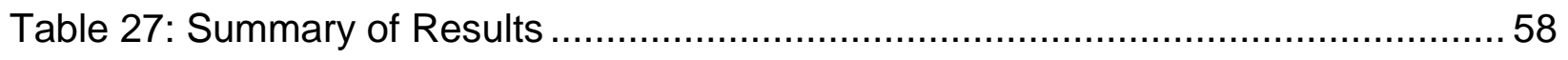




\section{LIST OF FIGURES}

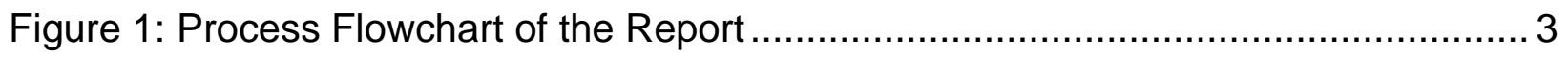

Figure 2: Illustration of a Roundabout Intersection (Inman, 2007) .............................. 7

Figure 3: ISD Needs for the Symmetrical Single-lane Roundabout (Easa, 2017) ........ 13

Figure 4: The Geometry of the Symmetrical Single-lane Roundabout (Easa, 2017) ..... 15

Figure 5: A Practical Illustration of the Issue With the Current Guidelines ................... 16

Figure 6: Geometry of a Symmetrical Single- Lane Roundabout for Approach Vehicle at

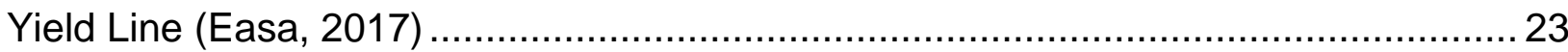

Figure 7: Geometry of a Symmetrical Single- Lane Roundabout for Approach Vehicle

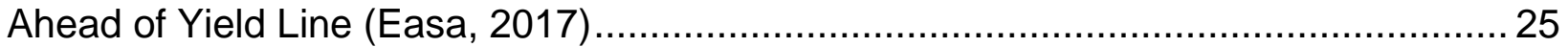

Figure 8: Reliability Index and Performance Function (Easa, 2000) ............................ 29

Figure 9: An Example of Coordinate Transformation for an Arbitrary Function $g(x)(D u$, $2005)$

Figure 10: The Algorithm of Finding (MPP) and Reliability Index on the Limit State

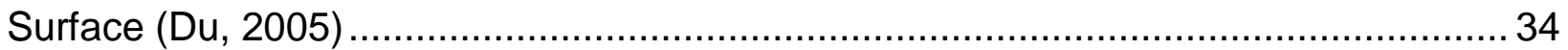

Figure 11: Solver Window of a Sample Worksheet .................................................. 40

Figure 12: FOSM Results, Maximum Lateral Clearance Results for Approach Vehicle at

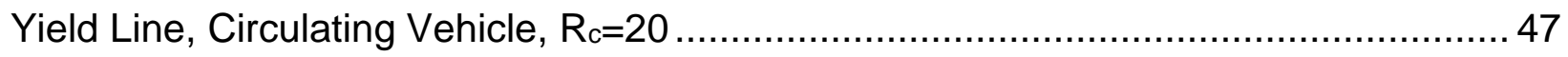

Figure 13: FOSM Results, Maximum Lateral Clearance Results for Approach Vehicle

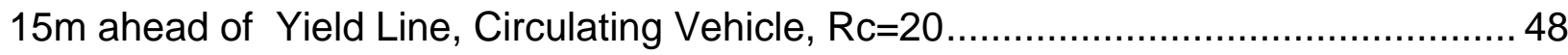


Figure 14: FOSM Results, Maximum Lateral Clearance Results for Approach Vehicle $15 \mathrm{~m}$ ahead of Yield Line, Entering Vehicle, Rc=20 50

Figure 15: AFOSM Results, Maximum Lateral Clearance Results for Approach Vehicle at Yield Line, Circulating Vehicle, $\mathrm{Rc}=20$ 53

Figure 16: AFOSM Results, Maximum Lateral Clearance Results for Approach Vehicle $15 \mathrm{~m}$ ahead of Yield Line, Circulating Vehicle, $\mathrm{Rc}=20$ 54

Figure 17: AFOSM Results, Maximum Lateral Clearance Results for Approach Vehicle

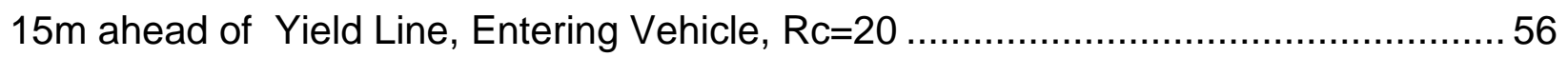

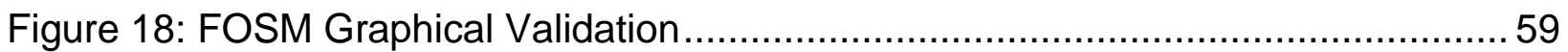

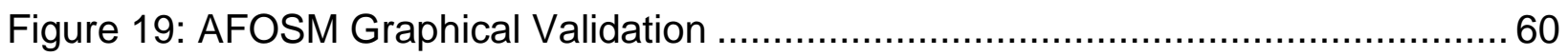




\section{INTRODUCTION}

The geometric design of a roundabout assigns sets of criteria to the geometric parameters to produce an optimal balance between capacity and safety of the roundabout. Geometric elements such as entry radii, entry width, entry and exit curves, stopping sight distance, and intersection sight distance (ISD). ISD is one of the most significant design parameters that should be controlled for adequacy when designing a roundabout (Rodegerdts et al., 2010).

The formulation of ISD includes finding several design variables such as speed, critical headway, and deceleration rate. Until this day, most studies and the design guidelines commonly own a deterministic nature to find the required ISD which means that they mostly rely on the extreme conditions i.e. highest or lowest possible values. Consequently, these methods totally neglect the variation of the variables and the possible correlations between them (Easa, 2000).

To resolve the short-comings of the previous deterministic models, this study has tried to apply reliability analysis methods to the current deterministic models (Easa, 2000). Even though the usage of reliability analysis was not very common during the past decades among transportation engineering studies it has been widely used in structural and geotechnical engineering. However, more recent studies in the field of transportation have developed and applied reliability-based models for different geometric design parameters (Hussain et al., 2015). This study was motivated by the importance of the adequacy of 
intersection sight distance as a design parameter together with the lack of studies on the case of applying risk and uncertainty to ISD formulation.

The proposed probabilistic method is based on the percentage of success/ failure of a performance under specified conditions, represented by the relationship between capacity and demand (Serrano, 2018). In other words, this method indicates how reliable the success of a design is by adding risk and uncertainty to it (AZARKHAIL et al., 2012).

An overview of the material covered in this project is outlined in the following flowchart: 


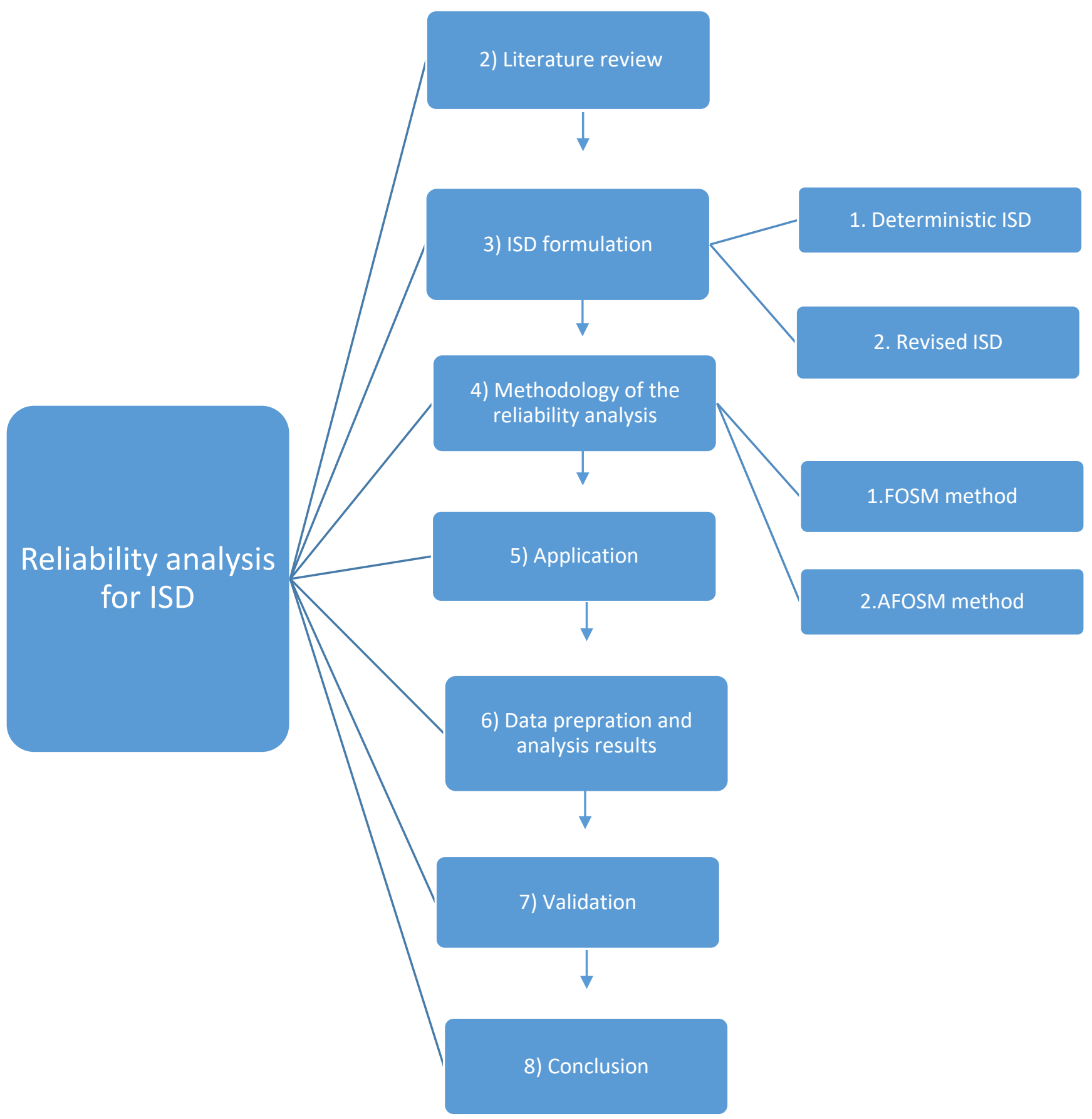

Figure 1: Process Flowchart of the Report 
Chapter 1-Introduction. This chapter contains a brief introduction to intersection sight distance, main motivation and inspiration of the study, and an overview of this report.

Chapter 2- Literature Review. Chapter 2 presents a detailed literature review of the ISD on a single-lane roundabout by comparing the differences between the existing worldwide guidelines. Moreover, this chapter provides a review on the reliability analysis method, its history and background of application especially in the field of transportation and geometric design.

Chapter 3- Deterministic Intersection Sight Distance. This chapter first explains the geometry of a symmetrical single-lane roundabout, then introduces the possible conflicting streams i.e. circulating stream and entering stream that should be controlled for adequacy of ISD on a roundabout. After formulating ISD this chapter also provides the formulation of lateral clearance. Further in this chapter, an issue with the existing design guidelines for intersection sight distance for the entering stream is discussed and consequently a revised model is presented to resolve the short-comings of the current model.

Chapter 4- Reliability Analysis Methodology. This chapter presents a detailed general methodology behind the two reliability methods used in this study; the first order second moment (FOSM) and the advanced first order second moment (AFOSM).

Chapter 5- Reliability Analysis of ISD. This section explains the procedure of applying the reliability analysis to the intersection sight distance using both FOSM and AFOSM methodologies through various steps. These two reliability approaches are applied to two different cases of approach vehicle i.e. Case 1: Approach vehicle located at yield line and Case 2: Approach vehicle located 15 meters ahead of yield line. 
Chapter 6- Application. In this chapter, both FOSM and AFOSM methodologies are applied to the ISD on a single-lane roundabout. This chapter contains tables with the required mean, variance, and covariance of random variables and all the other literature data needed for the analysis process. Further in this chapter, result tables are provided for all the possible cases listed below:

- FOSM results

- Circulating Vehicle $\left(D_{1}\right)$

$\circ$ Entering Vehicle $\left(D_{2}\right)$

- AFOSM results

- Circulating Vehicle $\left(D_{1}\right)$

$\circ$ Entering Vehicle $\left(D_{2}\right)$

Chapter 7- Validation. Chapter 7 includes a graphical validation of the proposed model using an application example.

Chapter 8- Conclusion. This chapter represents the final remarks of the study and potential recommendations.

APPENDIX- This section provides sample calculations. 


\section{LITERATURE REVIEW}

\subsection{Intersection Sight Distance}

A roundabout in general is a round shaped intersection that includes a central island around which traffic continuously flows in one direction. This intersection is also known as rotary, road circle or traffic circle. Figure 2 illustrates the general formation of a roundabout. A couple of design rules are needed to make sure the roundabout functions properly. Primarily the traffic that is already in the circulatory roadway has the right of the way meaning that the entering stream have to wait for the entering stream in the absence of utilizing traffic lights on the intersection. Second, the traffic should always move in a continuous circle around the central island and exit lanes should be used when exiting the rotary. The design speed on a roundabout is usually 25 to $40 \mathrm{~km} / \mathrm{h}$. The direction of the circulatory roadway is set by the country rule of driving. Moreover, a pedestrian island should also be provided at each entrance and exit lane to ensure the required refuge to pedestrians from coming traffic while crossing the road (Meth, 2013). Even though it has been proved statistically that roundabouts are safer than counterpart intersections with traffic lights there has been arguments about the implementation of this type of intersection throughout history. One of the main issues regarding the application of this intersection was the public resistance to accept the innovative design and the lack of public education on how to use the roundabouts (WSDOT, 2019).

America was quite ahead of Canada in regards of replacing the regular intersections with roundabouts. In Canada the first roundabout emerged as late as 1990's. Quebec only 
has built around 100 such in the late 1990s. Currently, in Canada there are more than 400 roundabouts and the number is still increasing as these intersections are becoming more common with time. The traffic flows in a single direction which is clockwise only with an average design speed of $25 \mathrm{~km} / \mathrm{h}$ based on design rules in Canada. The recent updates and improvements in design have enhanced safety, functioning, and capability to handle traffic of the implemented roundabouts (TAC.(2017b)).

While roundabouts have an excellent safety record in comparison to other type of intersection control measures, many improvements can be done to a roundabout design to ensure maximum safety for the drivers, pedestrians and cyclists. Safety issues of roundabouts are a result of design deficiencies of various geometric parameters. Due to the increasing footprint of a roundabout, it is important that the intersection is correctly designed. Consequently, the safety of a roundabout is directly related to paying careful attention to geometric design elements such as stopping sight distance and intersection sight distance (Thompson, 2009).

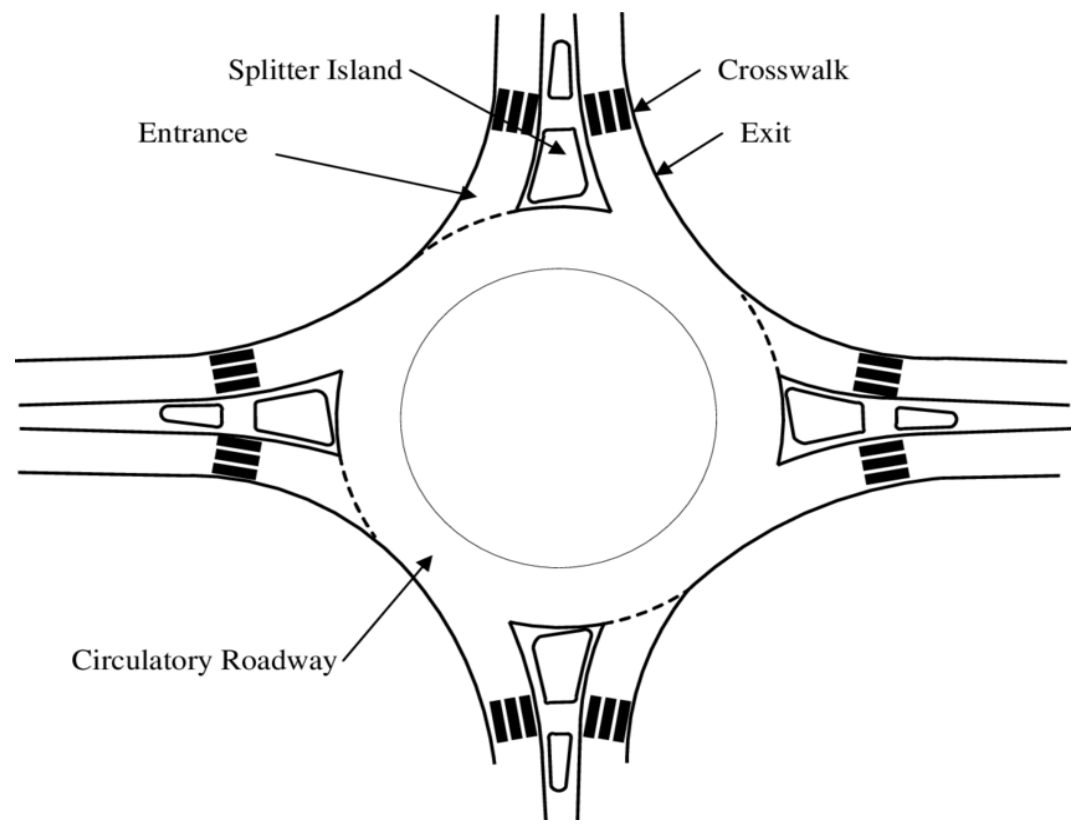

Figure 2: Illustration of a Roundabout Intersection (Inman, 2007) 
One of the geometric elements to be considered for the design of a roundabout is the intersection sight distance (ISD). According to Federal Highway Administration, ISD is required when drivers who do not own the right of the way, need to find an adequate gap to safely enter the conflicting stream of the circulatory roadway (Rodegerdts et al., 2010). For ISD on roundabouts valuable guidelines are established by Federal Highway Administration (FHWA: An Informational Guide), American Association of State Highways and Transportation Officials (ASSHTO), Transportation Association of Canada (TAC), guidelines of United Kingdom (DRDNI) and Australia (GQ).

For vehicles at each entry, intersection sight distance provided by FHWA and NCHRP considers two different conflicting points which should be checked with regards to the geometric design individually, namely entering and circulating approaches. A sight triangle for each conflicting approach is considered which is bordered by the approach leg, the conflicting leg, and the line that connects the two together. Research shows that a 15 meters length for the approach leg is sufficient enough to prevent high crash frequencies since it provides enough time for the drivers to yield or slow down the vehicle before entering the roundabout. Moreover, it restricts the driver's excessive eyesight, since a length of more than 15 meters can lead to a higher vehicle speed and adverse safety impacts. A study by Easa et al. suggests that ISD on roundabouts should be checked for two different cases i.e. an approach vehicle $15 \mathrm{~m}$ before the crosswalk which is the case that has already been considered in the Canadian guidelines and an immobile vehicle at the yield line (Rodegerdts et al., 2010).

Worldwide guidelines on roundabout geometric design such as the United Kingdom and Australian guidebooks also provide analytical models for intersection sight distance. 
Australian guideline (GQ) considers two different criteria for the intersection sight distance. First, the sightline for the stationary vehicle at the yield line should be checked for both circulatory and entering streams considering a driver eye height and an object height of $1.15 \mathrm{~m}$. The second criterion checks the adequacy of the sightline for a driver ahead of the yield line prior to entering the circulatory roadway. This criterion only considers the entering stream as the conflicting approach. Australian guideline estimates the intersection sight distance based on observation and reaction time plus stopping distance considering variable amounts for the length of the approach leg which varies dependently with the 85th percentile speed on the entry curve (GQ, 2013). United Kingdom guidelines on the other hand, check the conflicting stream only for the circulating approach and for speed limits greater than $40 \mathrm{mph}$, at the length of 15 meters ahead of the yield line beside the sightline controls for the stationary vehicle at the yield line for both conflicting streams. These guidelines controls the adequacy of the visibility distance considering that the distance varies dependently with the inscribed circle diameter (DRDNI, 2007). Table 1 shows an example of a comparison between different ISD models including United States, United Kingdom and Australian analytical models for different speeds approach length has been considered 15 meters for all the cases.

Table 1: ISD Requirements for Australian, United Kingdom, and USA Guidelines

\begin{tabular}{|l|l|l|l|l|}
\hline & $\begin{array}{l}\text { Australia } \\
(G Q, 2013)\end{array}$ & $\begin{array}{l}\text { USA } \\
\text { (Rodegerdts et } \\
\text { al., 2010) }\end{array}$ & \multicolumn{2}{|c|}{$\begin{array}{l}\text { United Kingdom } \\
\text { (DRDNI, 2007) }\end{array}$} \\
\hline $\begin{array}{l}\text { Circulating } \\
\text { Speed } \\
\left(V_{\text {cir }}\right)(\mathrm{Km} / \mathbf{h})\end{array}$ & $\begin{array}{l}\text { (4s desirable } \\
\text { observation }\end{array}$ & & $\begin{array}{l}\text { Inscribed } \\
\text { circle } \\
\text { Diameter }(\mathrm{m})^{*}\end{array}$ \\
\hline
\end{tabular}




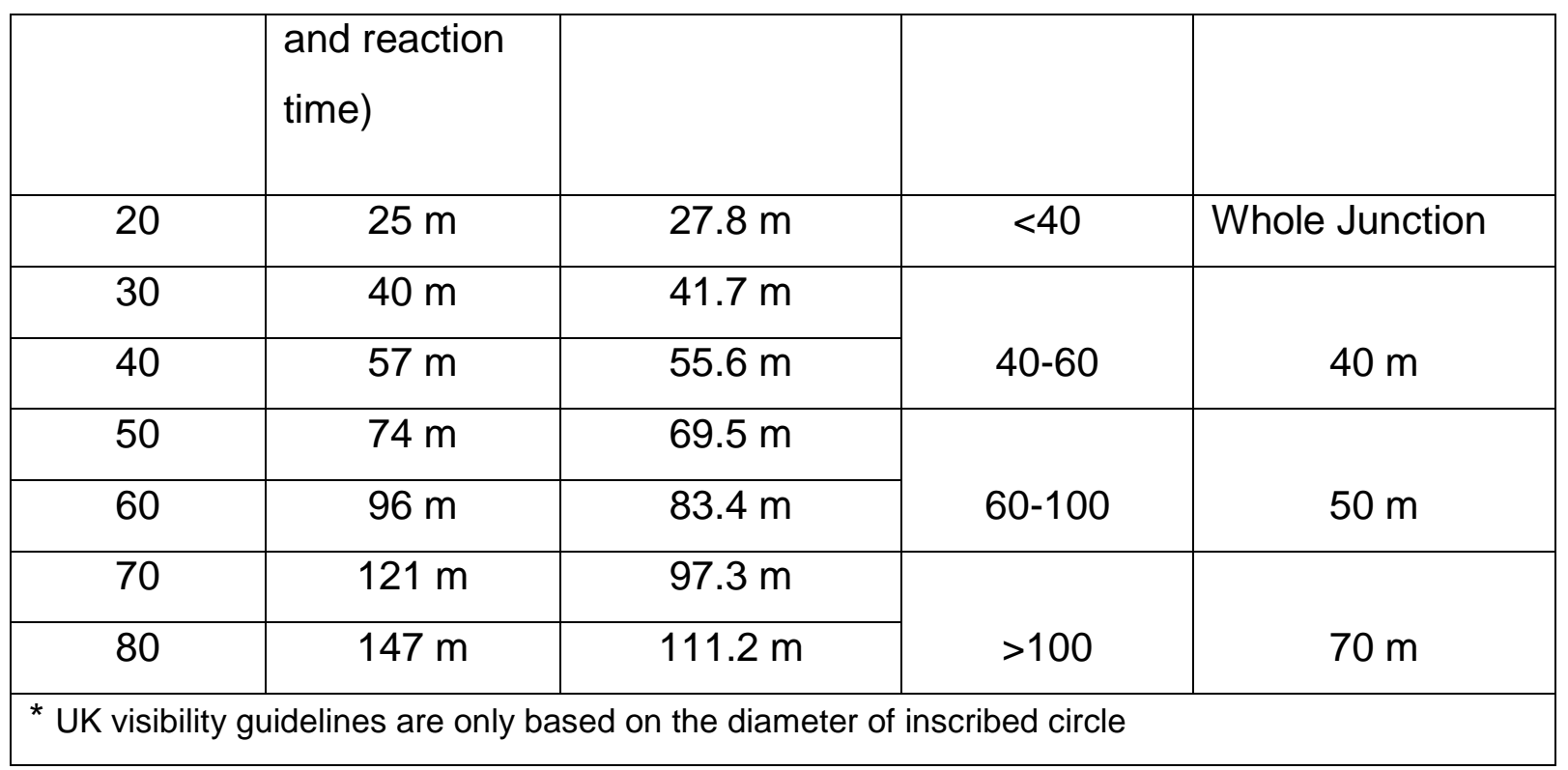

\subsection{Application of Reliability Analysis in Transportation}

The application of the reliability concept has evolved significantly during the past decade in many different aspects of engineering design. In particular, structural engineering and design-based studies have always been a step ahead of other categories due to the high importance of disaster reduction, durable, and earthquake resistant structures. Recently, transportation-related studies also have been taking advantage of the analysis to improve and optimize the safety of the design and for more reliable results (CHUNGUANG et al., 2000).

Following the same concept as structural engineering which is the limit state design concept considering a safety margin for the design, highway geometric design based studies have been using the probabilistic methods. For instance, a study done by Faghri et al., in 1988 applies the reliability and risk assessment to the prediction of hazards at rail-highway grade crossing followed by comparing the results with the performance of five other recognized techniques which eventually shows an improvement in the stability 
and performance of the design in comparison with previously developed models (FAGHRI et al., 1988). A more recent study by Felipe (1996), reviews the application of the reliability concept to highway horizontal curves which resulted in a new model capable of considering behavioral attributes of road, tire, vehicle, and driver all together (Felipe , 1996). Moreover, in 2000 a study was presented by Easa et al., to assess the performance of reliability analysis approach to intersection sight distance involving the existing obstructions for various cases. This study also shows promising improvements comparing to current ASSHTO design values as reliability and risk is added to the calculations (Easa, 2000). Many others have also practiced the method into their studies such as analysis of PSD using first-order reliability method by Serrano (2014), reliability analysis of truck scape ramp by Greto (2016), and risk-based framework for accommodating uncertainty in highway geometric design by Ismail and Sayed (2009).

A common conclusion resulted from all of the recent studies with respect to application of statistical methods to the deterministic models is that these new models have verified to be more realistic, optimal, and reliable to be used for future designs. 


\section{DETERMINISTIC INTERSECTION SIGHT DISTANCE}

The ISD should be checked at all of the four entries of the roundabout for two different scenarios as mentioned before i.e. vehicle ahead of the yield line (usually $15 \mathrm{~m}$ ) and vehicle at the yield line. Moreover, for each case (Points a and a' in Figure 3), two different conflicting streams should be checked individually namely a) upstream entering vehicle with left-turn or through movements (Point b' in Figure 3) and b) vehicles in the conflicting circulatory stream (Point b in Figure 3 ). By developing a sight triangle for the conflicting approaches adequate ISD can be accomplished by the drivers to proceed safely into the circulatory roadway. The sight triangle as mentioned before is consistent of three lines, the approach leg, the conflicting leg and the line that connects the two. By naming the conflicting point as $c$ in Figure 3 ac and a'c would be the approach legs, bc $\left(D_{1}\right)$ and b'c $\left(D_{2}\right)$ on the curved path would be the conflicting legs and eventually, ba and b'a' would be the third legs. Table 2 shows the length of the conflicting leg for both the circulating and entering streams in metric and U.S. Customary scales based on FHWA geometric design guideline (FHWA, 2000).

Table 2: Length of the conflicting leg for both the circulating and entering streams in metric and U.S. Customary scales (FHWA, 2000)

\begin{tabular}{|r|c|c|}
\hline & \multicolumn{2}{|c|}{ The length of the conflicting leg } \\
\hline $\begin{array}{l}\text { Vehicle Ahead of Yield Line / } \\
\text { Stationary Vehicle At Yield Line }\end{array}$ & Metric (m) & U.S. Customary (ft) \\
\hline Circulating vehicles & $D_{1}=0.278 t_{c} V_{C i r}$ & $D_{1}=1.468 t_{c} V_{C i r}$ \\
\hline Entering vehicles & $D_{2}=0.278 t_{c} V_{E n t}$ & $D_{2}=1.468 t_{c} V_{E n t}$ \\
\hline
\end{tabular}


where $t_{c}(\mathrm{~s})$ is the critical headway for the vehicle to enter the roundabout, $V_{C i r}$ (Metric:

$\mathrm{km} / \mathrm{h}$, U.S. Customary: Mph) is the circulating speed of the vehicle in the circulatory roadway and $V_{E n t}$ (Metric: $\mathrm{km} / \mathrm{h}$, U.S. Customary: Mph) is the entering speed of the vehicle entering the roundabout from the upstream entry (FHWA, 2000).

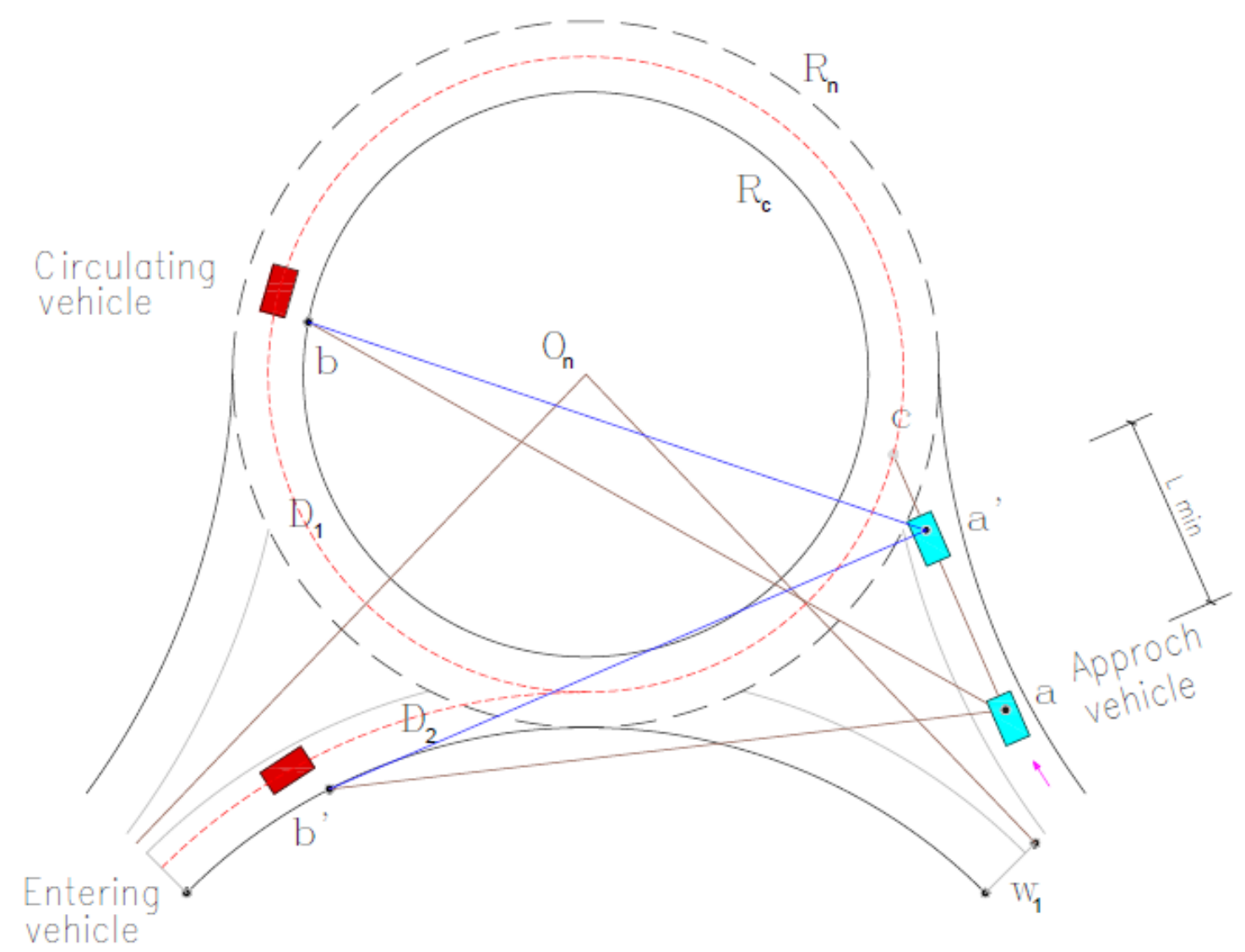

Figure 3: ISD Needs for the Symmetrical Single-lane Roundabout (Easa, 2017)

\subsection{Geometry of the Symmetrical Single-lane Roundabout}

Symmetrical single-lane roundabout is an at grade intersection with single lanes at each entry. Furthermore, it includes simple entry/exit curves which are same in the radius. 
Figure 4 displays the geometry of symmetrical single-lane roundabout. To ease the calculations a coordinate system is considered for the roundabout with the origin of $O$ which is located at the center of the entry curve. Y-axis of the coordinate system passes through point $O$ and divides the curve into two symmetrical pieces. Positive $X$ values are on the right of the $\mathrm{Y}$-axis and negative ones are on the left direction. $\mathrm{R}$ is the entry/exit radius which is located in an angle of 45 degrees ( $\mathrm{i}$ angle) from the $\mathrm{Y}$-axis. The total angle of the curve from the start point to the finish point is 90 degrees. $R_{C}$ is the radius of the center island in meters and $R_{n}(\mathrm{~m})$ is the radius of the inscribed circle which can be computed using Equation (1) (WSDOT, WSDOT Design Manual: Roundabouts, Chapter 1320, 2017).

$$
R_{n}=\frac{R(1-\cos (i))+w}{\cos (i)}
$$

Where $w$ is the distance between the centerline of the approach leg and the curve. Since i angle for symmetrical roundabouts is always equal to 45 degrees, by having the values for $R$ and $w, R_{n}$ can be easily calculated in meters (Easa, 2017). 


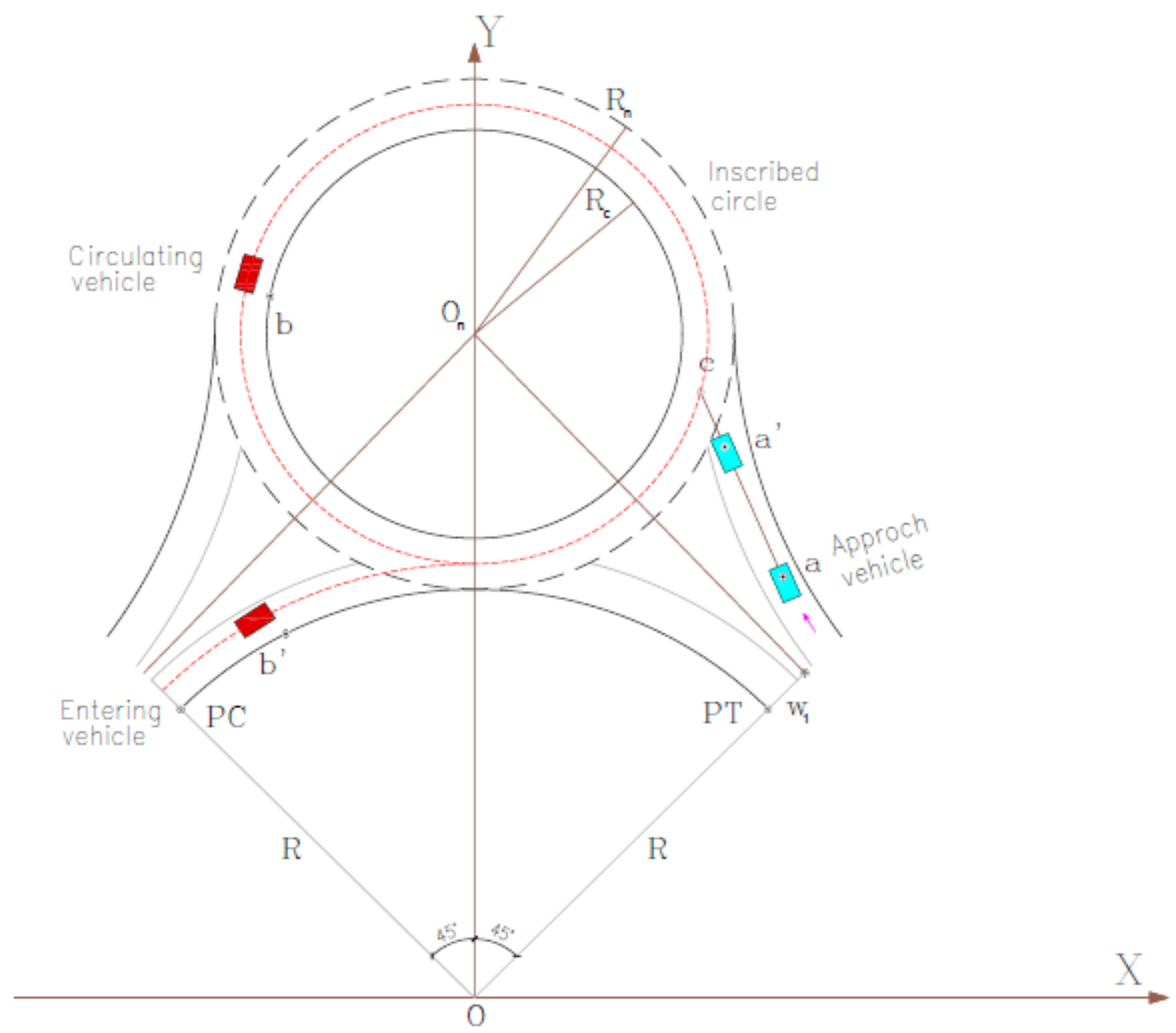

Figure 4: The Geometry of the Symmetrical Single-lane Roundabout (Easa, 2017)

\subsection{Revised Model}

In a recent study developed by Easa et al. (2017) (DESIGN GUIDELINES FOR SYMMETRICAL SINGLE-LANE ROUNDABOUTS BASED ON INTERSECTION SIGHT DISTANCE) a revised model is introduced for analytical ISD controls. As shown in Table 2 it is obvious that in calculating $D_{2}$ using the given formula only $V_{E n t}$ is considered for the entire distance which cannot be true since vehicles have to slow down while entering the 
circulating roadway and after finding a proper gap to enter the roundabout they should proceed with the $V_{\text {Cir. }}$ Figure 5 illustrates this issue graphically. Therefore, the aforementioned formula requires revisions to be more accurate. It is suggested by WSDOT and NCHRP to use the average of entering and circulating speeds instead of just $V_{E n t}$ for the length of the conflicting approach. The recommended formula for $D_{2}$ is shown in Equation (2).

$D_{2}=0.278 t_{c}\left(\frac{V_{\text {ent }}+V_{\text {cir }}}{2}\right)-d_{c i r}\left(\frac{V_{\text {ent }}-V_{\text {cir }}}{2 V_{\text {cir }}}\right)$

where $D_{2}=$ length of entering vehicle leg of sight triangle $(\mathrm{m}), V_{C i r}=$ design speed of conflicting circulating movement $(\mathrm{km} / \mathrm{h}), V_{E n t}=$ design speed of conflicting entering movement $(\mathrm{km} / \mathrm{h})$, and $d_{C i r}=$ distance travelled alongside the circulatory roadway $(\mathrm{m})$.

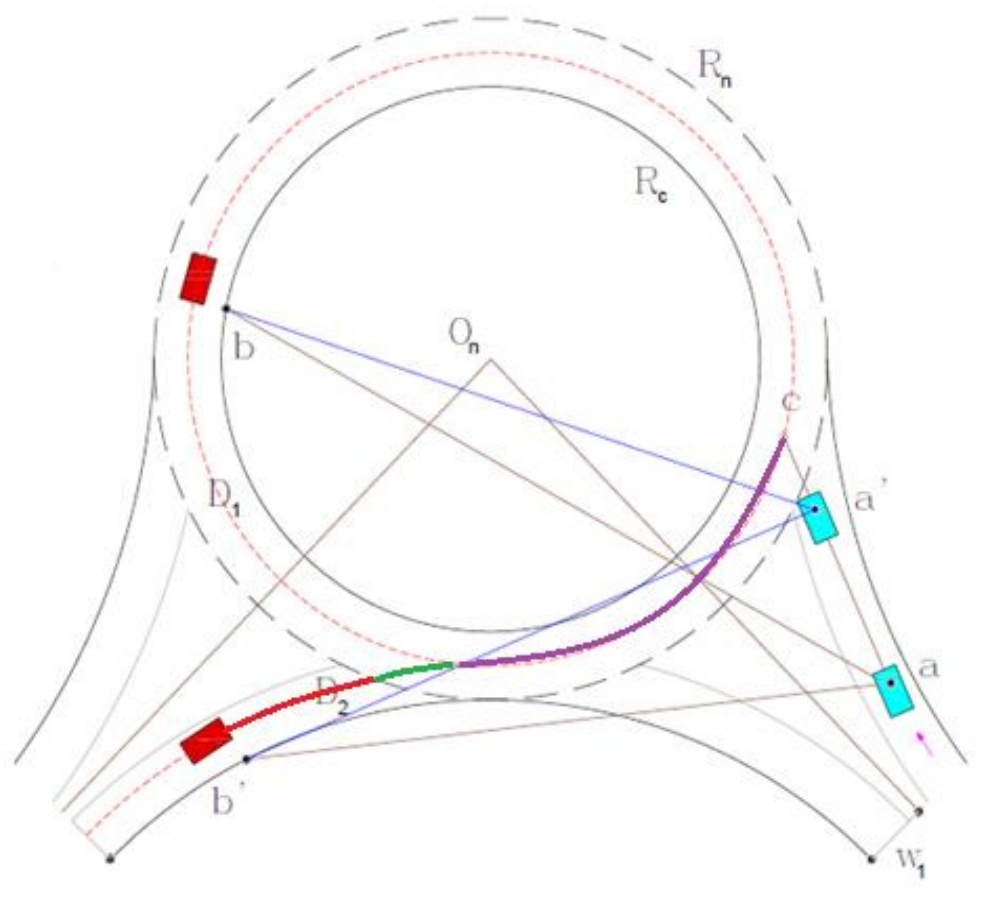

Figure 5: A Practical Illustration of the Issue with the Current Guidelines 
In this study a more accurate analytical model is presented which considers the deceleration of the vehicle while slowing down from the entering speed to circulating speed before entering the circulatory roadway. Based on this model the length of the conflicting approach is defined as sum of three different distances as shown in Equation (3).

$$
D_{2}=d_{\text {Ent }}+d_{\text {deceleration }}+d_{\text {Cir }}
$$

where $D_{2}=$ length of entering vehicle leg of sight triangle $(\mathrm{m}), d_{E n t}=$ distance travelled along the entering roadway, $d_{\text {deceleration }}=$ distance during deceleration, and $d_{c i r}=$ distance travelled alongside the circulatory roadway $(\mathrm{m})$. Equation (3) can be rewritten by assuming that $d_{\text {deceleration }}$ is the distance where the vehicle decelerates from $V_{E n t}$ to $V_{\text {Cir }}$ (Equation (4)), and the critical headway $\left(t_{c}\right)$ is equal to 5 s (Equation (5)), Equation (6) would be formulated by substituting Equations (4) and (5) into Equation (3).

$$
d_{\text {deceleration }}=\frac{\left(V_{E n t}{ }^{2}-V_{C i r}^{2}\right)}{25.92 d}
$$

where $V_{C i r}=$ design speed of conflicting circulating movement $(\mathrm{km} / \mathrm{h}), V_{\text {ent }}=$ design speed of conflicting entering movement $(\mathrm{km} / \mathrm{h})$, and $d$ is the deceleration rate.

$t_{\text {Ent }}+t_{\text {deceleration }}+t_{\text {Cir }}=t_{C}=5 \mathrm{~s}$

$$
D_{2}=d_{C i r}+\left(\frac{V_{E n t}^{2}-V_{C i r}^{2}}{25.92 d}\right)+0.278 V_{E n t}\left(5-t_{C i r}-t_{\text {decceleration }}\right)
$$

Knowing that $t_{\text {Cir }}$ can be written in terms of $V_{C \text { ir }}$ and $d_{C \text { ir }}\left(\right.$ Equation (7)), and also $t_{\text {deceleration }}$ can be rewritten in terms of $V_{\text {cir }}$ and $V_{\text {ent }}$ (Equation (8)), Equation (6) can be simplified to Equation (9). 


$$
\begin{aligned}
& t_{C i r}=\frac{d_{C i r}}{0.278 V_{C i r}} \\
& t_{\text {decceleration }}=\frac{0.278\left(V_{E n t}-V_{\text {cir }}\right)}{d} \\
& D_{2}=0.278 t_{c} V_{\text {ent }}+d_{C i r}\left(1-\frac{V_{E n t}}{V_{C i r}}\right)-\frac{\left(V_{E n t}-V_{C i r}\right)^{2}}{25.92 d}
\end{aligned}
$$

\subsection{Deterministic ISD Formulation}

As previously mentioned ISD must be checked for two cases i.e. Case1: Approach vehicle at yield line and Case 2: Approach vehicle ahead of yield line. These cases will be discussed in this section using the deterministic formulation. To provide adequate lateral clearance and a full eyesight of the entire vehicle on the conflicting paths to a driver, it is considered that sightline starts from the driver's eye and ends at the front of the conflicting vehicle (Easa, 2017).

\subsubsection{Case 1: Approach Vehicle at Yield Line}

To be able to provide sufficient sightline to the approach vehicle at the yield line for both conflicting approaches i.e. circulating and entering vehicles, it is important to make few assumptions. First, it is assumed that the point of the driver's eye (i) lies at a specified distance from the splitter island $\left(L_{i}\right)$ within the entry width. Secondly, the distance between point "i" and the curb on the right of the approach vehicle $(A)$ is also a specified distance (usually 2 meter according to FHWA). Finally, it is assumed that the entry width line is 
located perpendicular to the approach vehicle path line (ic).Figure 6 depicts the geometry of the roundabout for Case 1 (Easa, 2017).

As shown in the figure the approach leg is the line which starts from the eye of the driver and ends at the conflicting point (ic). The conflicting leg starts from the conflicting vehicle (entering or circulating) continues along with the curb and ends at the conflicting point (lines bc and b'c) and finally, the sightlines would be ib and ib'. To be able to formulate the sightline followed by determining the lateral clearance first coordinates of the major points should be determined in the coordinate system shown in Figure 6. Following steps provide the framework to find the required coordinates (Easa, 2017).

\section{Step 1: Finding the Coordinates of Approach Vehicle}

Coordinates of point " $i$ " can be found by knowing that this point is located on line "ic" and using the third assumption (ic is perpendicular to the entry width line). Since the slope of the entry width line is known, the slope $(m)$ of the approach leg can be determined using the following equation.

$$
m_{i c}=-\frac{1}{m_{i O^{\prime}}}=-\frac{x_{O^{\prime}}-x_{i}}{y_{O^{\prime}}-y_{i}}
$$

where $O^{\prime}$ is the origin of the right curb as shown in Figure 6. By knowing mic, coordinates of point "i" can be found by first finding the angle " $\alpha$ " from a three-sided known triangle called $\triangle S O O^{\prime} O n$. Where "S" is the corresponding point between the splitter island and the entry width line. To find " $a$ ", first angle $\angle O$ 'SOn should be determined Equation (11) from there " $a$ " can be derived using Equation (12). 


$$
\begin{aligned}
& \hat{S}=<O^{\prime} S O_{n}=\left[\cos ^{-1}\left(\frac{R_{n}{ }^{2}+(R+w)^{2}-\left(R_{n}+R\right)^{2}}{2 R_{n}(R+w)}\right)\right] \\
& \alpha=\sin ^{-1}\left\{\frac{R+w}{R_{n}+R} \sin \hat{S}\right\}
\end{aligned}
$$

where $w$ is the entry width, $R$ is the radius of the curb and $R_{n}$ is the radius of the inscribed circle. Knowing that $\beta=180-\alpha-\hat{S}$, Equation (13) and (14), formulate the coordinates of point "i".

$x_{i}=\left(R_{n}+R\right)-\left(R+w-L_{i}\right) \cos (\beta)$

$y_{i}=\left(R_{n}+R\right)-\left(R+w-L_{i}\right) \sin (\beta)$

\section{Step 2: Finding the Coordinates of the Conflicting point}

By having the coordinates of point "i", coordinates of "c" can be determined by solving the equations of line "ic" and the circulatory path where "c" is located on, simultaneously (Equations (15) and (16)) . The process is formulated using the following equations.

$$
\begin{aligned}
& x=x_{i}+\frac{y-y_{i}}{m_{i c}} \\
& x^{2}+\left(y-y_{n}\right)^{2}=\left(R_{c}+A\right)^{2}
\end{aligned}
$$

By substituting $\mathrm{x}$ from Equation (15) into Equation (16), $\mathrm{y}_{\mathrm{c}}$ can be derived as below, $\mathrm{x}_{\mathrm{c}}$ can then be determined by substituting $y_{c}$ into Equation (15). 


$$
\begin{aligned}
& y_{c}=\frac{-b \pm \sqrt{b^{2}-4 a c}}{2 a}= \\
& \frac{\left[\frac{2\left(\frac{y_{i}}{m_{i c}}-x_{i}\right)}{m_{i c}}+2 y_{n}\right] \pm \sqrt{\left[-\frac{2\left(\frac{y_{i}}{m_{i c}}-x_{i}\right)}{m_{i c}}-2 y_{n}\right]^{2}-4\left(\frac{1}{m_{i c}{ }^{2}}+1\right)\left[\left(\frac{y_{i}}{m_{i c}}-x_{i}\right)^{2}-\left(\left(R_{c}+A\right)^{2}-y_{n}{ }^{2}\right)\right]}}{2\left(\frac{1}{m_{i c}{ }^{2}}+1\right)}
\end{aligned}
$$

Step 3: Finding the Coordinates of the Conflicting Vehicles

After finding the coordinates of the conflicting point the next step is finding the coordinates of the conflicting vehicles. For the coordinates of the circulating vehicle (point $b), \alpha_{c}$ which is the corresponding angle to point " $\mathrm{c}$ " at "On" should first be determined given by Equation (18). Given $\alpha_{\mathrm{c}}$ the angle from point "b" to the line $\mathrm{O}_{\mathrm{n}} \mathrm{O}$ would be equal to $\left[\mathrm{a}_{\mathrm{c}}+\left(D_{1} /\left(R_{c}+A\right.\right.\right.$ ))], where $D_{1}$ is given in Table 2. As a result, the coordinates of "b" are as shown in Equations (19) and (20).

$$
\begin{aligned}
& \alpha_{c}=\sin ^{-1}\left[\frac{\left(R+R_{n}\right)-y_{c}}{\left(R_{c}+A\right)}\right] \\
& x_{b}=R_{c} \cos \left[\alpha_{c}+\frac{D_{1}}{\left(R_{c}+A\right)}\right] \\
& y_{b}=\left(R_{n}+R\right)-R_{c} \sin \left[\alpha_{c}+\frac{D_{1}}{\left(R_{c}+A\right)}\right]
\end{aligned}
$$

For the coordinates of the entering vehicle (point b'), since it includes two sections, one on the circulatory roadway and on the entry curve it should be first checked to see whether 
the entering vehicle lies on the tangent or it lies on the curve, after that using $D_{2}$ from Equation (9) the coordinates of the point can be derived. In other words, by computing the path $L$ which is equal to $\left[\mathrm{D}_{2}-\mathrm{dcir}_{\mathrm{r}}\right.$, if " $\mathrm{L}$ " is smaller than $(R \times \hat{J})$ the entering vehicle is located on the entry curve; otherwise it is on the tangent. Let $(R \times \hat{J})$ be the beginning of the entry curve and $\hat{J}$ the angle of the entry curve. After discovering the location of the entering vehicle, coordinates of the point can be derived for positive and negative amounts of "L" by considering " $\mathrm{Y}$ " as the angle between $\mathrm{Ob}$ ' and the beginning of the entry curve equal to Equation (21) as follows.

$\gamma=\sin ^{-1}[L /(R+A)]$

$x_{b^{\prime}}=\left(R_{n}+R\right)-(R+A) \cos (J-\gamma) \quad \mathrm{L} \geq 0$

$y_{b^{\prime}}=\left(R_{n}+R\right)-(R+A) \sin (J-\gamma) \quad \mathrm{L} \geq 0$

For the case where $L$ is negative (vehicle on the tangent) " $\mathrm{"} \mathrm{would} \mathrm{be} \mathrm{defined} \mathrm{as}$ Equation (24). Thus, the coordinates of the conflicting vehicle on the entry curve would be as below.

$$
\begin{aligned}
& \gamma=\tan ^{-1}[L /(R+A)] \\
& x_{b^{\prime}}=\left(R_{n}+R\right)-\left[L^{2}+(R+A)^{2}\right]^{0.5} \cos (J+\gamma) \quad \mathrm{L}<0 \\
& y_{b^{\prime}}=\left(R_{n}+R\right)-\left[L^{2}+(R+A)^{2}\right]^{0.5} \sin (J+\gamma) \quad \mathrm{L}<0
\end{aligned}
$$




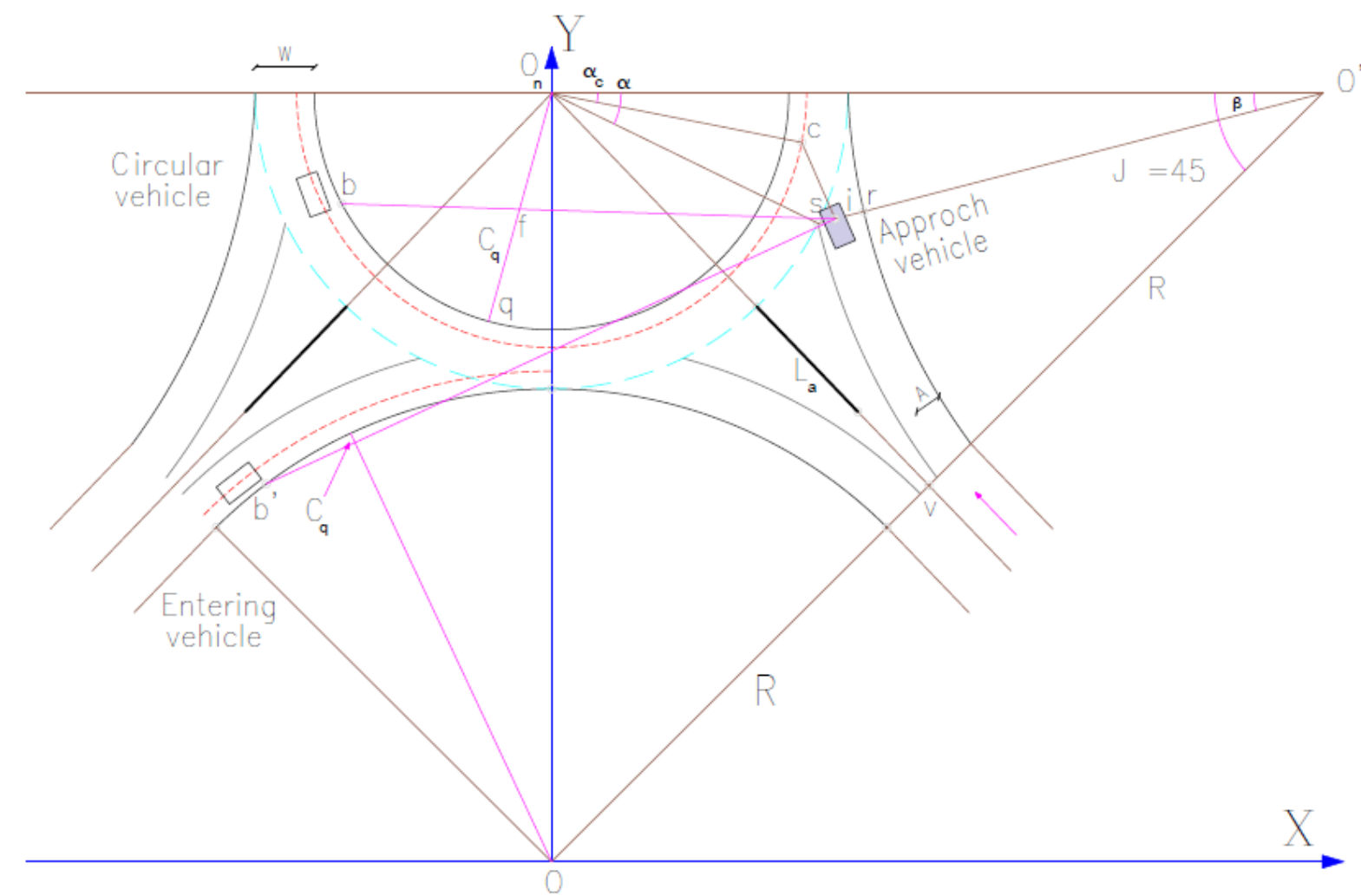

Figure 6: Geometry of a Symmetrical Single- Lane Roundabout for Approach Vehicle at Yield Line (Easa, 2017)

\subsubsection{Case 2: Approach Vehicle Ahead of the Yield Line}

An approach vehicle located at a specific distance ( $L$ min) ahead of the yield line also needs a clear sight distance of the conflicting approaches. Let $L$ min be the sum of three distances i.e. the near edge of the crosswalk to the end of the splitter island (usually $6 \mathrm{~m}$ ) plus the crosswalk width (usually $3 \mathrm{~m}$ ) plus the face of the splitter Island to the far edge of the crosswalk (typically $6 \mathrm{~m}$ ), then the distance KP as depicted in Figure 7 is typically assumed to be around $15 \mathrm{~m}$ (Rodegerdts et al., 2010). In this case driver's eye is located at $L_{\min }$ from the edge of the inscribed circle (a). Same as the previous Case 1 a stepwise approach is also taken for this case to generate the formulas of the required coordinates (Easa, 2017). 


\section{Step 1: Finding the Coordinates of Approach Vehicle}

To find the coordinates of the approach vehicle (a) same as the third step of the first case (coordinates of the entering vehicle), it is needed to see whether the approach vehicle lies on the tangent or the curve. Similar approach can be applied to find the coordinates of point "a" using Equations (21) to (26) considering the distance $P Q$ is equal to $\left[\left(R_{n}+\right.\right.$ $\left.R) \sin (J)-R_{n}\right]$ and $L$ equals to [PQ- $\left.L_{\min }\right]$.

\section{Step 2: Finding the Coordinates of the Conflicting point}

The coordinates of "c"' can be found completely similar to the previous case using Equations (10) to (17).

Step 3: Finding the Coordinates of the Conflicting Vehicles

This step can also be done using Equations (18) to (26) to find the coordinates of the conflicting vehicles (point $b$ and b'). 


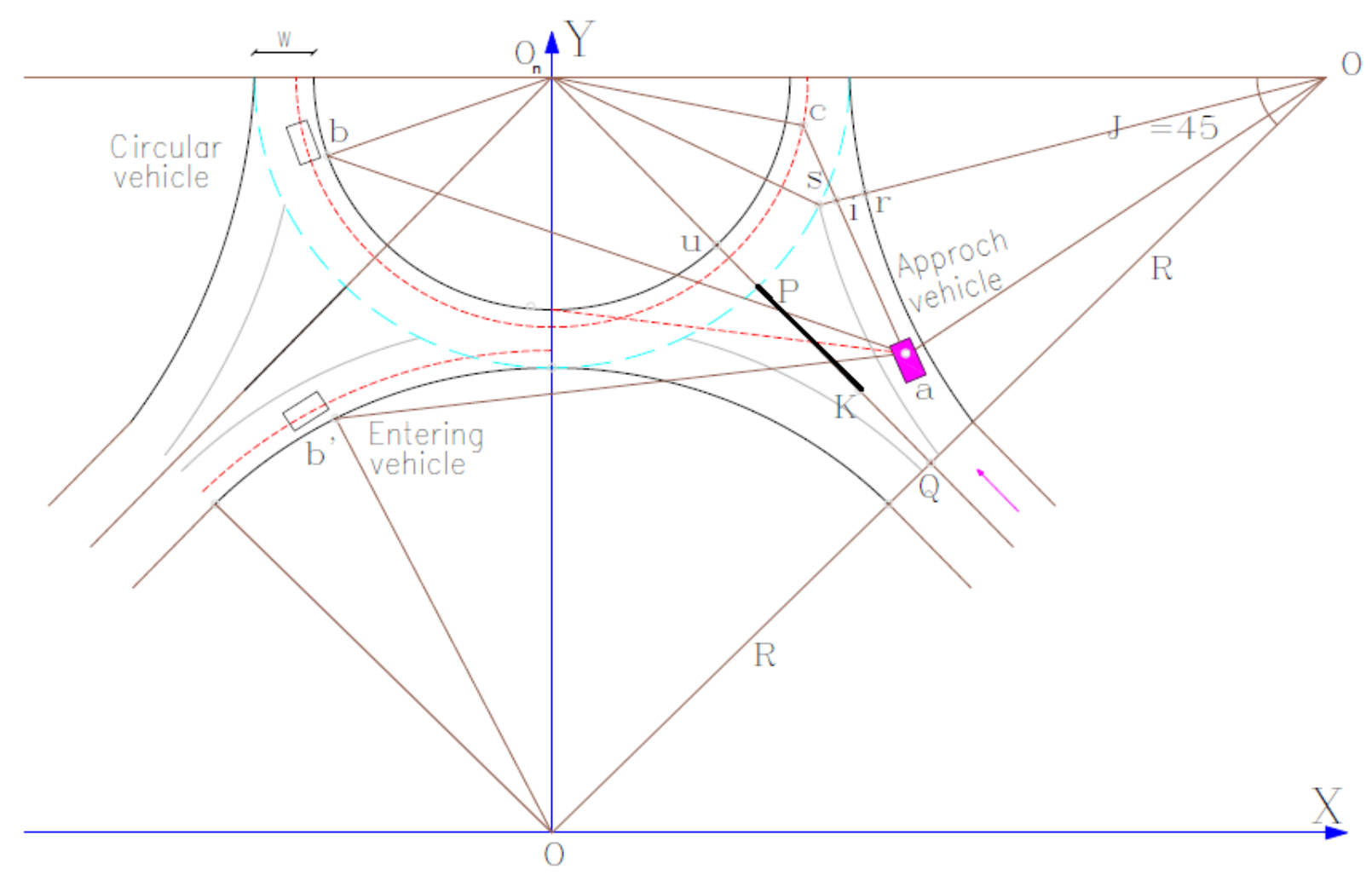

Figure 7: Geometry of a Symmetrical Single- Lane Roundabout for Approach Vehicle Ahead of Yield Line (Easa, 2017)

\subsubsection{Lateral Clearance Formulation}

The lateral clearance can be formulated for both of the cases using the coordinates of the approach vehicle and the conflicting points. In this section lateral clearance would be formulated for Case 1 as an example, Case 2 can be configured taking the same approach. Having the coordinates of point " $\mathrm{l}$ " and "b" for the conflicting-circulating vehicle the slope of the line "ib" is given by:

$$
m_{i c}=\frac{\left(y_{b}-y_{i}\right)}{\left(x_{b}-x_{i}\right)}
$$


Considering a point q which is located on the central island's curb the slope of the line "Onq" can be formulated as Equation (28).

$m_{O_{n} q}=\frac{\left(y_{O_{n}}-y_{q}\right)}{\left(x_{O_{n}}-x_{q}\right)}=\frac{y_{n}-y_{q}}{x_{q}}$

By solving the equations for line "Onq" and "ib" simultaneously, the coordinates of the mutual arbitrary point (f) can be derived as Equations (29) and (30). The lateral clearance $\left(c_{q}\right)$ can then be determined for the arbitrary point " $q$ " by deducting the length of the line "Onf" from $R_{c}$ as shown in Equation (31).

$$
\begin{aligned}
& x_{f}=\frac{y_{i}-y_{q}-x_{i} \mathrm{~m}_{i b}+x_{q} m_{O_{n} q}}{m_{O_{n} q}-\mathrm{m}_{i b}} \\
& y_{f}=y_{q}+\left(x_{f}-x_{q}\right) m_{O_{n} q} \\
& C_{q}=R_{c}-\sqrt{x_{f}^{2}+\left(y_{n}-y_{f}\right)^{2}}
\end{aligned}
$$

The required Lateral clearance at any point within the sightline can be determined using above equations. The maximum lateral clearance can also be determined using optimization which is going to be discussed in the following sections. Table 3 and Table 4 show the maximum lateral clearance requirements for ISD of a circulating and entering vehicle provided by Easa et al.,(2017). 
Table 3:The Maximum Lateral Clearance Requirements for ISD of a Circulating Vehicle (Easa, 2017)

\begin{tabular}{|c|c|c|c|c|c|c|c|c|c|c|}
\hline \multirow{4}{*}{$\begin{array}{l}R_{c} \\
(\mathrm{~m})\end{array}$} & \multicolumn{10}{|c|}{ Design Speed of Circulatory Vehicle, $V_{c i r}(\mathrm{~km} / \mathrm{h})^{\star}$} \\
\hline & \multicolumn{2}{|c|}{20} & \multicolumn{2}{|c|}{25} & \multicolumn{2}{|c|}{30} & \multicolumn{2}{|c|}{35} & \multicolumn{2}{|c|}{40} \\
\hline & \multicolumn{2}{|c|}{$\begin{array}{c}C_{m} \text { (ISD) } \\
(\mathrm{m})\end{array}$} & \multicolumn{2}{|c|}{$\begin{array}{c}C_{m} \text { (ISD) } \\
(\mathrm{m})\end{array}$} & \multicolumn{2}{|c|}{$\begin{array}{c}C_{m} \text { (ISD) } \\
(\mathrm{m})\end{array}$} & \multicolumn{2}{|c|}{$\begin{array}{c}C_{m} \text { (ISD) } \\
\text { (m) }\end{array}$} & \multicolumn{2}{|c|}{$\begin{array}{c}C_{m} \text { (ISD) } \\
(\mathrm{m})\end{array}$} \\
\hline & $\begin{array}{l}\text { 15-m } \\
\text { ahead }\end{array}$ & $\begin{array}{l}\text { Yield } \\
\text { line }\end{array}$ & $\begin{array}{c}\text { 15-m } \\
\text { ahead }\end{array}$ & $\begin{array}{l}\text { Yield } \\
\text { line }\end{array}$ & $\begin{array}{l}\text { 15-m } \\
\text { ahead }\end{array}$ & $\begin{array}{l}\text { Yield } \\
\text { line }\end{array}$ & $\begin{array}{c}15-m \\
\text { ahead }\end{array}$ & $\begin{array}{c}\text { Yield } \\
\text { line }\end{array}$ & $\begin{array}{c}\text { 15-m } \\
\text { ahead }\end{array}$ & $\begin{array}{c}\text { Yield } \\
\text { line }\end{array}$ \\
\hline 20 & 0 & 0.5 & 0.1 & 2 & 1.5 & 4.3 & - & - & - & - \\
\hline 25 & 0 & 0.1 & 0 & 1 & 0.1 & 2.7 & - & - & - & - \\
\hline 30 & 0 & 0 & 0 & 0.4 & 0 & 1.7 & 0.1 & 3.4 & - & - \\
\hline 35 & 0 & 0 & 0 & 0.1 & 0 & 1 & 0 & 2.4 & 0.2 & 4.2 \\
\hline 40 & 0 & 0 & 0 & 0 & 0 & 0.5 & 0 & 1.6 & 0 & 3.1 \\
\hline $\begin{array}{l}{ }^{*} \text { The } \\
\text { assun }\end{array}$ & $\begin{array}{l}\mathrm{e} \mathrm{C}_{\mathrm{m}} \\
\text { hat } \mathrm{D}\end{array}$ & $\begin{array}{l}\text { can k } \\
8 \mathrm{tc} \mathrm{V}_{\mathrm{c}}\end{array}$ & $\begin{array}{l}\text { sed for } \\
\text { ad } D 2=\end{array}$ & nterir & & $n g V_{E}$ & yiven th & urrent & ideline & \\
\hline
\end{tabular}

Table 4: The Maximum Lateral Clearance Requirements for ISD of a Entering Vehicle (Easa, 2017)

\begin{tabular}{|c|c|c|c|c|c|c|}
\hline \multirow{4}{*}{$\begin{array}{c}\text { Entry } \\
\text { Radius, } \\
\boldsymbol{R}_{1}(\mathrm{~m})\end{array}$} & \multicolumn{6}{|c|}{ Design Speed of Entering Vehicle, $V_{E n t}(\mathrm{~km} / \mathrm{h})$} \\
\hline & \multicolumn{2}{|c|}{30} & \multicolumn{2}{|c|}{35} & \multicolumn{2}{|c|}{40} \\
\hline & \multicolumn{2}{|c|}{$\begin{array}{l}C_{m} \\
(\mathrm{~m})\end{array}$} & \multicolumn{2}{|c|}{$\begin{array}{l}C_{m} \\
(\mathrm{~m})\end{array}$} & \multicolumn{2}{|c|}{$\begin{array}{l}C_{m} \\
(\mathrm{~m})\end{array}$} \\
\hline & $V_{\text {Cir }}=20 \mathrm{~km} / \mathrm{h}$ & $V_{\text {Cir }}=25 \mathrm{~km} / \mathrm{h}$ & $\begin{array}{c}V_{\text {Cir }}=20 \\
\mathrm{~km} / \mathrm{h}\end{array}$ & $\begin{array}{c}V_{\text {Cir }}=25 \\
\mathrm{~km} / \mathrm{h}\end{array}$ & $\begin{array}{c}V_{\text {Cir }}=20 \\
\mathrm{~km} / \mathrm{h}\end{array}$ & $\begin{array}{c}V_{\text {Cir }}=25 \\
\mathrm{~km} / \mathrm{h}\end{array}$ \\
\hline 15 & - & - & - & - & - & - \\
\hline 20 & 3.5 & 5.9 & - & - & - & - \\
\hline 25 & 1.7 & 3.7 & - & - & - & - \\
\hline 30 & 0.6 & 2.2 & 0.8 & 2.5 & - & - \\
\hline 35 & 0.1 & 1.1 & 0.1 & 1.2 & 0.1 & 1.4 \\
\hline 40 & 0.1 & 0.4 & 0.1 & 0.4 & 0.1 & 0.5 \\
\hline 45 & 0 & 0 & 0 & 0 & 0 & 0.1 \\
\hline
\end{tabular}




\section{RELIABILITY ANALYSIS METHODOLOGY}

In order to perform a reliability analysis, a probability function must be established based on how the demands are being responded by the supplies. In this case, failure occurs when provided supplies are less than design demands. Therefore, the probability of failure $\left(\mathrm{P}_{f}\right)$ is correspondent to the negative side of the probability function and the positive side can be named as the safety region as illustrated in Figure 8. Assuming $g(x)$ as the performance function, $\mathrm{R}(\mathrm{x})$ as the resistance or supply indicator, and $\mathrm{S}(\mathrm{x})$ as the representative for the demand, $g(x)$ would be equal to the difference between $R(x)$ and $\mathrm{S}(\mathrm{x})$ as shown in Equation (33). Consequently, the probability density function for performance function $g(x)$ or $P_{g}$ is equal to $P(R-S)$. In this case, if $P(g=R-S<0)$ the probability distributions lies in the failure region $\left(P_{f}\right)$ and when R-S is equal to zero the probability lies on the point of failure or the Y-axis as shown in Figure 8. Equation (32) demonstrates the formulation of the probability of failure for random variables. Because of the lack of information on the exact distribution of $g(x)$ and its tails end, the standard deviation $\left(\sigma_{g}\right)$ and the mean values $\left(\mathrm{m}_{g}\right)$ of the performance function should be used regarding the reliability analysis which is shown in Equation (34). Assuming that the distance from the point of failure to $\mathrm{m}_{g}$ is equal to $\beta \sigma_{g}$ Equation (35) will be formed. From Equation (34) and (35), Equation (36) will be concluded. Since $\beta$ is influenced by both $R$ and $\mathrm{S}$ uncertainties it is a more reliable factor than the traditional factor of safety (Serrano, 2018).

$P_{f}=P\left[g\left(x_{i}\right)<0\right]=1-P\left[g\left(x_{i}\right) \geq 0\right]$ 
$g(x)=R(x)-S(x)$

$m_{g}=m_{R}-m_{s}$

$m_{g}-\beta \sigma_{g}=0$

$\beta=\frac{\left(m_{R}-m_{S}\right)}{\sigma_{g}}$

In this study two different reliability analysis methods will be used to add uncertainty and risk to find the ISD on a single-lane roundabout i.e. the first order second moment (FOSM) and the advanced first order second moment (AFOSM). These methods will be explained in details in the following paragraphs.

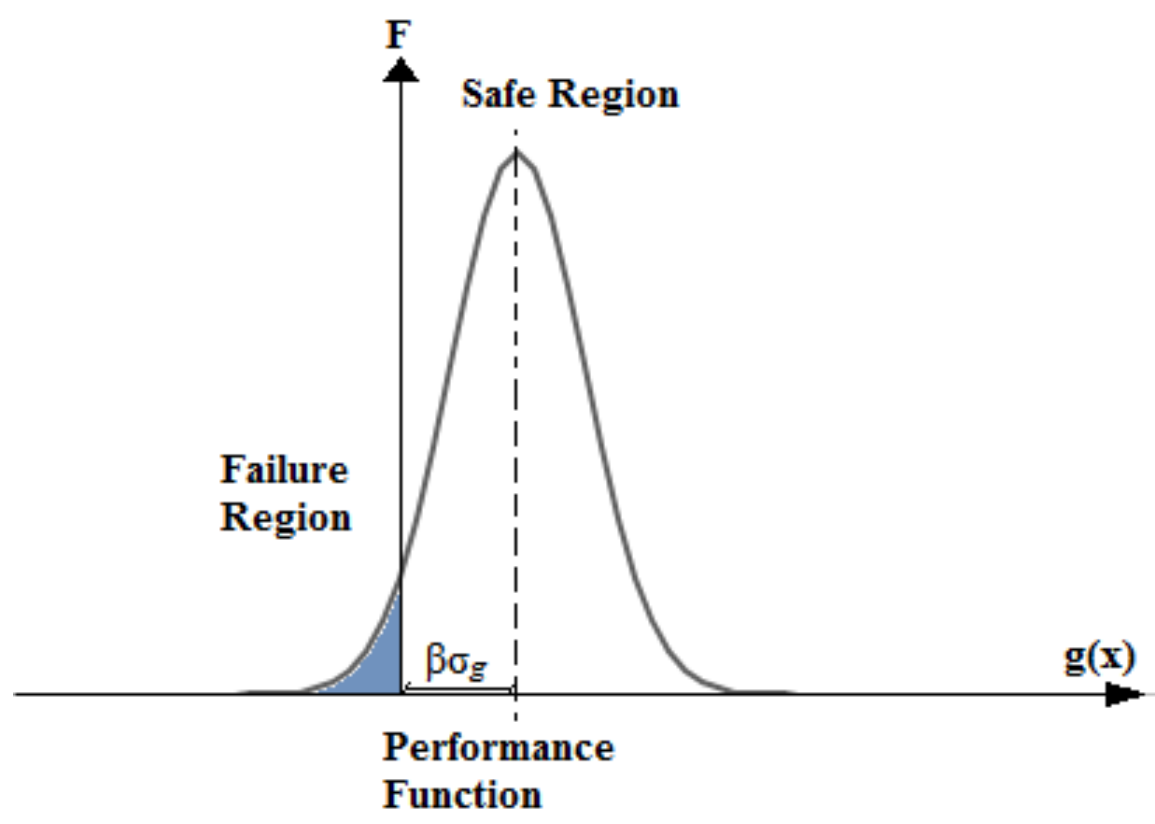

Figure 8: Reliability Index and Performance Function (Easa, 2000) 


\subsection{First Order Second Moment Method (FOSM)}

The first order second moment method is one of the most common methods in reliability analysis among the field of engineering. This method comes from approximating or linearizing the function $\mathrm{g}(\mathrm{x})$ using the Taylor series, where $\mathrm{x}=\left(\mathrm{x}_{1}, \mathrm{x}_{2}, \ldots, \mathrm{x}_{\mathrm{n}}\right)$, and each $\mathrm{x}_{\mathrm{i}=1, \mathrm{n}}$ is a random variable of the function $g(x)(D u, 2005)$. Taylor expansion for the function $g(x)$ is presented in Equation (37) (Easa, 2000).

$g(x)=g\left(\mu_{x}\right)+\sum_{i=1}^{n} \frac{\partial g\left(\mu_{x}\right)}{\partial x_{i}}\left(x_{i}-\mu_{x_{i}}\right)+\frac{1}{2} \sum_{i=1}^{n} \sum_{j=1}^{n} \frac{\partial^{2} g\left(\mu_{x}\right)}{\partial x_{i} \partial x_{j}}\left(x_{i}-\mu_{x_{i}}\right)\left(x_{j}-\mu_{x_{j}}\right)+c$

Where $\mu_{\mathrm{x}}$ is the mean point at which $\mathrm{x}_{\mathrm{i}}$ would become approximated using the FOSM method and $\mathrm{c}$ is the representative of higher order terms of the Taylor series expansion. For the first order second moment method only the first order terms from Equation (37) are needed, therefore, Equation (37) will be simplified into Equation (38). Having Equation (38) the variance $\left(\sigma^{2} g\right)$ and mean $\left(\mu_{g}\right)$ of the $g(x)$ are given as in Equations (39) and (40) (Easa, 2000).

$$
\begin{aligned}
& g(x)=z=g\left(\mu_{x_{1}}, \mu_{x_{2}}, \ldots, \mu_{x_{n}}\right)+\sum_{i=1}^{n} \frac{\partial g\left(\mu_{x}\right)}{\partial x_{i}}\left(x_{i}-\mu_{x_{i}}\right) \\
& \sigma^{2}(g)=\operatorname{var}[z]=\sum_{i=1}^{n}\left(\frac{\partial g\left(\mu_{x}\right)}{\partial x_{i}}\right)^{2} \partial^{2} x_{i}+\sum_{i}^{n} \sum_{j}^{n}\left(\frac{\partial g\left(\mu_{x}\right)}{\partial x_{i}}\right)\left(\frac{\partial g\left(\mu_{x}\right)}{\partial x_{j}}\right) \operatorname{cov}\left[x_{i}, x_{j}\right] \\
& \mu_{g}=E[z]=g\left(\mu_{x_{1}}, \mu_{x_{2}}, \ldots, \mu_{x_{n}}\right)
\end{aligned}
$$


In statistics, COV or covariance is used when there are correlations between random variables. Equation (41) shows the definition of covariance. Where $\rho_{x_{i}, x_{j}}$ is the correlation coefficient ranging from $(-1)$ to $(+1)$ (Hildebrand, 2009).

$\operatorname{cov}\left[x_{i}, x_{j}\right]=\rho_{x_{i}, x_{j}} \sigma_{x_{i}} \sigma_{x_{j}}$

In conclusion CV or the coefficient of variation for a random variable can be defined as shown in Equation (42) (Easa, 2000) .

$C V_{x_{i}}=\frac{\sigma_{x_{i}}}{\mu_{x_{i}}}$

Moreover, the previously mentioned reliability index would be defined as below.

$$
\beta=\frac{\mu_{g}}{\sigma_{g}}
$$

\subsection{Advanced First Order Second Moment Method (AFOSM)}

Advanced first order second moment method was developed to upgrade the previous version in a few short-comings such as the issue of invariance meaning that FOSM works perfectly for a linear safety margin but for a non-linear limit state function this approach will face some errors since it uses first-order approximations. The AFOSM method is considered as the second most common reliability analysis approach after FOSM. To avoid the invariance properties in the further steps of the approach this method concentrates on linearizing the function $\mathrm{g}(\mathrm{x})$ not only about the point of failure, but also focuses on the linearity of the failure conditions which means variables would be 
transformed into a standardized coordinate system and are linearized about the most probable point in that new system (DENOEL, 2017).

$$
u_{i}=\frac{\left(x_{i}-\mu_{x_{i}}\right)}{\sigma_{x_{i}}}
$$

By transforming all of the variables into the u-space coordinate system using Equation (44) the limit state of the function $g(x)$ will be reduced to $g(u)$ meaning that in the new standardized coordinate system (u-space), the reliability index would be defined as the minimum distance between the origin of the $u$-space coordinate system and the limit state surface of the function. Figure 9 depicts an example of coordinate transformation for an arbitrary function $g(x)$ (MPP, safe region, and failure region are shown in the figure). In that case, the new coordinate system's failure region for function $z=g(u)$ can be determined using the following equations. By keeping the assumption of linearity of the function, Equation (45) can be developed. Therefore, $\beta$ or the reliability index can be obtained by using a Lagrange multiplier resulting in Equation (46). Finally $\beta$ can be optimized to the minimal value using Equation (47) for the non-linear case of the limit state surfaces (Serrano, 2018) (DENOEL, 2017).

$$
\begin{aligned}
& z=g\left(u_{i}\right)=g\left(u_{1}\left(x_{1}\right), u_{2}\left(x_{2}\right), \ldots, u_{n}\left(x_{n}\right)\right)=0 \\
& z=g\left(u_{i}\right)=0 \Leftrightarrow u_{1} a_{1}+u_{2} a_{2}+\ldots+u_{n} a_{n}=a_{0} \Leftrightarrow\{a\}^{T}\{u\}=a_{0} \\
& \beta_{u}=\min \left(\sqrt{u^{T} \cdot u}\right)
\end{aligned}
$$


Since calculating the probability of failure and reliability analysis is difficult to be done in the u-space standard coordinate system, numerical methods have been developed to ease up the calculation process. The flowchart shown in Figure 10 similar to the one developed by Du (2005) demonstrates the algorithm of finding the most probable point (MPP) and reliability index on the limit state surface, step by step and through an iterative procedure. This approach uses Jacobi's method to transform the covariance matrix into its corresponding normalized version. Therefore, even correlated variables would be transformed to an uncorrelated space (Du, 2005).
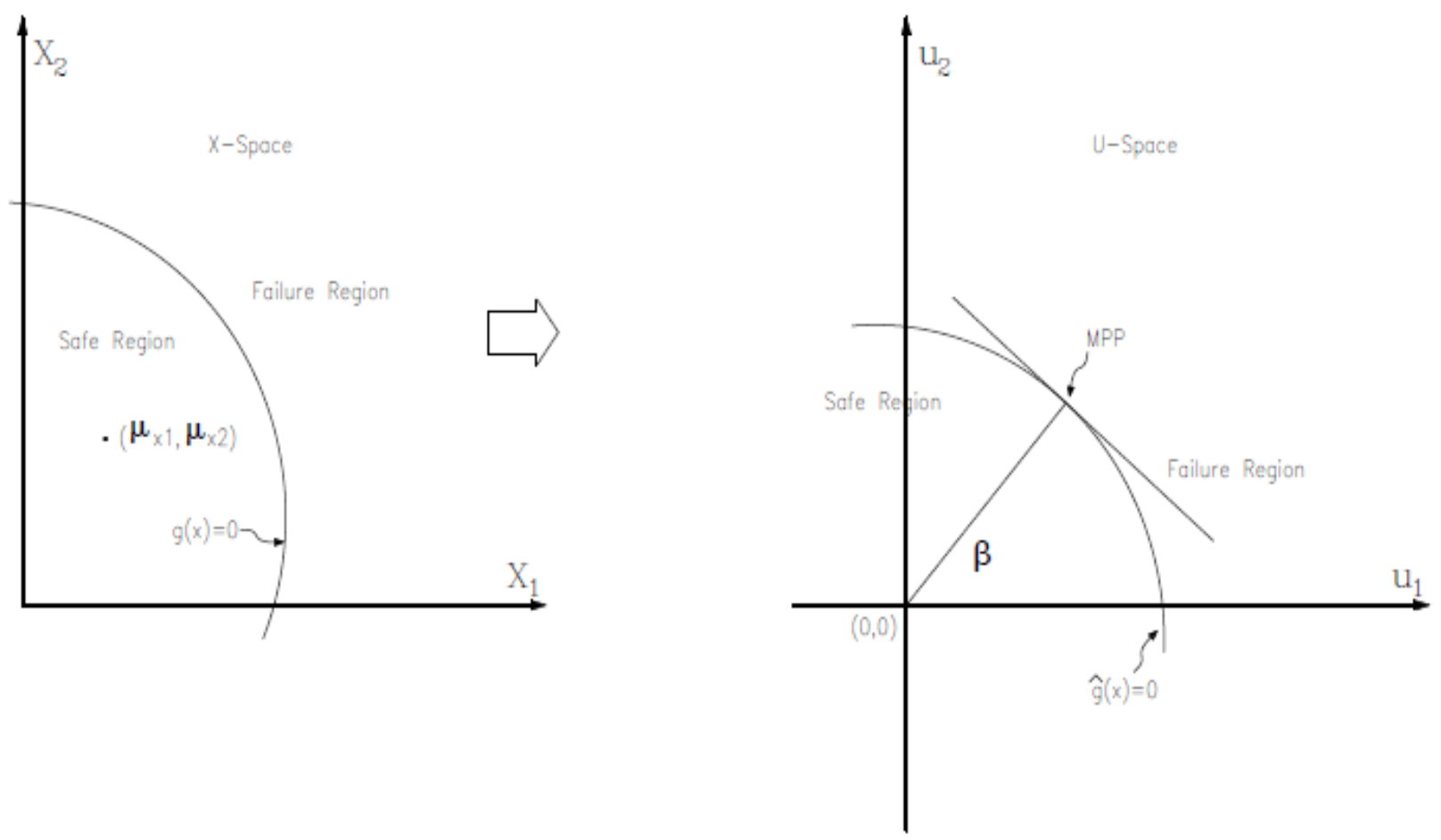

Figure 9: An Example of Coordinate Transformation for an Arbitrary Function $g(x)(D u, 2005)$ 


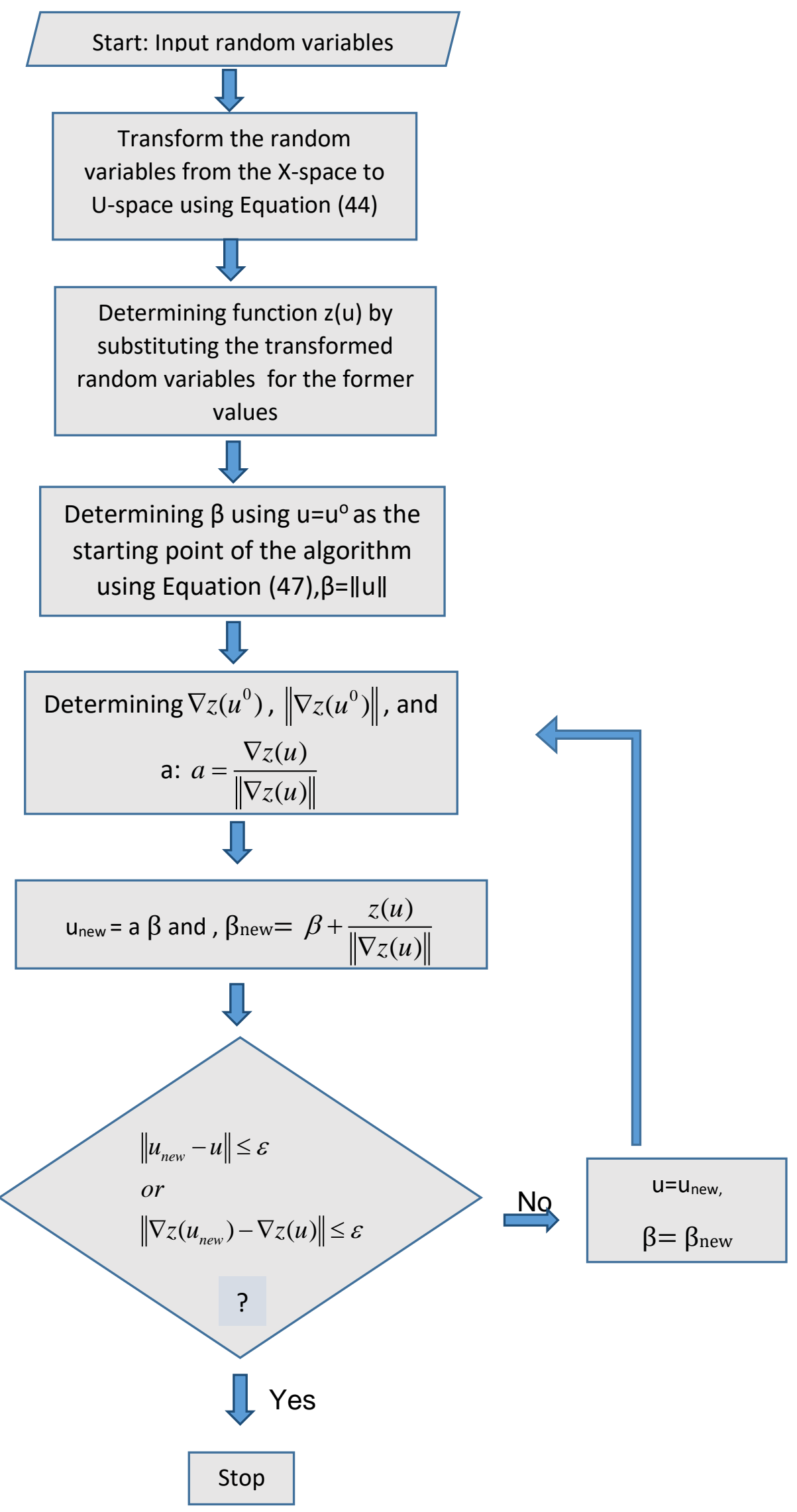

21 


\section{RELIABILITY ANALYSIS of INTERSECTION SIGHT DISTANCE}

In this section FOSM and AFOSM reliability methods will be used to add risk and uncertainty to the previously discussed deterministic models. These methods will first be applied to the revised model followed by the application to the former model. In the end, both results will be compared with each other to determine the differences and the shortcomings of the previous model.

\subsection{FOSM}

The deterministic model discussed in the second chapter considers $V_{C i r}, V_{E n t}, \mathrm{~d}$ and $t_{c}$ as constant variables with known values in the conflicting approaches $\left(D_{1}\right.$ and $\left.D_{2}\right)$ formulated as follows:

$$
\begin{aligned}
& D_{1}=0.278 t_{c} V_{C i r} \\
& D_{2}=0.278 t_{c} V_{E n t}+d_{C i r}\left(1-\frac{V_{E n t}}{V_{C i r}}\right)-\frac{\left(V_{E n t}-V_{C i r}\right)^{2}}{25.92 d}
\end{aligned}
$$

The following steps describe the application of FOSM method to find the maximum lateral clearance $(\mathrm{Cm})$.

\section{Step 1: Finding the Mean and the Variance}

The random variables considered for the intersection sight distance i.e. $D_{1}$ and $D_{2}$ would be $V_{C i r}, V_{E n t}, t_{c}$, and $d$ (deceleration rate). Therefore, the values for $E\left[D_{1}\right], E\left[D_{2}\right], \operatorname{Var}\left[D_{1}\right.$ ], and $\operatorname{Var}\left[\mathrm{D}_{2}\right]$ would be as follows:

$$
E\left[D_{1}\right]=0.278 \mu_{V_{c i r}} \mu_{t_{c}}
$$


$E\left[D_{2}\right]=0.278 \mu_{V_{E n t}} \mu_{t_{c}}+d_{C i r}\left[1-\frac{\mu_{V_{E n t}}}{\mu_{V_{C i r}}}\right]-\frac{\left(\mu_{V_{E n t}}-\mu_{V_{C i r}}\right)^{2}}{25.92 \mu_{d}}$

$\operatorname{Var}\left[D_{1}\right]=\left(\partial D_{1} / \partial V_{C i r}\right)^{2} \partial V_{C i r}^{2}+\left(\partial D_{1} / \partial t_{C}\right)^{2} \partial t_{C}{ }^{2}$

$\operatorname{Var}\left[D_{2}\right]=\left(\partial D_{2} / \partial V_{E n t}\right)^{2} \partial V_{E n t}^{2}+\left(\partial D_{2} / \partial t_{C}\right)^{2} \partial t_{C}{ }^{2}+\left(\partial D_{2} / \partial V_{C i r}\right)^{2} \partial V_{C i r}{ }^{2}+$

$\left(\partial D_{2} / \partial d\right)^{2} \partial d^{2}+2\left(\partial D_{2} / \partial V_{E n t}\right)\left(\partial D_{2} / \partial d\right) \operatorname{cov}\left(V_{E n t}, d\right)$

$+2\left(\partial D_{2} / \partial V_{C i r}\right)\left(\partial D_{2} / \partial d\right) \operatorname{cov}\left(V_{C i r}, d\right)$

\section{Step 2: Finding the First Derivative}

The first derivatives, evaluated at the mean values of the random variable of Equation (52) are given by

$\partial D_{1} / \partial V_{C i r}=0.278 t_{c}$

$\partial D_{1} / \partial t_{c}=0.278 V_{C i r}$

And the first derivatives, evaluated at the mean values of the random variables of Equation (53) are given by

$\partial D_{2} / \partial V_{E n t}=0.278 t_{c}-\frac{d_{C i r}}{V_{C i r}}-\frac{\left[2 \times\left(V_{E n t}-V_{C i r}\right)\right]}{25.92 d}$

$\partial D_{2} / \partial V_{C i r}=\frac{d_{C i r} \times V_{E n t}}{V_{C i r}^{2}}+\frac{\left[2 \times\left(V_{E n t}-V_{C i r}\right)\right]}{25.92 d}$

$\partial D_{2} / \partial d=\frac{\left[\left(V_{E n t}-V_{c i r}\right)^{2}\right]}{25.92 d^{2}}$

$\partial D / \partial t_{c}=0.278 V_{E n t}$ 


\section{Step 3: Design Procedure}

For the purpose of design procedure safety margin should be evaluated which is defined as the difference between the demand and the supply. For this case, the demand would be the required $I S D_{r}$ and the available $I S D_{a}$ would be considered as the supply and therefore, safety margin $(F)$ would be defined as $F=I S D_{a}-I S D_{r}$. As previously discussed in the $3^{\text {rd }}$ chapter the non-compliance happens when the demand exceeds the available supply, for that reason, $\mathrm{F}<0$ represents the non-compliance and $\mathrm{F} \geq 0$ would be the safe state. Consequently the mean and variance of $F$ i.e. $E[F]$ and $\operatorname{Var}[F]$, are given by $E[F]$ $=E\left[I S D_{a}\right]-E\left[I S D_{r}\right]$ and $\operatorname{Var}[F]=\operatorname{Var}\left[I S D_{a}\right]+\operatorname{Var}\left[I S D_{r}\right]$. Moreover, as previously discussed in chapter 3 the reliability index $(\beta)$ is given by $\beta=E[F] / \sigma_{F}$ and the probability of failure is given by $P_{f}=\emptyset(-\beta)=1-\emptyset(\beta)$. Where the corresponding $\beta$ for each $P_{f}$ can be obtained from the standard normal variant tables as shown in Table 5 (Hussain et al., 2015). Consequently, the available intersection sight distance can be calculated as follows:

$$
I S D_{a}=E\left[I S D_{r}\right]+\beta \sigma_{F}
$$

Table 5: Corresponding $\beta$ values for respective probability of failure (Hussain et al., 2015)

\begin{tabular}{|c|c|}
\hline Probability of Failure, Pf & Reliability Index, $\boldsymbol{\beta}$ \\
\hline $1 \%$ & 2.33 \\
\hline $2 \%$ & 2.06 \\
\hline $3 \%$ & 1.88 \\
\hline $4 \%$ & 1.75 \\
\hline $5 \%$ & 1.64 \\
\hline $6 \%$ & 1.55 \\
\hline $7 \%$ & 1.47 \\
\hline $8 \%$ & 1.40 \\
\hline $9 \%$ & 1.34 \\
\hline
\end{tabular}




\begin{tabular}{|l|c|}
\hline $10 \%$ & 1.28 \\
\hline
\end{tabular}

\section{Step 4: Setting Mean, Variance and Coefficient of Variation to Random Variables}

As previously mentioned, the reliability analysis method requires to use the mean, variance, and covariance of random variables, but since there is a lack of available databases for the required random variables, the extreme values with few assumptions were used in this study to derive the mean values for the random variables. The extreme values were obtained from NCHRP Report 672 . The relationship between the extreme value and the mean is shown in Equation (62) (Hussain et al., 2015).

$$
\mu_{x_{i}}=\frac{E_{x_{i}}}{1-Z C V_{x_{i}}}
$$

where $\mu_{x_{i}}$ is the mean of the random variable, $E_{x_{i}}$ is the extreme value corresponding to a certain percentile, $Z$ is the number of standard deviations corresponding to a certain percentile, and finally $C V_{x_{i}}$ is the coefficient of variation for the random variable. Note that for a certain percentile $Z$ can be obtained from the $Z$-score tables. The value is positive for a high percentile and it is negative for a low percentile (Easa, 2000). By finding the mean values of the random variables for a given coefficient of variation the standard deviation for different variables can be calculated using Equation (62).

$$
\sigma_{x_{i}}=C V \cdot \mu_{x_{i}}
$$

Since $d_{d}$ is correlated with both $V_{E n t}$ and $V_{C i r}$ the corresponding covariance should be calculated using Equation (41). In this study, correlation coefficient $\left(\rho_{x_{i}, x_{j}}\right)$ between $V_{E n t}$ 
and $d_{d}$ was assumed to be +0.5 because of the direct relationship of the two variables and it was assumed to be -0.5 for $V_{\text {cir }}$ and $d_{d}$ since less (more) deceleration rate is needed if the circulating speed is high (low). Having all the required input data $E[F], \operatorname{Var}[F]$, and eventually $I S D_{a}$ can be calculated. Note that to calculate the $\operatorname{Var}[\mathrm{F}]$, obtained mean values should be substituted into Equations (53) to (59).

\section{Step 5: Maximum Lateral Clearance Determination}

As previously mentioned in Chapter 2 , the maximum required lateral clearance can be formulated by having the required sight distance using the coordinates of the approach and conflicting vehicle for the deterministic formulation. Same as the deterministic model, for the case of the probabilistic formulation the same approach was taken to determine the lateral clearance (Equations 27 to 31 ) using the $I S D_{a}$ calculated from previous steps. The maximum lateral clearance or $\mathrm{C}_{\mathrm{m}}$ then can be calculated using one of the Microsoft Excel add-ins called Solver. To find the maximum distance $X_{q}$ which is the horizontal coordinate of an arbitrary point at which the lateral clearance is maximum, was taken as the changing variable and solving the following optimization model

Maximize $Z=C_{q}$

Subjected to the following constraints

$$
\begin{aligned}
& X_{q}<X_{U} \\
& X_{q}>X_{L}
\end{aligned}
$$


and

$Y_{q}<Y_{F}$ (For circulating vehicle as the conflicting stream)

or

$Y_{q}>Y_{F}($ For Entering vehicle as the conflicting stream)

where $X_{u}$ and $X_{L}$ are the upper and lower limits, respectively for the arbitrary point. In this case, the lower limit would be the X-coordinate of the conflicting vehicle (b or b') and the upper limit would be the $\mathrm{X}$-coordinate of point $u$ which is shown in Figure 7. Figure 11 shows a snapshot of the Solver window for a sample worksheet.

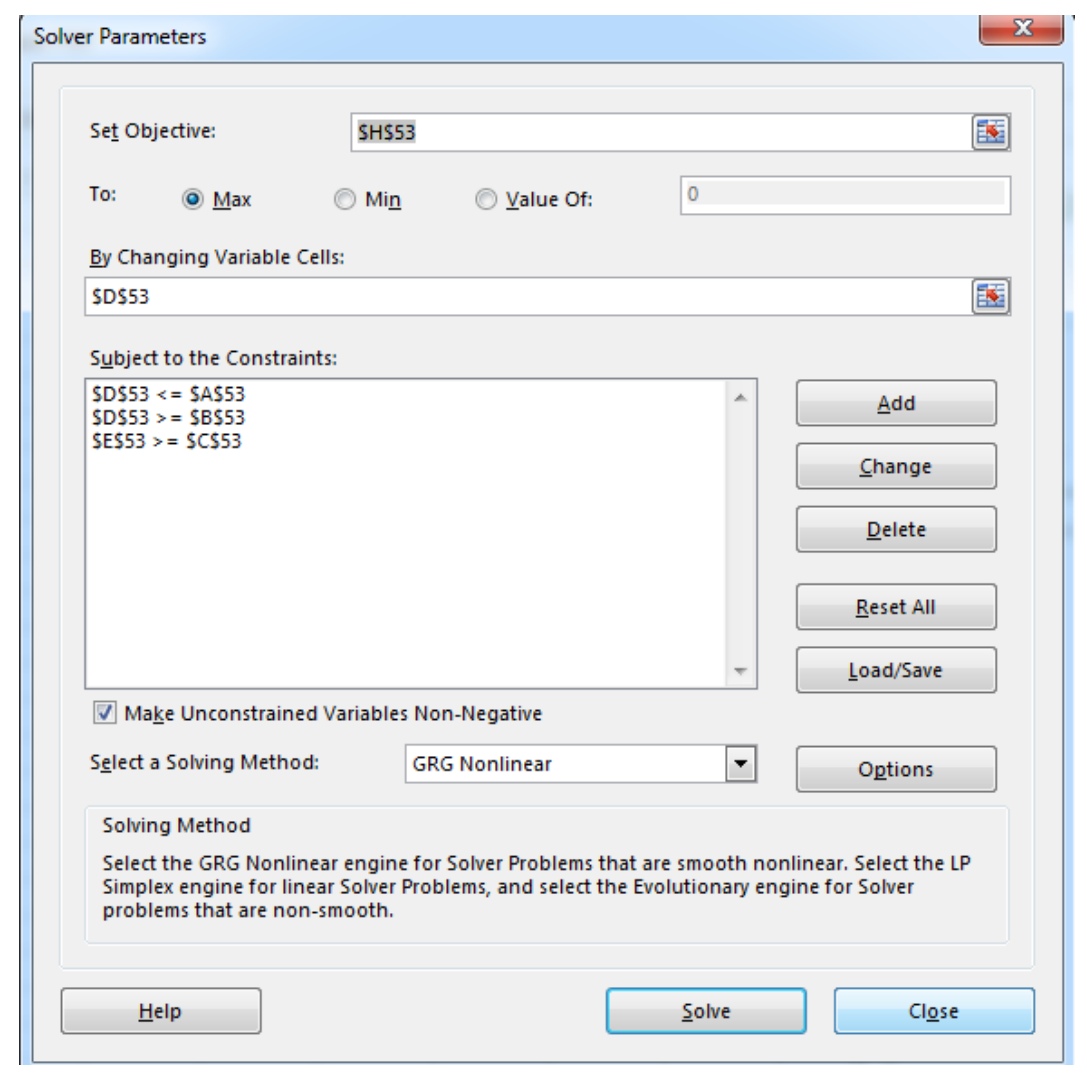

Figure 11: Solver Window of a Sample Worksheet

\subsection{AFOSM}

The following steps describe the application of AFOSM method to find the maximum lateral clearance $\left(\mathrm{C}_{\mathrm{m}}\right)$. 
Step 1: Transforming Random Variables into u-Space

Assuming that the random variables are distributed normally the random variables i.e. $V_{c i r}, V_{e n t}, t_{c}$, and $d$ (deceleration rate) can be transformed to the u-space coordinate system using Equation (44). Equations (63) and (64) show the transformed variables for $D_{1}$ and $D_{2}$ respectively.

$u=\left(V_{C i r}, t_{C}\right)=\left(\mu_{V_{C i r}}+u_{V_{C i r}} \sigma_{V_{C i r}}, \mu_{t_{C}}+u_{t_{C}} \sigma_{t_{C}}\right)$

$u=\left(V_{C i r}, V_{E n t}, t_{C}, d\right)=\left(\mu_{V_{C i r}}+u_{V_{C i r}} \sigma_{V_{G i r}}, \mu_{V_{E n t}}+u_{V_{V_{E n t}}} \sigma_{V_{E n t}}, \mu_{t_{C}}+u_{t_{C}} \sigma_{t_{C}}, \mu_{d}+u_{d} \sigma_{d}\right)$

Step 2: Safety Margin (F) Determination

As previously mentioned in section 5.1 , for the purpose of design it is crucial to formulate the safety margin $\left(F=I S D_{a}-I S D_{r}\right)$. In the case of AFOSM method, random variables should be replaced by the transformed values of Equations (63) and (64). Therefore, the transformed safety margin function is given by

$$
\begin{aligned}
& H(Y)=F_{D_{1}}=I S D_{a}-0.278\left(\mu_{V_{C i r}}+u_{V_{C i r}} \sigma_{V_{C i r}}\right)\left(\mu_{t_{C}}+u_{t_{C}} \sigma_{t_{C}}\right) \\
& H(Y)=F_{D_{2}}=I S D_{a}-\left[0.278\left(\mu_{V_{E n t}}+u_{V_{V_{E H}}} \sigma_{V_{E n t}}\right)\left(\mu_{t_{C}}+u_{t_{C}} \sigma_{t_{C}}\right)+d_{C i r}\left[1-\frac{\left(\mu_{V_{E n t}}+u_{V_{E n t}} \sigma_{V_{E n t}}\right)}{\left(\mu_{V_{C i r}}+u_{V_{C i r}} \sigma_{V_{C i r}}\right)}\right]\right. \\
& \left.-\frac{\left(\left(\mu_{V_{E n t}}+u_{V_{E n t}} \sigma_{V_{E E t}}\right)-\left(\mu_{V_{C i r}}+u_{V_{C i r}} \sigma_{V_{C i r}}\right)\right)^{2}}{25.92\left(\mu_{d}+u_{d} \sigma_{d}\right)}\right]
\end{aligned}
$$

Step 3: Finding the First Derivatives

The first derivatives, evaluated at the mean values of the random variable of Equation (65) are given by 


$$
\begin{aligned}
& H_{1}^{\prime}=\frac{\partial F_{D_{1}}}{\partial u_{V_{C i r}}}=-0.278\left(\mu_{t_{C}}+u_{t_{C}} \sigma_{t_{C}}\right) \sigma_{V_{C i r}} \\
& H_{2}^{\prime}=\frac{\partial F_{D_{1}}}{\partial u_{t_{C}}}=-0.278\left(\mu_{V_{C i r}}+u_{V_{C i r}} \sigma_{V_{C i r}}\right) \sigma_{t_{C}}
\end{aligned}
$$

The first derivatives, evaluated at the mean values of the random variable of Equation (66) are given by

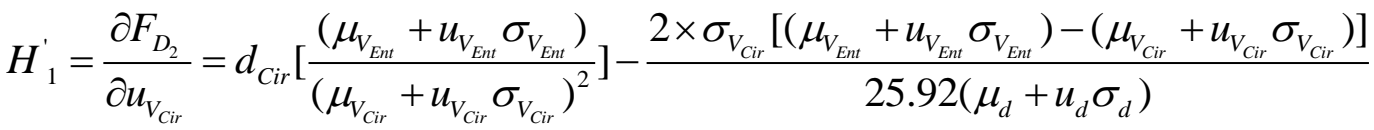

$$
\begin{aligned}
& H_{2}^{\prime}=\frac{\partial F_{D_{2}}}{\partial u_{V_{E n t}}}=-0.278\left(\mu_{t_{C}}+u_{t_{C}} \sigma_{t_{C}}\right) \sigma_{V_{E n t}}+d_{C i r} \frac{\sigma_{V_{E n t}}}{\left(\mu_{V_{C i r}}+u_{V_{C i r}} \sigma_{V_{C i r}}\right)} \\
& +\frac{2 \times \sigma_{V_{E n t}}\left[\left(\mu_{V_{E n t}}+u_{V_{E n u}} \sigma_{V_{E n t}}\right)-\left(\mu_{V_{C i r}}+u_{V_{C i r}} \sigma_{V_{C i r}}\right)\right]}{25.92\left(\mu_{d}+u_{d} \sigma_{d}\right)} \\
& H_{3}^{\prime}=\frac{\partial F_{D_{2}}}{\partial u_{t_{C}}}=-0.278\left(\mu_{V_{E n t}}+u_{V_{E n t}} \sigma_{V_{E n t}}\right) \sigma_{t_{C}} \\
& H_{4}^{\prime}=\frac{\partial F_{D_{2}}}{\partial u_{d}}=-\frac{\sigma_{d}\left[\left(\mu_{V_{E n}}+u_{V_{E u t}} \sigma_{V_{E n t}}\right)-\left(\mu_{V_{C i r}}+u_{V_{C i r}} \sigma_{V_{C i r}}\right)\right]^{2}}{\left(\mu_{d}+u_{d} \sigma_{d}\right)^{2}}
\end{aligned}
$$

Step 4: Setting Mean, Variance and Coefficient of Variation to Random Variables

As previously shown in the step 4 of FOSM approach, the same procedure should be used to set the mean values, standard deviation, and CV to random variables. In this study, same mean and coefficient of variations were used for both FOSM and AFOSM. Standard deviation can be calculated using Equation (62).

Step 5: Design Procedure 
For the purpose of design an iterative approach is required until $\beta$ is converged. For the first iteration $u_{V_{C i r}}, u_{V_{E u}}, u_{t_{C}}$, and $u_{d}$ were considered to be equal to $\beta$ equal to zero (Smith, 1986).

$Y_{i}=u_{V_{\text {Cir }}}=u_{V_{\text {Ent }}}=u_{t_{C}}=u_{d}=\beta=0$

Next, the first derivative values $\left(H_{i}^{\prime}\right)$ can be obtained for the first time by substituting the values from Equation (73) together with the introduced data in step 4 into Equations (67) to (72). $F_{D_{1}}$ and $F_{D_{2}}$ can also be found by substituting the mentioned values into Equations (65) and (66) for $D_{1}$ and $D_{2}$ respectively. Note that an estimated $I S D_{a}$ is required for the first set of calculation.

Next, standard deviation of $F$ can be calculated using the following equation.

$$
\sigma_{F}=\sqrt{\sum\left(H_{i}^{\prime}\right)^{2}}
$$

For the next iteration $Y_{i}$ values can be calculated using Equation (75).

$$
Y_{i}=-\frac{H_{i}^{\prime}}{\sigma_{F}}\left[\beta+\frac{H(Y)}{\sigma_{F}}\right]
$$

Finally $\beta$ can be evaluated using the following equation.

$$
\beta=\sqrt{\sum\left(Y_{i}\right)^{2}}
$$

This process repeatedly continuous until $\beta$ converges. 


\section{APPLICATION}

\subsection{Data Preparation}

Table 6 and Table 7 display literature data and mean values of the random variables for the case of this study for $D_{1}$ and $D_{2}$.

Table 6: Literature Data, Extreme, and Mean values of Random Variables for the Circulating Vehicle

\begin{tabular}{|c|c|c|c|c|c|}
\hline & \multicolumn{5}{|c|}{$D_{1}$} \\
\hline Random variable & $\begin{array}{c}\text { Extreme } \\
\text { value }\end{array}$ & CV & Percentile & Reference & Mean value \\
\hline$t_{c}$ & $5 \mathrm{~s}$ & 0.01 & $99 \%$ & $\mathrm{NCHRP}$ & 4.87 \\
\hline $\mathrm{V}_{\text {Cir }}$ (single-lane) & Varies & 0.1 & $90 \%$ & * & Varies \\
\hline & $\begin{array}{l}\text { * Vcir mean val } \\
\text { design paramet }\end{array}$ & & om a data colle & $\begin{array}{l}\text { ed to see the infl } \\
\text { lovak et al., } 2018\end{array}$ & ence of entry \\
\hline
\end{tabular}

Table 7: Literature Data, Extreme, and Mean values of Random Variables for the Entering Vehicle

\begin{tabular}{|c|c|c|c|c|c|}
\hline & \multicolumn{5}{|c|}{$\mathrm{D}_{2}$} \\
\hline $\begin{array}{l}\text { Random } \\
\text { variable }\end{array}$ & $\begin{array}{c}\text { Extreme } \\
\text { value }\end{array}$ & CV & Percentile & Reference & $\begin{array}{l}\text { Mean } \\
\text { value }\end{array}$ \\
\hline$t_{c}$ & $5 \mathrm{~s}$ & 0.01 & $99 \%$ & NCHRP & 4.87 \\
\hline $\mathrm{V}_{\text {cir }}$ (single-lane) & Varies & 0.1 & $90 \%$ & * & Varies \\
\hline $\begin{array}{l}\text { VEnt (single- } \\
\text { lane) }\end{array}$ & Varies & 0.1 & $90 \%$ & NCHRP & Varies \\
\hline d deceleration & $1.28 \mathrm{~m} / \mathrm{s}^{\wedge} 2$ & 0.1 & $90 \%$ & NCHRP & 1.10 \\
\hline & $\begin{array}{l}\text { * Vcir mean valu } \\
\text { design parameter }\end{array}$ & $\begin{array}{l}\text { obtaine } \\
\text { ee safet }\end{array}$ & $\begin{array}{l}\text { m a data collect } \\
\text { a roundabout }(\mathrm{N}\end{array}$ & $\begin{array}{l}d \text { to see the influe } \\
\text { vak et al., 2018) }\end{array}$ & of entry \\
\hline
\end{tabular}




\subsection{FOSM Results}

Following tables and figures show the generated maximum lateral clearance values for the case of approach vehicle at the yield line and (Case 1) and approach vehicle 15 meters ahead of yield line (Case 2) for both circulating and entering streams various inscribe circle radiuses.

6.2.1 Circulating vehicle $\left(D_{1}\right)$

Table 8: FOSM results, Probabilistic Maximum Lateral Clearance for Circulating Vehicle, $V_{\text {cir }}=20 \mathrm{Km} / \mathrm{h}$

\begin{tabular}{|c|c|c|c|c|c|c|c|c|c|c|}
\hline \multicolumn{11}{|c|}{ Vcir=20 Km/h } \\
\hline \multirow{3}{*}{$\begin{array}{c}\text { Circulating vehicle (D1) } \\
\mathrm{Rc} \\
\mathrm{Pf} \\
\end{array}$} & \multicolumn{10}{|c|}{ Cm (Maximum Lateral Clearance), (m) } \\
\hline & \multicolumn{5}{|c|}{ at yield } & \multicolumn{5}{|c|}{ 15-m ahead } \\
\hline & $1 \%$ & $2 \%$ & $3 \%$ & $4 \%$ & $5 \%$ & $1 \%$ & $2 \%$ & $3 \%$ & $4 \%$ & $5 \%$ \\
\hline ( & 0.13 & 0.08 & 0.06 & 0.04 & 0.03 & 0.00 & 0.00 & 0.00 & 0.00 & 0.00 \\
\hline 25 & 0.00 & 0.00 & 0.00 & 0.00 & 0.00 & 0.00 & 0.00 & 0.00 & 0.00 & 0.00 \\
\hline 30 & 0.00 & 0.00 & 0.00 & 0.00 & 0.00 & 0.00 & 0.00 & 0.00 & 0.00 & 0.00 \\
\hline 35 & 0.00 & 0.00 & 0.00 & 0.00 & 0.00 & 0.00 & 0.00 & 0.00 & 0.00 & 0.00 \\
\hline 40 & 0.00 & 0.00 & 0.00 & 0.00 & 0.00 & 0.00 & 0.00 & 0.00 & 0.00 & 0.00 \\
\hline
\end{tabular}

Table 9: FOSM results, Probabilistic Maximum Lateral Clearance for Circulating Vehicle, $V_{\text {cir }}=25 \mathrm{Km} / \mathrm{h}$

\begin{tabular}{|c|c|c|c|c|c|c|c|c|c|c|}
\hline \multicolumn{11}{|c|}{ Vcir $=25 \mathrm{Km} / \mathrm{h}$} \\
\hline \multirow{2}{*}{ Circulating vehicle (D1) } & \multicolumn{10}{|c|}{ Cm (Maximum Lateral Clearance), (m) } \\
\hline & \multicolumn{5}{|c|}{ at yield } & \multicolumn{5}{|c|}{ 15-m ahead } \\
\hline $\begin{array}{l}\mathrm{Rc} \\
\mathrm{Pf}\end{array}$ & $1 \%$ & $2 \%$ & $3 \%$ & $4 \%$ & $5 \%$ & $1 \%$ & $2 \%$ & $3 \%$ & $4 \%$ & $5 \%$ \\
\hline 20 & 2.15 & 1.94 & 1.82 & 1.72 & 1.64 & 0.08 & 0.00 & 0.00 & 0.00 & 0.00 \\
\hline 25 & 0.96 & 0.87 & 0.80 & 0.75 & 0.70 & 0.00 & 0.00 & 0.00 & 0.00 & 0.00 \\
\hline
\end{tabular}




\begin{tabular}{|c|c|c|c|c|c|c|c|c|c|c|}
\hline 30 & 0.39 & 0.34 & 0.28 & 0.28 & 0.25 & 0.00 & 0.00 & 0.00 & 0.00 & 0.00 \\
\hline 35 & 0.08 & 0.06 & 0.04 & 0.04 & 0.03 & 0.00 & 0.00 & 0.00 & 0.00 & 0.00 \\
\hline 40 & 0.00 & 0.00 & 0.00 & 0.00 & 0.00 & 0.00 & 0.00 & 0.00 & 0.00 & 0.00 \\
\hline
\end{tabular}

Table 10: FOSM results, Probabilistic Maximum Lateral Clearance for Circulating Vehicle, $V_{\text {cir }}=30 \mathrm{Km} / \mathrm{h}$

\begin{tabular}{|c|c|c|c|c|c|c|c|c|c|c|}
\hline \multicolumn{11}{|c|}{ Vcir=30 Km/h } \\
\hline \multirow{3}{*}{$\begin{array}{l}\text { Circulating vehicle (D1) } \\
\qquad \mathrm{Rc} \\
\mathrm{Pf}\end{array}$} & \multicolumn{10}{|c|}{ Cm (Maximum Lateral Clearance), (m) } \\
\hline & \multicolumn{5}{|c|}{ at yield } & \multicolumn{5}{|c|}{ 15-m ahead } \\
\hline & $1 \%$ & $2 \%$ & $3 \%$ & $4 \%$ & $5 \%$ & $1 \%$ & $2 \%$ & $3 \%$ & $4 \%$ & $5 \%$ \\
\hline 20 & 4.67 & 4.33 & 4.11 & 3.95 & 3.81 & 1.66 & 1.39 & 1.22 & 1.10 & 1.00 \\
\hline 25 & 2.75 & 2.58 & 2.45 & 2.35 & 2.26 & 0.31 & 0.19 & 0.12 & 0.08 & 0.04 \\
\hline 30 & 1.39 & 1.31 & 1.23 & 1.18 & 1.13 & 0.00 & 0.00 & 0.00 & 0.00 & 0.00 \\
\hline 35 & 0.75 & 0.68 & 0.64 & 0.61 & 0.57 & 0.00 & 0.00 & 0.00 & 0.00 & 0.00 \\
\hline 40 & 0.33 & 0.29 & 0.26 & 0.23 & 0.21 & 0.00 & 0.00 & 0.00 & 0.00 & 0.00 \\
\hline
\end{tabular}

Table 11: FOSM results, Probabilistic Maximum Lateral Clearance for Circulating Vehicle, $V_{\text {cir }}=35 \mathrm{Km} / \mathrm{h}$

\begin{tabular}{|c|c|c|c|c|c|c|c|c|c|c|}
\hline \multicolumn{11}{|c|}{ Vcir $=35 \mathrm{Km} / \mathrm{h}$} \\
\hline \multirow{3}{*}{$\begin{array}{l}\text { Circulating vehicle (D1) } \\
\qquad \mathrm{Rc} \\
\mathbf{P f} \\
\end{array}$} & \multicolumn{10}{|c|}{ Cm (Maximum Lateral Clearance), (m) } \\
\hline & \multicolumn{5}{|c|}{ at yield } & \multicolumn{5}{|c|}{$15-\mathrm{m}$ ahead } \\
\hline & $1 \%$ & $2 \%$ & $3 \%$ & $4 \%$ & $5 \%$ & $1 \%$ & $2 \%$ & $3 \%$ & $4 \%$ & $5 \%$ \\
\hline 20 & $-^{*}$ & 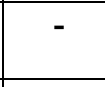 & - & - & - & & & & & - \\
\hline 25 & 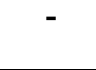 & - & - & - & - & - & - & & - & - \\
\hline 30 & 2.37 & 2.23 & 2.18 & 2.12 & 2.05 & 0.00 & 0.00 & 0.00 & 0.00 & 0.00 \\
\hline 35 & 1.45 & 1.40 & 1.35 & 1.31 & 1.28 & 0.00 & 0.00 & 0.00 & 0.00 & 0.00 \\
\hline 40 & 0.86 & 0.79 & 0.73 & 0.67 & 0.63 & 0.00 & 0.00 & 0.00 & 0.00 & 0.00 \\
\hline
\end{tabular}


Table 12: FOSM results, Probabilistic Maximum Lateral Clearance for Circulating Vehicle, $V_{\text {cir }}=40 \mathrm{Km} / \mathrm{h}$

\begin{tabular}{|c|c|c|c|c|c|c|c|c|c|c|}
\hline \multicolumn{11}{|c|}{ Vcir $=40 \mathrm{Km} / \mathrm{h}$} \\
\hline \multirow{3}{*}{$\begin{array}{l}\text { Circulating vehicle (D1) } \\
\text { Rc } \\
\text { Pf }\end{array}$} & \multicolumn{10}{|c|}{ Cm Cm (Maximum Lateral Clearance), (m) } \\
\hline & \multicolumn{5}{|c|}{ at yield } & \multicolumn{5}{|c|}{ 15-m ahead } \\
\hline & $1 \%$ & $2 \%$ & $3 \%$ & $4 \%$ & $5 \%$ & $1 \%$ & $2 \%$ & $3 \%$ & $4 \%$ & $5 \%$ \\
\hline ( & $-^{*}$ & - & - & - & - & - & - & - & - & - \\
\hline 25 & - & - & - & - & - & - & - & - & - & - \\
\hline 30 & - & - & - & - & - & - & - & - & - & - \\
\hline 35 & 2.08 & 1.93 & 1.89 & 1.85 & 1.81 & 0.00 & 0.00 & 0.00 & 0.00 & 0.00 \\
\hline 40 & 1.20 & 1.09 & 1.01 & 0.94 & 0.88 & 0.00 & 0.00 & 0.00 & 0.00 & 0.00 \\
\hline
\end{tabular}

Maximum lateral clearance, circulating vehicle, approach vehicle at yield line, $R c=20$
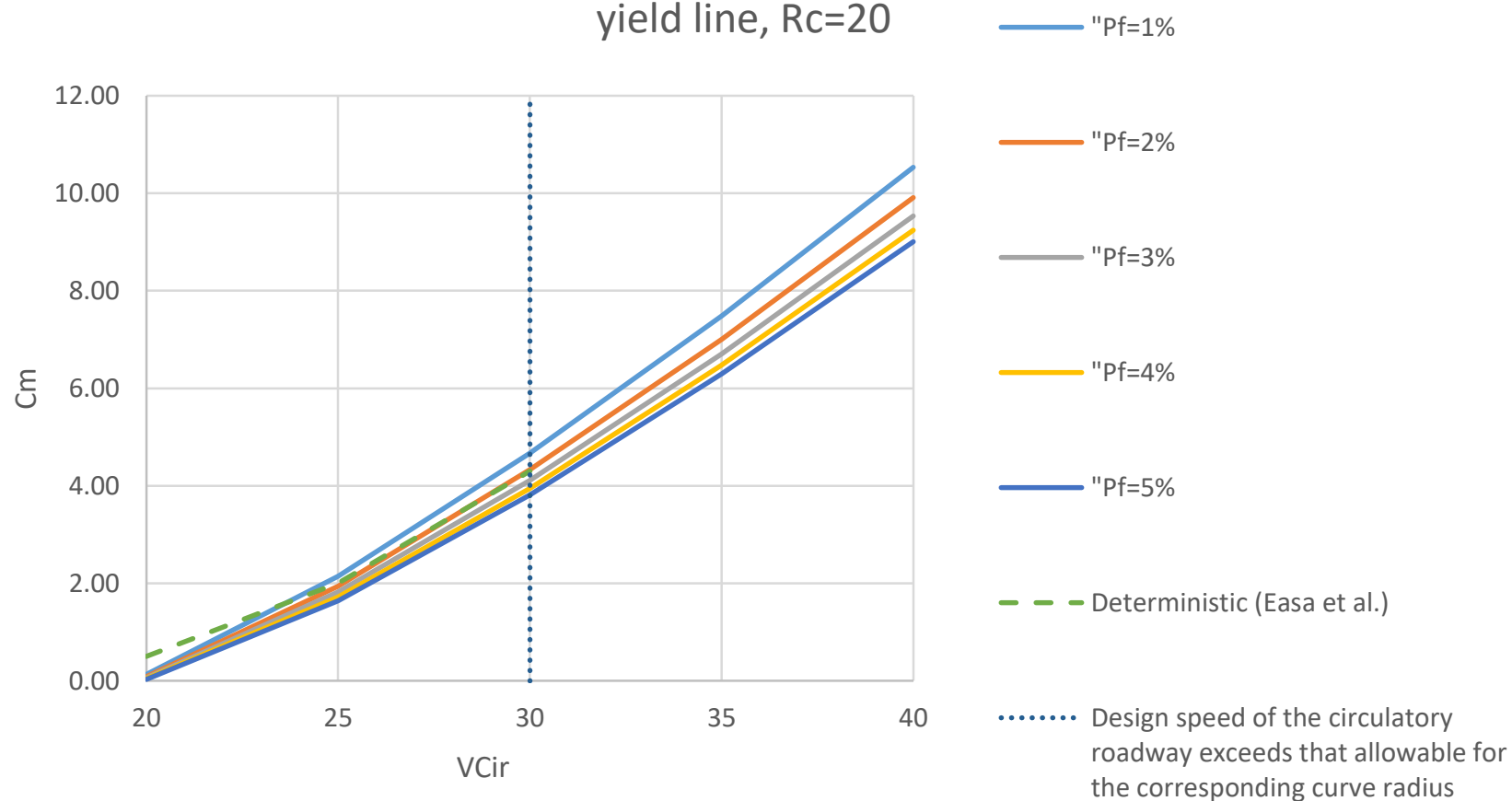
the corresponding curve radius

Figure 12: FOSM Results, Maximum Lateral Clearance Results for Approach Vehicle at Yield Line, Circulating Vehicle, $R_{c}=20$ 
Maximum lateral clearance, circulating vehicle, approach vehicle $15 \mathrm{~m}$ ahead of yield line, $\mathrm{Rc}=20$

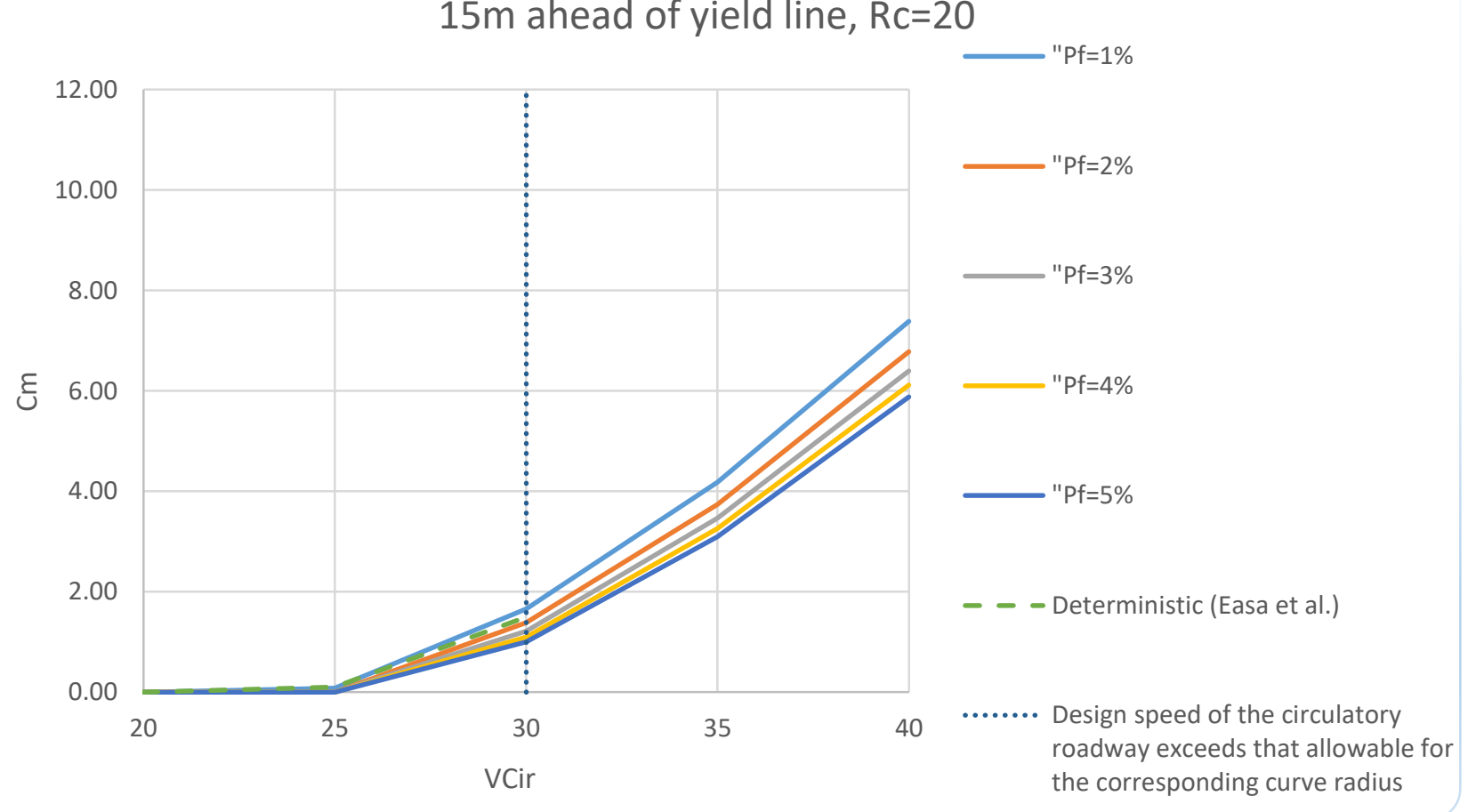

Figure 13: FOSM Results, Maximum Lateral Clearance Results for Approach Vehicle 15m ahead of Yield Line, Circulating Vehicle, $R c=20$

\subsubsection{Entering vehicle $\left(D_{2}\right)$}

Table 13: FOSM results, Probabilistic Maximum Lateral Clearance for Entering Vehicle, $V_{\text {cir }}=25 \mathrm{Km} / \mathrm{h}, V_{\mathrm{Ent}}=30 \mathrm{Km} / \mathrm{h}$

\begin{tabular}{|c|c|c|c|c|c|c|c|c|c|c|}
\hline \multicolumn{11}{|c|}{ Vcir $=25 \mathrm{Km} / \mathrm{h}$, Vent $=30 \mathrm{Km} / \mathrm{h}$} \\
\hline \multirow{3}{*}{$\begin{array}{c}\text { Entering vehicle (D2) } \\
\mathrm{Rc} \\
\mathrm{Pf}\end{array}$} & \multicolumn{10}{|c|}{ Cm (Maximum Lateral Clearance), (m) } \\
\hline & \multicolumn{5}{|c|}{ at yield } & \multicolumn{5}{|c|}{ 15-m ahead } \\
\hline & $1 \%$ & $2 \%$ & $3 \%$ & $4 \%$ & $5 \%$ & $1 \%$ & $2 \%$ & $3 \%$ & $4 \%$ & $5 \%$ \\
\hline 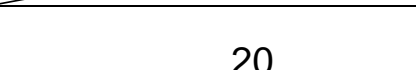 & 0.00 & 0.00 & 0.00 & 0.00 & 0.00 & 0.92 & 0.82 & 0.76 & 0.72 & 0.68 \\
\hline 25 & 0.00 & 0.00 & 0.00 & 0.00 & 0.00 & 0.01 & 0.01 & 0.00 & 0.00 & 0.00 \\
\hline 30 & 0.00 & 0.00 & 0.00 & 0.00 & 0.00 & 0.00 & 0.00 & 0.00 & 0.00 & 0.00 \\
\hline 35 & 0.00 & 0.00 & 0.00 & 0.00 & 0.00 & 0.00 & 0.00 & 0.00 & 0.00 & 0.00 \\
\hline 40 & 0.00 & 0.00 & 0.00 & 0.00 & 0.00 & 0.00 & 0.00 & 0.00 & 0.00 & 0.00 \\
\hline
\end{tabular}


Table 14: FOSM results, Probabilistic Maximum Lateral Clearance for Entering Vehicle, $V_{\text {cir }}=25 \mathrm{Km} / \mathrm{h}, V_{E n t}=35 \mathrm{Km} / \mathrm{h}$

\begin{tabular}{|c|c|c|c|c|c|c|c|c|c|c|}
\hline \multicolumn{11}{|c|}{ Vcir $=25 \mathrm{Km} / \mathrm{h}$, Vent $=35 \mathrm{Km} / \mathrm{h}$} \\
\hline \multirow{2}{*}{ Entering vehicle (D2 ) } & \multicolumn{10}{|c|}{ Cm (Maximum Lateral Clearance), (m) } \\
\hline & \multicolumn{5}{|c|}{ at yield } & \multicolumn{5}{|c|}{$15-m$ ahead } \\
\hline $\begin{array}{l}\text { Rc } \\
\text { Pf }\end{array}$ & $1 \%$ & $2 \%$ & $3 \%$ & $4 \%$ & $5 \%$ & $1 \%$ & $2 \%$ & $3 \%$ & $4 \%$ & $5 \%$ \\
\hline 20 & 0.00 & 0.00 & 0.00 & 0.00 & 0.00 & 1.29 & 1.20 & 1.14 & 1.09 & 1.05 \\
\hline 25 & 0.00 & 0.00 & 0.00 & 0.00 & 0.00 & 0.02 & 0.01 & 0.00 & 0.00 & 0.00 \\
\hline 30 & 0.00 & 0.00 & 0.00 & 0.00 & 0.00 & 0.00 & 0.00 & 0.00 & 0.00 & 0.00 \\
\hline 35 & 0.00 & 0.00 & 0.00 & 0.00 & 0.00 & 0.00 & 0.00 & 0.00 & 0.00 & 0.00 \\
\hline 40 & 0.00 & 0.00 & 0.00 & 0.00 & 0.00 & 0.00 & 0.00 & 0.00 & 0.00 & 0.00 \\
\hline
\end{tabular}

Table 15: FOSM results, Probabilistic Maximum Lateral Clearance for Entering Vehicle $V_{\text {cir }}=25 \mathrm{Km} / \mathrm{h}, V_{\text {Ent }}=40 \mathrm{Km} / \mathrm{h}$

\begin{tabular}{|c|c|c|c|c|c|c|c|c|c|c|}
\hline \multicolumn{11}{|c|}{ Vcir=25 Km/h, Vent=40 Km/h } \\
\hline \multirow{3}{*}{$\begin{array}{l}\text { Entering vehicle (D2) } \\
\mathrm{Rc} \\
\mathrm{Pf}\end{array}$} & \multicolumn{10}{|c|}{ Cm (Maximum Lateral Clearance), $(\mathrm{m})$} \\
\hline & \multicolumn{5}{|c|}{ at yield } & \multicolumn{5}{|c|}{ 15-m ahead } \\
\hline & $1 \%$ & $2 \%$ & $3 \%$ & $4 \%$ & $5 \%$ & $1 \%$ & $2 \%$ & $3 \%$ & $4 \%$ & $5 \%$ \\
\hline 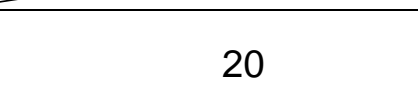 & $-{ }^{*}$ & - & - & - & - & - & - & - & - & - \\
\hline 25 & 0.00 & 0.00 & 0.00 & 0.00 & 0.00 & 0.05 & 0.03 & 0.02 & 0.02 & 0.01 \\
\hline 30 & 0.00 & 0.00 & 0.00 & 0.00 & 0.00 & 0.00 & 0.00 & 0.00 & 0.00 & 0.00 \\
\hline 35 & 0.00 & 0.00 & 0.00 & 0.00 & 0.00 & 0.00 & 0.00 & 0.00 & 0.00 & 0.00 \\
\hline 40 & 0.00 & 0.00 & 0.00 & 0.00 & 0.00 & 0.00 & 0.00 & 0.00 & 0.00 & 0.00 \\
\hline
\end{tabular}

Table 16: FOSM results, Probabilistic Maximum Lateral Clearance for Entering Vehicle, $V_{\text {cir }}=25 \mathrm{Km} / \mathrm{h}, V_{\text {Ent }}=45 \mathrm{Km} / \mathrm{h}$

\begin{tabular}{|l|c|c|}
\hline \multicolumn{2}{|c|}{ Vcir=25 Km/h, Vent=45 Km/h } \\
\hline \multirow{2}{*}{ Entering vehicle (D2) } & Cm (Maximum Lateral Clearance), (m) \\
\cline { 2 - 3 } & at yield & $15-\mathrm{m}$ ahead \\
\hline
\end{tabular}




\begin{tabular}{|c|c|c|c|c|c|c|c|c|c|c|}
\hline $\mathbf{R C}$ & $1 \%$ & $2 \%$ & $3 \%$ & $4 \%$ & $5 \%$ & $1 \%$ & $2 \%$ & $3 \%$ & $4 \%$ & $5 \%$ \\
\hline $\mathbf{P f}$ & $-{ }^{*}$ & - & - & - & - & - & - & - & - & - \\
\hline 20 & - & - & - & - & - & - & - & - & - & - \\
\hline 25 & 0.00 & 0.00 & 0.00 & 0.00 & 0.00 & 0.00 & 0.00 & 0.00 & 0.00 & 0.00 \\
\hline 30 & 0.00 & 0.00 & 0.00 & 0.00 & 0.00 & 0.00 & 0.00 & 0.00 & 0.00 & 0.00 \\
\hline 35 & 0.00 & 0.00 & 0.00 & 0.00 & 0.00 & 0.00 & 0.00 & 0.00 & 0.00 & 0.00 \\
\hline 40 & & & & &
\end{tabular}

* Design speed of the circulatory roadway exceeds the allowable corresponding curve radius

Maximum lateral clearance, entering vehicle, approach vehicle $15 \mathrm{~m}$ ahead of yield line, $\mathrm{Rc}=20$ "Pf=1\%

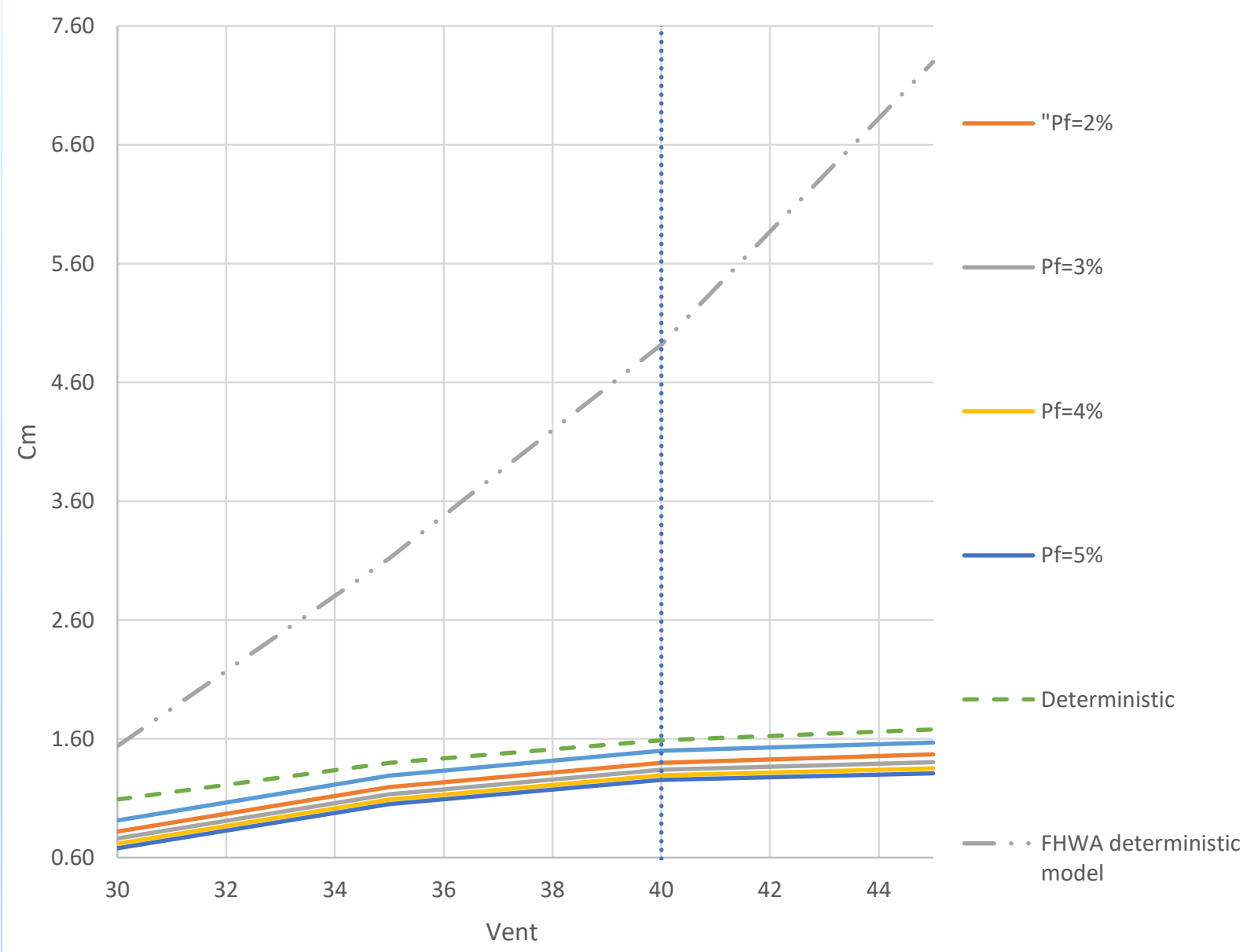

Figure 14: FOSM Results, Maximum Lateral Clearance Results for Approach Vehicle 15m ahead of Yield Line, Entering Vehicle, $R c=20$ 


\subsection{AFOSM Results}

6.3.1 Circulating vehicle $\left(D_{1}\right)$

Table 17: AFOSM Results, Probabilistic Maximum Lateral Clearance for Circulating Vehicle, Vcir=20 Km/h

\begin{tabular}{|c|c|c|c|c|c|c|c|c|c|c|}
\hline \multicolumn{11}{|c|}{ Vcir=20 Km/h } \\
\hline \multirow{3}{*}{$\begin{array}{l}\text { Circulating vehicle (D1) } \\
\text { Rc } \\
\text { Pf } \\
\end{array}$} & \multicolumn{10}{|c|}{ Cm (Maximum Lateral Clearance), (m) } \\
\hline & \multicolumn{5}{|c|}{ at yield } & \multicolumn{5}{|c|}{ 15-m ahead } \\
\hline & $1 \%$ & $2 \%$ & $3 \%$ & $4 \%$ & $5 \%$ & $1 \%$ & $2 \%$ & $3 \%$ & $4 \%$ & $5 \%$ \\
\hline 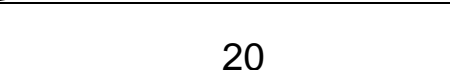 & 0.13 & 0.09 & 0.06 & 0.04 & 0.03 & 0.22 & 0.00 & 0.00 & 0.00 & 0.00 \\
\hline 25 & 0.00 & 0.00 & 0.00 & 0.00 & 0.00 & 0.00 & 0.00 & 0.00 & 0.00 & 0.00 \\
\hline 30 & 0.00 & 0.00 & 0.00 & 0.00 & 0.00 & 0.00 & 0.00 & 0.00 & 0.00 & 0.00 \\
\hline 35 & 0.00 & 0.00 & 0.00 & 0.00 & 0.00 & 0.00 & 0.00 & 0.00 & 0.00 & 0.00 \\
\hline 40 & 0.00 & 0.00 & 0.00 & 0.00 & 0.00 & 0.00 & 0.00 & 0.00 & 0.00 & 0.00 \\
\hline
\end{tabular}

Table 18: AFOSM Results, Probabilistic Maximum Lateral Clearance for Circulating Vehicle, $V_{\text {cir }}=25 \mathrm{Km} / \mathrm{h}$

\begin{tabular}{|c|c|c|c|c|c|c|c|c|c|c|}
\hline \multicolumn{11}{|c|}{ Vcir $=25 \mathrm{Km} / \mathrm{h}$} \\
\hline \multirow{2}{*}{ Circulating vehicle (D1) } & \multicolumn{10}{|c|}{ Cm (Maximum Lateral Clearance), (m) } \\
\hline & \multicolumn{5}{|c|}{ at yield } & \multicolumn{5}{|c|}{$15-\mathrm{m}$ ahead } \\
\hline $\begin{array}{l}\mathrm{Rc} \\
\mathrm{Pf}\end{array}$ & $1 \%$ & $2 \%$ & $3 \%$ & $4 \%$ & $5 \%$ & $1 \%$ & $2 \%$ & $3 \%$ & $4 \%$ & $5 \%$ \\
\hline 20 & 2.15 & 1.95 & 1.84 & 1.72 & 1.64 & 0.31 & 0.20 & 0.14 & 0.11 & 0.08 \\
\hline 25 & 0.96 & 0.86 & 0.80 & 0.75 & 0.00 & 0.00 & 0.00 & 0.00 & 0.00 & 0.00 \\
\hline 30 & 0.29 & 0.00 & 0.00 & 0.00 & 0.00 & 0.00 & 0.00 & 0.00 & 0.00 & 0.00 \\
\hline 35 & 0.00 & 0.00 & 0.00 & 0.00 & 0.00 & 0.00 & 0.00 & 0.00 & 0.00 & 0.00 \\
\hline 40 & 0.00 & 0.00 & 0.00 & 0.00 & 0.00 & 0.00 & 0.00 & 0.00 & 0.00 & 0.00 \\
\hline
\end{tabular}


Table 19: AFOSM Results, Probabilistic Maximum Lateral Clearance for Circulating Vehicle, $V_{\text {cir }}=30 \mathrm{Km} / \mathrm{h}$

\begin{tabular}{|c|c|c|c|c|c|c|c|c|c|c|}
\hline \multicolumn{11}{|c|}{ Vcir=30 Km/h } \\
\hline \multirow{2}{*}{ Circulating vehicle (D1 ) } & \multicolumn{10}{|c|}{ Cm (Maximum Lateral Clearance), $(\mathrm{m})$} \\
\hline & \multicolumn{5}{|c|}{ at yield } & \multicolumn{5}{|c|}{ 15-m ahead } \\
\hline $\begin{array}{l}\mathrm{Rc} \\
\mathrm{Pf} \\
\end{array}$ & $1 \%$ & $2 \%$ & $3 \%$ & $4 \%$ & $5 \%$ & $1 \%$ & $2 \%$ & $3 \%$ & $4 \%$ & $5 \%$ \\
\hline 20 & 4.68 & 4.34 & 4.11 & 3.95 & 3.82 & 1.67 & 1.39 & 1.23 & 1.11 & 1.01 \\
\hline 25 & 2.75 & 2.57 & 2.45 & 2.34 & 2.29 & 0.30 & 0.18 & 0.11 & 0.06 & 0.03 \\
\hline 30 & 1.40 & 1.38 & 1.30 & 1.27 & 1.24 & 0.00 & 0.00 & 0.00 & 0.00 & 0.00 \\
\hline 35 & 0.85 & 0.78 & 0.64 & 0.54 & 0.47 & 0.00 & 0.00 & 0.00 & 0.00 & 0.00 \\
\hline 40 & 0.40 & 0.29 & 0.22 & 0.20 & 0.14 & 0.00 & 0.00 & 0.00 & 0.00 & 0.00 \\
\hline
\end{tabular}

Table 20: AFOSM Results, Probabilistic Maximum Lateral Clearance for Circulating Vehicle, $V_{\text {cir }}=35 \mathrm{Km} / \mathrm{h}$

\begin{tabular}{|c|c|c|c|c|c|c|c|c|c|c|}
\hline \multicolumn{11}{|c|}{ Vcir=35 Km/h } \\
\hline \multirow{2}{*}{ Circulating vehicle (D1) } & \multicolumn{10}{|c|}{ Cm (Maximum Lateral Clearance), (m) } \\
\hline & \multicolumn{5}{|c|}{ at yield } & \multicolumn{5}{|c|}{ 15-m ahead } \\
\hline $\begin{array}{l}\mathrm{Rc} \\
\mathrm{Pf}\end{array}$ & $1 \%$ & $2 \%$ & $3 \%$ & $4 \%$ & $5 \%$ & $1 \%$ & $2 \%$ & $3 \%$ & $4 \%$ & $5 \%$ \\
\hline 20 & $-^{*}$ & - & - & - & - & - & - & - & - & - \\
\hline 25 & - & - & - & - & - & - & - & - & - & - \\
\hline 30 & 2.96 & 2.89 & 2.77 & 2.64 & 2.51 & 0.57 & 0.41 & 0.32 & 0.25 & 0.20 \\
\hline 35 & 1.93 & 1.84 & 1.74 & 1.67 & 1.59 & 0.00 & 0.00 & 0.00 & 0.00 & 0.00 \\
\hline 40 & 1.18 & 1.16 & 1.11 & 1.08 & 1.05 & 0.00 & 0.00 & 0.00 & 0.00 & 0.00 \\
\hline
\end{tabular}

Table 21: AFOSM Results, Probabilistic Maximum Lateral Clearance for Circulating Vehicle, $V_{\text {cir }}=40 \mathrm{Km} / \mathrm{h}$

\begin{tabular}{|c|c|c|c|c|c|c|c|c|c|c|}
\hline \multicolumn{7}{|c|}{ Vcir=40 Km/h } \\
\hline \multirow{2}{*}{ Circulating vehicle (D1) } & \multicolumn{7}{|c|}{ at yield } & & \\
\cline { 2 - 8 } & \multicolumn{6}{|c|}{ 15-m ahead } \\
\hline Rc & $1 \%$ & $2 \%$ & $3 \%$ & $4 \%$ & $5 \%$ & $1 \%$ & $2 \%$ & $3 \%$ & $4 \%$ & $5 \%$ \\
\hline Pf &
\end{tabular}




\begin{tabular}{|c|c|c|c|c|c|c|c|c|c|c|}
\hline 20 & $-^{*}$ & - & - & - & - & - & - & - & - & - \\
\hline 25 & - & - & - & - & - & - & - & - & - & - \\
\hline 30 & - & - & - & - & - & - & - & - & - & - \\
\hline 35 & 2.86 & 2.75 & 2.65 & 2.53 & 2.64 & 0.30 & 0.13 & 0.03 & 0.00 & 0.00 \\
\hline 40 & 1.82 & 1.74 & 1.59 & 1.44 & 1.30 & 0.00 & 0.00 & 0.00 & 0.00 & 0.00 \\
\hline
\end{tabular}

* Design speed of the circulatory roadway exceeds the allowable corresponding curve radius

Maximum lateral clearance, circulating vehicle, approach vehicle at yield line, $\mathrm{Rc}=20$ "Pf=1\%

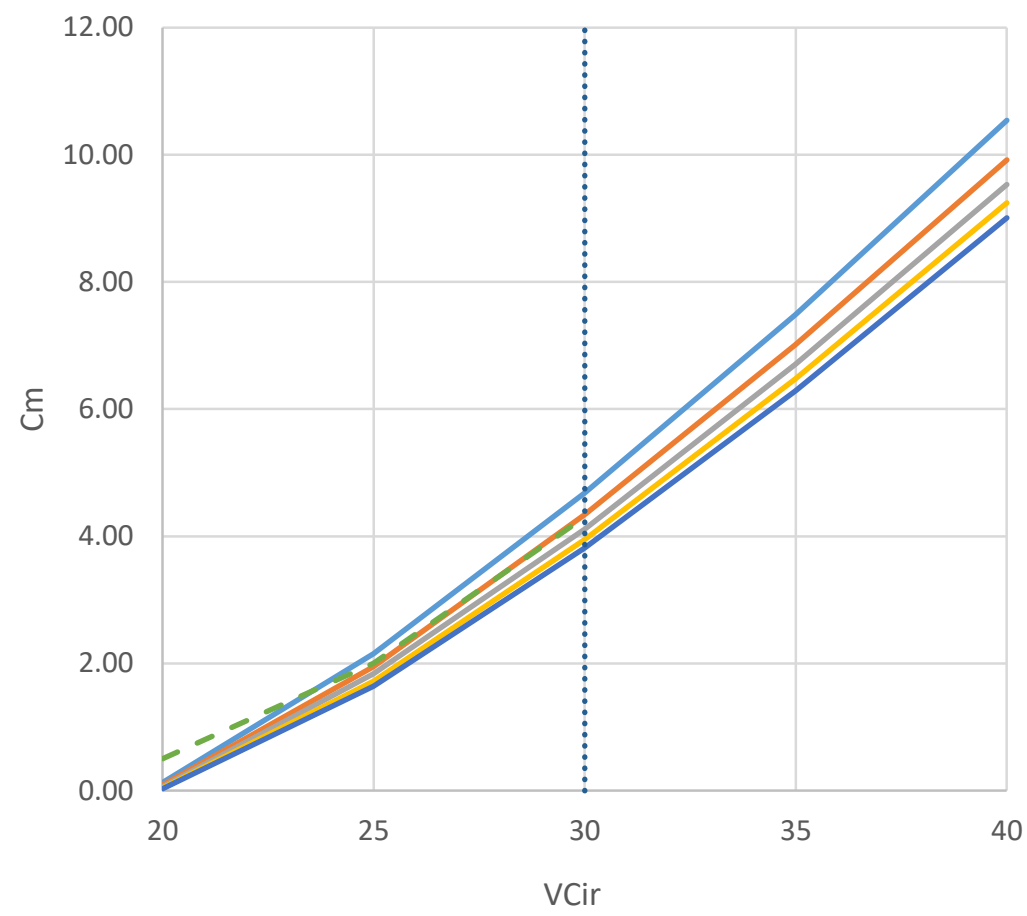

- - Deterministic (Easa et al.)

Design speed of the circulatory roadway exceeds that allowable for the corresponding curve radius

Figure 15: AFOSM Results, Maximum Lateral Clearance Results for Approach Vehicle at Yield Line, Circulating Vehicle, $R c=20$ 


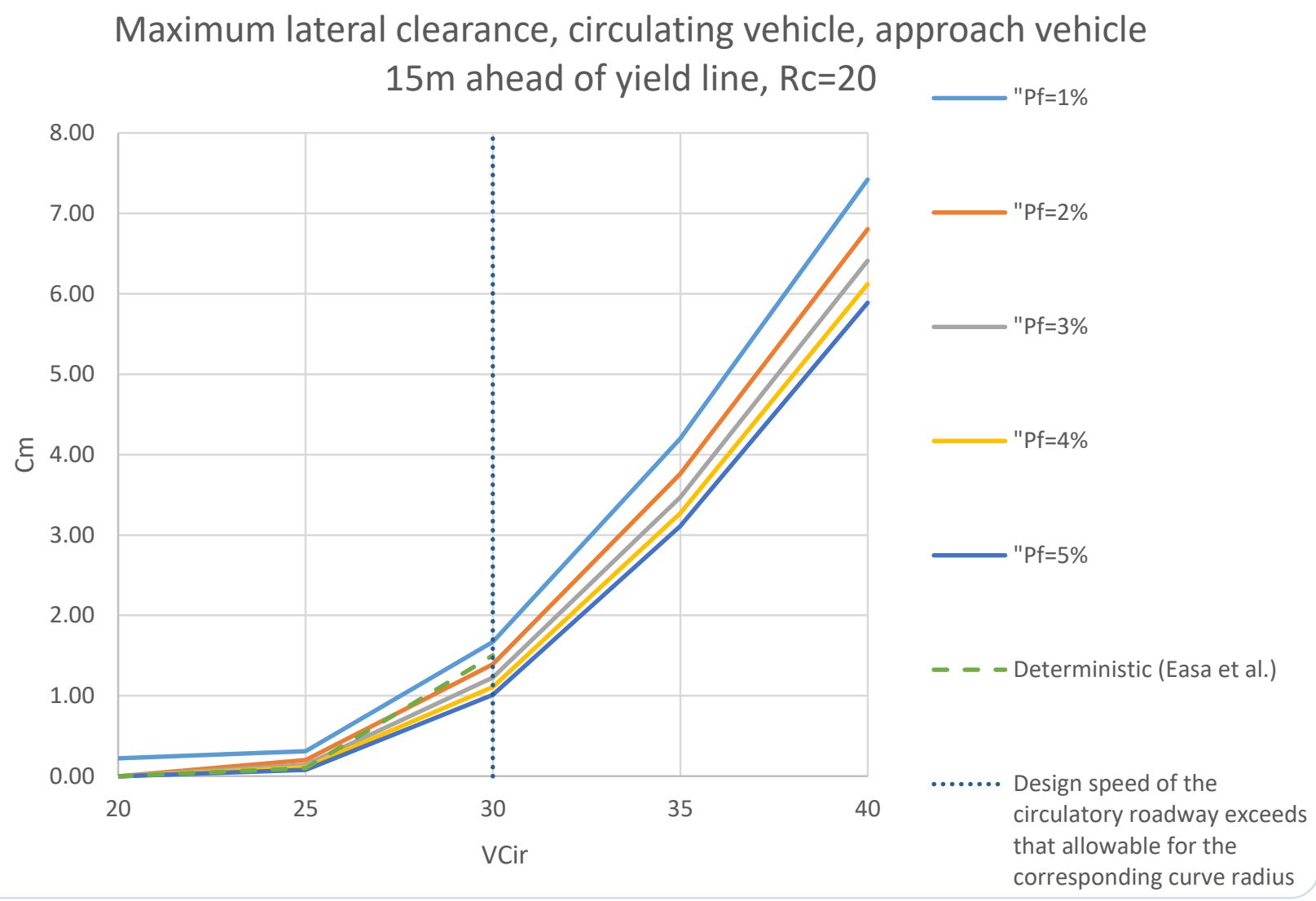

Figure 16: AFOSM Results, Maximum Lateral Clearance Results for Approach Vehicle 15m ahead of Yield Line, Circulating Vehicle, $R c=20$

\subsubsection{Entering vehicle $\left(D_{2}\right)$}

Table 22: AFOSM Results, Probabilistic Maximum Lateral Clearance for Entering Vehicle, $V_{\text {cir }}=25 \mathrm{Km} / \mathrm{h}, V_{\mathrm{Ent}}=30$ $\mathrm{Km} / \mathrm{h}$

\begin{tabular}{|c|c|c|c|c|c|c|c|c|c|c|}
\hline \multicolumn{11}{|c|}{ Vcir $=25 \mathrm{Km} / \mathrm{h}$, Vent $=30 \mathrm{Km} / \mathrm{h}$} \\
\hline \multirow{3}{*}{$\begin{array}{c}\text { Entering vehicle (D2) } \\
\text { Rc } \\
\mathrm{Pf}\end{array}$} & \multirow{2}{*}{\multicolumn{5}{|c|}{$\begin{array}{l}\text { Cm (Maximum Later } \\
\text { at yield }\end{array}$}} & \multirow{2}{*}{\multicolumn{5}{|c|}{ 15-m ahead }} \\
\hline & & & & & & & & & & \\
\hline & $1 \%$ & $2 \%$ & $3 \%$ & $4 \%$ & $5 \%$ & $1 \%$ & $2 \%$ & $3 \%$ & $4 \%$ & $5 \%$ \\
\hline 20 & 0.00 & 0.00 & 0.00 & 0.00 & 0.00 & 1.01 & 0.95 & 0.86 & 0.82 & 0.78 \\
\hline 25 & 0.00 & 0.00 & 0.00 & 0.00 & 0.00 & 0.03 & 0.02 & 0.01 & 0.01 & 0.01 \\
\hline
\end{tabular}




\begin{tabular}{|c|c|c|c|c|c|c|c|c|c|c|}
\hline 30 & 0.00 & 0.00 & 0.00 & 0.00 & 0.00 & 0.00 & 0.00 & 0.00 & 0.00 & 0.00 \\
\hline 35 & 0.00 & 0.00 & 0.00 & 0.00 & 0.00 & 0.00 & 0.00 & 0.00 & 0.00 & 0.00 \\
\hline 40 & 0.00 & 0.00 & 0.00 & 0.00 & 0.00 & 0.00 & 0.00 & 0.00 & 0.00 & 0.00 \\
\hline
\end{tabular}

Table 23: AFOSM Results, Probabilistic Maximum Lateral Clearance for Entering Vehicle, $V_{\text {cir }}=25 \mathrm{Km} / \mathrm{h}, V_{\text {Ent }}=35$ $\mathrm{Km} / \mathrm{h}$

\begin{tabular}{|c|c|c|c|c|c|c|c|c|c|c|}
\hline \multicolumn{10}{|c|}{ Vcir=25 Km/h, Vent=35 Km/h } \\
\hline Entering vehicle (D2 ) & \multicolumn{10}{|c|}{ Cm (Maximum Lateral Clearance), (m) } \\
\cline { 2 - 12 } & $1 \%$ & $2 \%$ & $3 \%$ & $4 \%$ & $5 \%$ & $1 \%$ & $2 \%$ & $3 \%$ & $4 \%$ & $5 \%$ \\
\hline $\mathbf{R C}$ & 0.01 & 0.00 & 0.00 & 0.00 & 0.00 & 1.36 & 1.31 & 1.26 & 1.20 & 1.15 \\
\hline $\mathbf{P f}$ & 0.00 & 0.00 & 0.00 & 0.00 & 0.00 & 0.03 & 0.03 & 0.02 & 0.02 & 0.01 \\
\hline 20 & 0.00 & 0.00 & 0.00 & 0.00 & 0.00 & 0.00 & 0.00 & 0.00 & 0.00 & 0.00 \\
\hline 25 & 0.00 & 0.00 & 0.00 & 0.00 & 0.00 & 0.00 & 0.00 & 0.00 & 0.00 & 0.00 \\
\hline 30 & 0.00 & 0.00 & 0.00 & 0.00 & 0.00 & 0.00 & 0.00 & 0.00 & 0.00 & 0.00 \\
\hline 35 & & 10.00 &
\end{tabular}

Table 24: AFOSM Results, Probabilistic Maximum Lateral Clearance for Entering Vehicle $V_{\text {cir }}=25 \mathrm{Km} / \mathrm{h}, V_{E n t}=40 \mathrm{Km} / \mathrm{h}$

\begin{tabular}{|c|c|c|c|c|c|c|c|c|c|c|}
\hline \multicolumn{11}{|c|}{ Vcir=25 Km/h, Vent $=40 \mathrm{Km} / \mathrm{h}$} \\
\hline \multirow{3}{*}{$\begin{array}{l}\text { Entering vehicle (D2) } \\
\text { Rc } \\
\text { Pf }\end{array}$} & \multicolumn{10}{|c|}{$\mathrm{Cm}$ (Maximum Lateral Clearance), (m) } \\
\hline & \multicolumn{5}{|c|}{ at yield } & \multicolumn{5}{|c|}{ 15-m ahead } \\
\hline & $1 \%$ & $2 \%$ & $3 \%$ & $4 \%$ & $5 \%$ & $1 \%$ & $2 \%$ & $3 \%$ & $4 \%$ & $5 \%$ \\
\hline 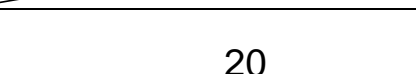 & $-^{*}$ & - & - & & 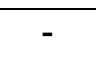 & - & & & & 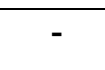 \\
\hline 25 & 0.00 & 0.00 & 0.00 & 0.00 & 0.00 & 0.05 & 0.04 & 0.04 & 0.03 & 0.03 \\
\hline 30 & 0.00 & 0.00 & 0.00 & 0.00 & 0.00 & 0.01 & 0.00 & 0.00 & 0.00 & 0.00 \\
\hline 35 & 0.00 & 0.00 & 0.00 & 0.00 & 0.00 & 0.00 & 0.00 & 0.00 & 0.00 & 0.00 \\
\hline 40 & 0.00 & 0.00 & 0.00 & 0.00 & 0.00 & 0.00 & 0.00 & 0.00 & 0.00 & 0.00 \\
\hline
\end{tabular}


Table 25: AFOSM Results, Probabilistic Maximum Lateral Clearance for Entering Vehicle, $V_{\text {cir }}=25 \mathrm{Km} / \mathrm{h}, V_{\text {Ent }}=45 \mathrm{Km} / \mathrm{h}$

\begin{tabular}{|c|c|c|c|c|c|c|c|c|c|c|}
\hline \multicolumn{11}{|c|}{ Vcir=25 Km/h, Vent=45 Km/h } \\
\hline \multirow{3}{*}{$\begin{array}{l}\text { Entering vehicle (D2) } \\
\text { Rc } \\
\text { Pf }\end{array}$} & \multicolumn{10}{|c|}{ Cm (Maximum Lateral Clearance), $(\mathrm{m})$} \\
\hline & \multicolumn{5}{|c|}{ at yield } & \multicolumn{5}{|c|}{ 15-m ahead } \\
\hline & $1 \%$ & $2 \%$ & $3 \%$ & $4 \%$ & $5 \%$ & $1 \%$ & $2 \%$ & $3 \%$ & $4 \%$ & $5 \%$ \\
\hline 20 & $-^{*}$ & - & - & - & - & - & - & - & - & - \\
\hline 25 & - & - & - & - & - & - & - & - & - & - \\
\hline 30 & 0.00 & 0.00 & 0.00 & 0.00 & 0.00 & 0.02 & 0.01 & 0.01 & 0.00 & 0.00 \\
\hline 35 & 0.00 & 0.00 & 0.00 & 0.00 & 0.00 & 0.00 & 0.00 & 0.00 & 0.00 & 0.00 \\
\hline 40 & 0.00 & 0.00 & 0.00 & 0.00 & 0.00 & 0.00 & 0.00 & 0.00 & 0.00 & 0.00 \\
\hline
\end{tabular}

* Design speed of the circulatory roadway exceeds the allowable corresponding curve radius

Maximum lateral clearance, entering vehicle, approach vehicle $15 \mathrm{~m}$ ahead of yield line, $\mathrm{Rc}=20$

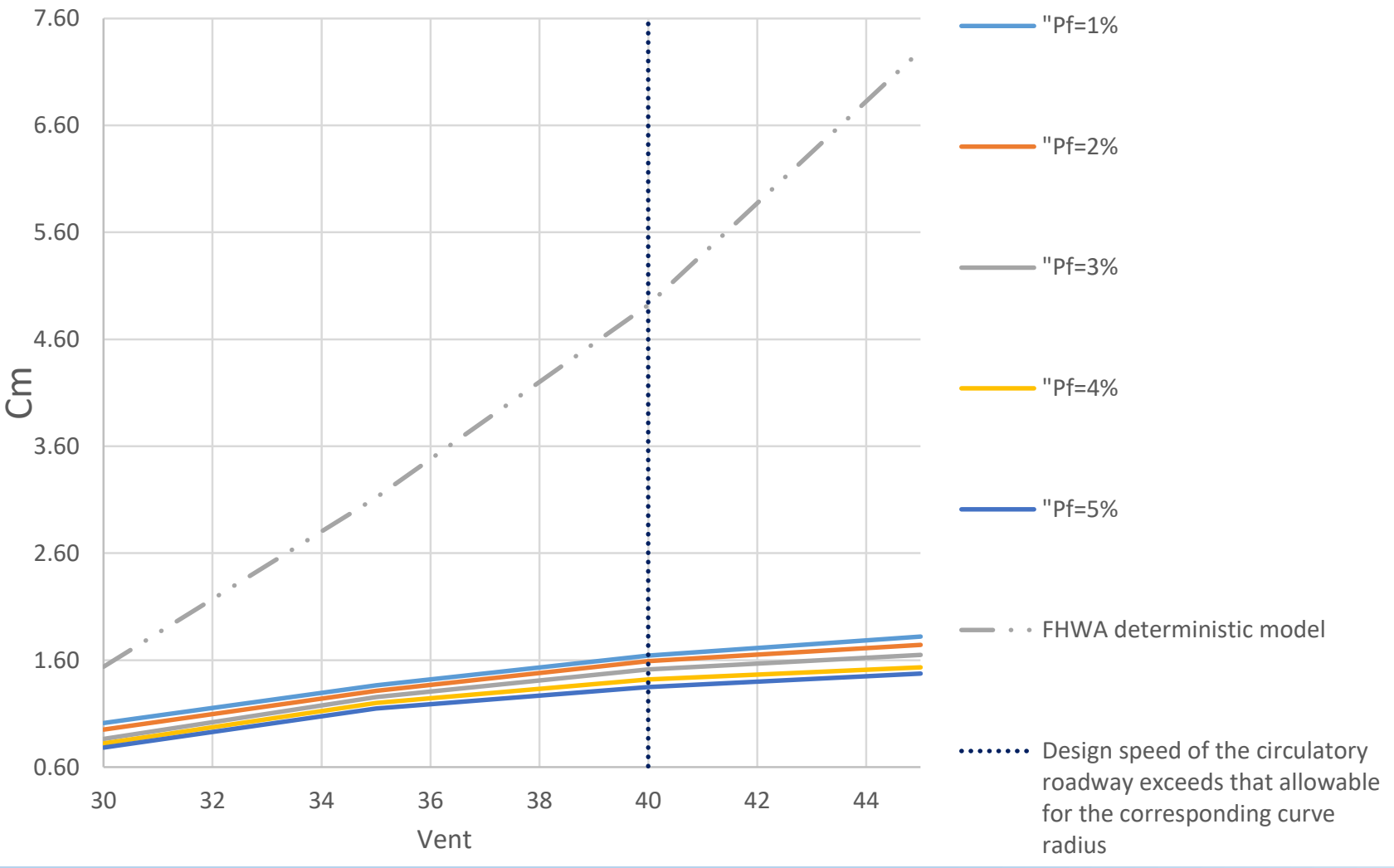

Figure 17: AFOSM Results, Maximum Lateral Clearance Results for Approach Vehicle 15m ahead of Yield Line, Entering Vehicle, $R c=20$ 


\subsection{Required Design Guidelines}

Few design elements such as the entry width and the distance between the driver's eye and the curb were assumed in the previous sections in order to be able to formulate the mathematical formulas using the available guidelines. The following table summarizes the mentioning assumptions (Easa, 2000).

Table 26: Required Design Elements (Rodegerdts et al., 2010)

\begin{tabular}{|l|c|}
\hline Design elements & Input data (Rodegerdts et al., 2010) \\
\hline Circulatory widths & $5 \mathrm{~m}$ \\
\hline Entry width & $5 \mathrm{~m}$ \\
\hline $\begin{array}{l}\text { Distance from the driver's eye of the } \\
\text { approach vehicle and the right curb }\end{array}$ & $2 \mathrm{~m}$ \\
\hline $\begin{array}{l}\text { Distance from the driver's eye of the } \\
\text { circulating vehicle and the curb of the central } \\
\text { island }\end{array}$ & $2 \mathrm{~m}$ \\
\hline $\begin{array}{l}\text { Distance from the curb to the centerline of the } \\
\text { road at the ends of the entry curve }\end{array}$ & $6 \mathrm{~m}$ \\
\hline $\begin{array}{l}\text { Crosswalk edge near the yield line from the } \\
\text { face of the splitter island }\end{array}$ & $6 \mathrm{~m}$ \\
\hline Crosswalk width & $3 \mathrm{~m}$ \\
\hline
\end{tabular}




\section{VALIDATION}

In this section the validation of the proposed model will be controlled graphically for both FOSM and AFOSM method through an application example.

Application example:

Consider a symmetrical single-lane roundabout with an inscribed circle radius of $25 \mathrm{~m}$, an entering speed of $25 \mathrm{~km} / \mathrm{h}$, and a circulating speed equal to $30 \mathrm{~km} / \mathrm{h}$. Assuming that circulatory width is equal to the entry width equal to $5 \mathrm{~m}, \mathrm{Lmin}$ is $15 \mathrm{~m}$, and both the distance from the driver's eye of the approach vehicle and the right curb and the distance from the driver's eye of the circulating vehicle and the curb of the central island are equal to $2 \mathrm{~m}$. For a coefficient of variation equal to 10 percent, correlation coefficient of +0.5 between $V_{E n t}$ and $d_{d}$ and a coefficient of -0.5 between $V_{\text {Cir }}$ and $d_{d}$, and a probability of failure equal to $2 \%$ maximum lateral clearance for both FOSM and AFOSM can be obtained from tables $9,13,18,22$. Following table summarizes the results.

Table 27: Summary of Results

\begin{tabular}{|c|c|c|}
\hline \multicolumn{3}{|c|}{ Vcir=25 Km/h, Vent=30 Km/h, Rc =25m, Pf=2\% } \\
\hline & \multicolumn{2}{|c|}{$\begin{array}{l}\text { Cm (Maximum Lateral Clearance) } \\
(\mathrm{m})\end{array}$} \\
\hline & at yield & 15-m ahead \\
\hline \multicolumn{3}{|l|}{ FOSM } \\
\hline Circulating vehicle (D1) & 0.87 & 0.00 \\
\hline Entering vehicle (D2) & 0.00 & 0.01 \\
\hline \multicolumn{3}{|l|}{ AFOSM } \\
\hline Circulating vehicle (D1) & 0.86 & 0.00 \\
\hline
\end{tabular}




\begin{tabular}{|l|l|l|}
\hline Entering vehicle (D2 ) & 0.00 & 0.02 \\
\hline
\end{tabular}

Following figures illustrate the results for the given example.

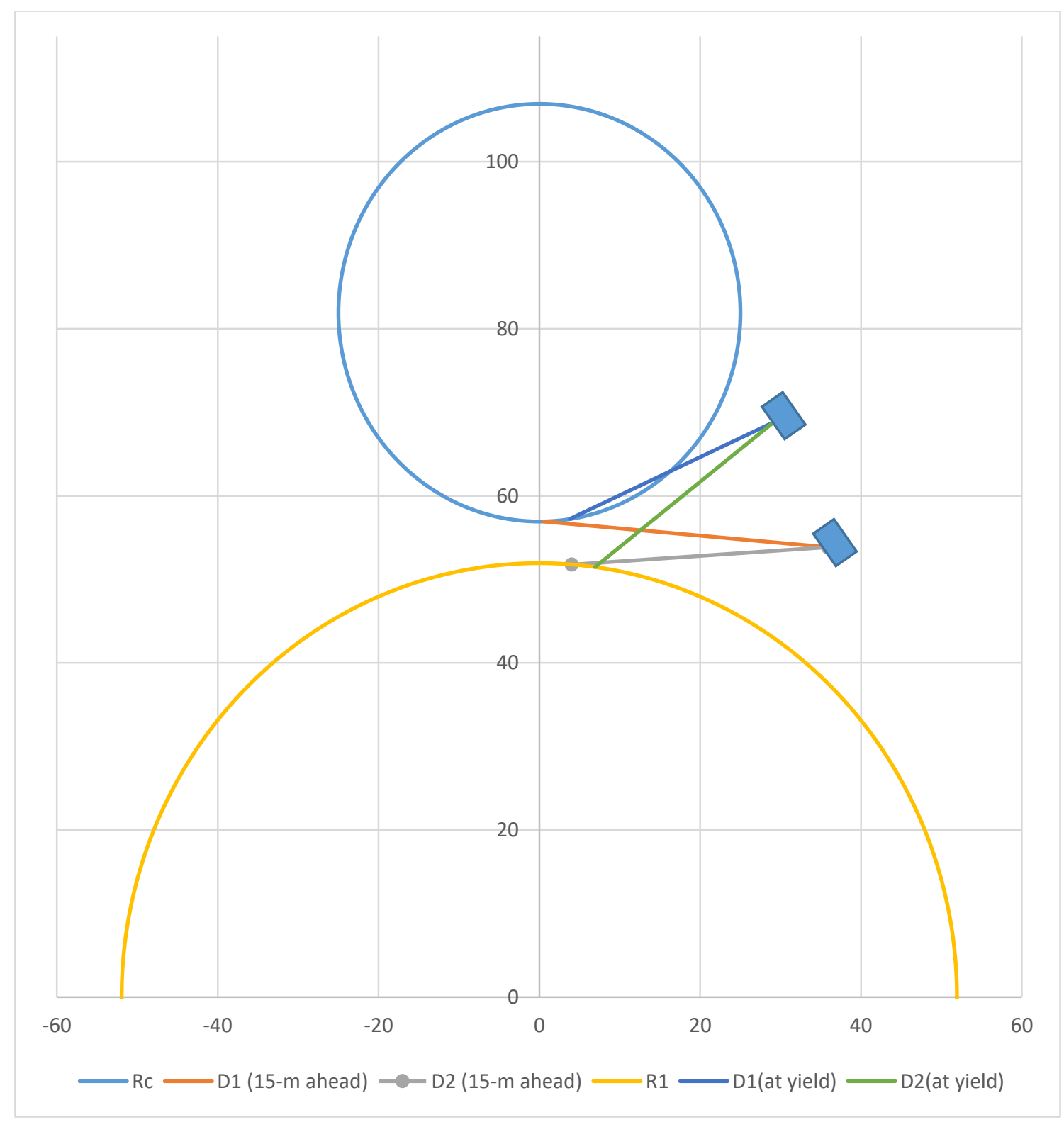

Figure 18: FOSM Graphical Validation 


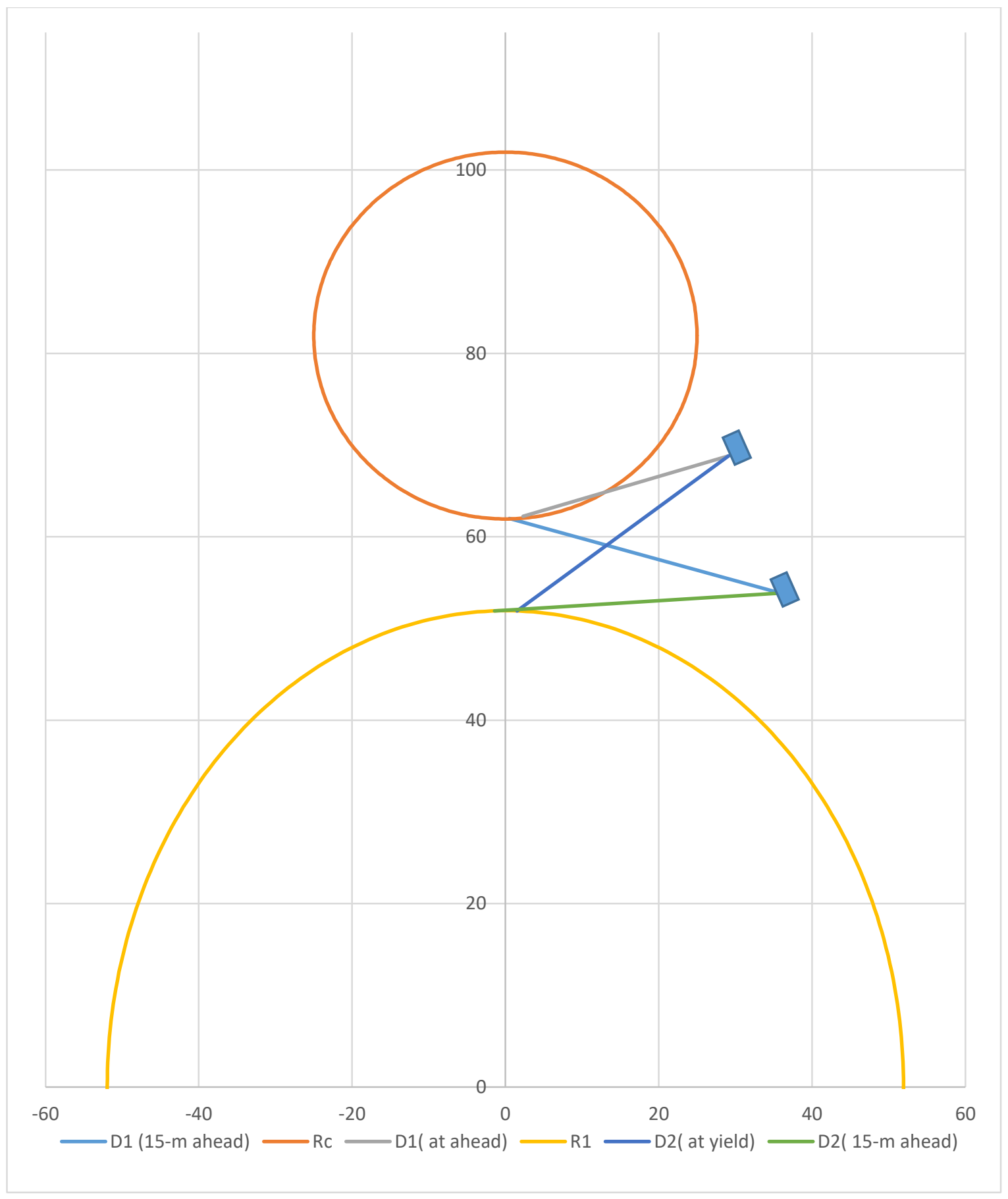

Figure 19: AFOSM Graphical Validation 


\section{CONCLUSION}

This study was mainly focused on adding risk and uncertainty to the previous deterministic models of intersection sight distance (ISD) on a single-lane roundabout as there is a randomness in the nature of the geometric design inputs. Thereby, two different probabilistic applications i.e. FOSM and AFOSM were used to compare the deterministic and probabilistic results. The maximum lateral clearance $\left(\mathrm{C}_{\mathrm{m}}\right)$ is the required clear sight zone for the drivers of a conflicting stream in order to detect the conflicting vehicle, react, and avoid a crash which depends on the required ISD. In this paper, $\mathrm{Cm}_{\mathrm{m}}$ was formulated and optimized using mathematical approaches for two different cases i.e. approach vehicle at yield line and approach vehicle 15 meters ahead of yield line. In this chapter, the outcome of the performed reliability analyses will be compared with the current deterministic results and further recommendations and conclusions will be provided.

Based on the results provided in the previous chapter following conclusions can be determined

1. The level of uncertainty and variability of the design inputs can affect the outcome as we can see the difference of the results with a change in the required probability of failure values.

2. Comparing the results of FOSM and AFOSM, it can be concluded that even though the results of the two somewhat agree with each other they have slight differences. The differences between the two methods are efficiency related. In other words, slightly larger outcomes resulted from AFOSM methodology shows the more 
comprehensive nature of this method and the lower FOSM values comparing to their deterministic counterparts determines a higher efficiency of this method considering a lesser safety factor.

3. The current deterministic results are more conservative for lower entering and circulating speeds and too low for the higher speeds.

4. Since AFOSM values are slightly higher than FOSM results, therefore, it is recommended to use the AFOSM results in practice for safety reasons and to reach a more conservative design.

5. It is obvious that higher probability of failure will yield a shorter required ISD. As we can see from the tables the results are in accordance with the expectations. In other words, the required maximum lateral clearance values drop as the probability of failure increases.

6. During this study, few assumptions and extreme values were used due to the lack of available database. For future studies, a further research and completion of valid database is highly recommended related to the circulating speed, entering speed, critical headway, and the deceleration rate. In other words, having a greater available database will increase the amount of input data which will add more dynamic and probability to the calculations based on real practical data. Consequently, a more detailed reliability analysis will be performed with more reliable final results. Hence, it is recommended to design ISD based on a lower probability of failure preferably less than $5 \%$ as the change in the length of maximum lateral clearance can significantly affect the reliability of the design. 
7. Reliability analysis approach is not limited to the two different methods that were undertaken in this study. In fact, both FOSM and AFOSM have shown to work efficiently only with the normally distributed random variables and where correlation between the variables is negligible. Therefore, it is recommended for future studies to consider other methods of reliability analysis such as FORM ellipsoid approach developed by Low and Tang (2007) to resolve the shortcomings of FOSM and AFOSM.

8. As mentioned earlier, the revised model was developed to resolve the issue with the current design guidelines which consider $V_{E n t}$ for the entire distance of D2 or the required intersection sight distance for the entering stream. Figure 14 and 17 illustrate a comparison between the results obtained from current guidelines and the revised model results. Obviously, the revised model provides more efficient results rather than the FHWA values that consider a high speed of $V_{\text {Ent }}$ for the entire distance. However, the higher the entry speed and the closer it is to the entering speed this difference will become smaller and for the case of $V_{E n t}=V_{\text {Cir }}$ the same results as the guideline values are expected. 


\section{APPENDIX}

Sample calculations

FOSM for Circulating Vehicle:

$$
\begin{gathered}
F=I S D_{a}-I S D_{r} \\
E[F]=E\left[I S D_{a}\right]-E\left[I S D_{r}\right] \text { and } \operatorname{Var}[F]=\operatorname{Var}\left[I S D_{a}\right]+\operatorname{Var}\left[I S D_{r}\right]
\end{gathered}
$$

Where

$$
\begin{gathered}
\beta=\mathrm{E}[\mathrm{F}] / \sigma_{F} \\
\text { and } \\
\sigma_{F}=\sqrt{\operatorname{Var}[F]} \\
\operatorname{Var}[F]=\sum_{i=1}^{n}\left(\frac{\partial g\left(\mu_{x}\right)}{\partial x_{i}}\right)^{2} \partial^{2} x_{i}+\sum_{i}^{n} \sum_{j}^{n}\left(\frac{\partial g\left(\mu_{x}\right)}{\partial x_{i}}\right)\left(\frac{\partial g\left(\mu_{x}\right)}{\partial x_{j}}\right) \operatorname{cov}\left[x_{i}, x_{j}\right] \\
\operatorname{Var}[F]=\operatorname{Var}\left[D_{1}\right]=\left(\partial D_{1} / \partial V_{C i r}\right)^{2} \partial V_{C i r}{ }^{2}+\left(\partial D_{1} / \partial t_{C}\right)^{2} \partial t_{C}{ }^{2}
\end{gathered}
$$

Where

$$
\begin{aligned}
& \partial D_{1} / \partial V_{C i r}=0.278 t_{c} \\
& \partial D_{1} / \partial t_{c}=0.278 V_{C i r}
\end{aligned}
$$

For given data sample calculations will be performed, $\beta=2.33$ 


\begin{tabular}{|c|c|c|c|c|c|}
\hline Random variable & Extreme value & CV & Z-value & Mean value & SD \\
\hline tc & $5 \mathrm{~s}$ & 0.01 & 2.58 & 4.87 & 0.05 \\
\hline Vcir(single-lane) & $35 \mathrm{Km} / \mathrm{h}$ & 0.1 & 1.64 & 30.07 & 3.01 \\
\hline
\end{tabular}

$$
\begin{gathered}
\partial D_{1} / \partial V_{C i r}=0.278 \times 4.87=1.354 \\
\partial D_{1} / \partial t_{c}=0.278 \times 30.07=8.359 \\
\operatorname{Var}[F]=\operatorname{Var}\left[D_{1}\right]=(1.354)^{2}(3.01)^{2}+(8.359)^{2}(0.05)^{2}=16.76701 \\
\sigma_{F}=\sqrt{\operatorname{Var}[F]}=4.094754 \\
I S D_{a}=E\left[I S D_{r}\right]+\beta \sigma_{F}=0.278 \times 4.87 \times 30.07+2.33 \times 4.094754=50.28 m
\end{gathered}
$$

\section{AFOSM for Circulating Vehicle:}

Transforming the variables into u-space assuming the random variables are normally distributed.

$$
u=\left(V_{C i r}, t_{C}\right)=\left(\mu_{V_{C i r}}+u_{V_{C i r}} \sigma_{V_{C i r}}, \mu_{t_{C}}+u_{t_{C}} \sigma_{t_{C}}\right)
$$

Therefore transformation function in u-space becomes:

$$
H(Y)=F_{D_{1}}=I S D_{a}-0.278\left(\mu_{V_{C i r}}+u_{V_{\text {Cir }}} \sigma_{V_{\text {Cir }}}\right)\left(\mu_{t_{C}}+u_{t_{C}} \sigma_{t_{C}}\right)
$$




$$
\begin{gathered}
\text { and } \\
\sigma_{F}=\sqrt{\sum\left(H_{i}^{\prime}\right)^{2}}
\end{gathered}
$$

Where

$$
\begin{gathered}
H_{1}^{\prime}=\frac{\partial F_{D_{1}}}{\partial u_{V_{C i r}}}=-0.278\left(\mu_{t_{C}}+u_{t_{C}} \sigma_{t_{C}}\right) \sigma_{V_{\text {Cir }}} \\
H_{2}^{\prime}=\frac{\partial F_{D_{1}}}{\partial u_{t_{C}}}=-0.278\left(\mu_{V_{C i r}}+u_{V_{C i r}} \sigma_{V_{C i r}}\right) \sigma_{t_{C}}
\end{gathered}
$$

For the first iteration it is assumed that $Y_{i}=u_{V_{C i r}}=u_{t_{C}}=\beta=0$ and ISDa is assumed to have the value of 50 meters.

For given data sample calculations will be performed, $\beta=2.33$

\begin{tabular}{|c|c|c|c|c|c|}
\hline Random variable & Extreme value & CV & Z-value & value & SD \\
\hline tc & $5 \mathrm{~s}$ & 0.01 & 2.58 & 4.87 & 0.05 \\
\hline Vcir(single-lane) & $35 \mathrm{Km} / \mathrm{h}$ & 0.1 & 1.64 & 30.07 & 3.01 \\
\hline
\end{tabular}

$$
\begin{gathered}
H(Y)=F_{D_{1}}=50-0.278 \times(30.07+0 \times 3.01) \times(4.87+0 \times 0.05)=9.26 \\
H_{1}^{\prime}=\frac{\partial F_{D_{1}}}{\partial u_{V_{\text {Cir }}}}=-0.278 \times(4.87+0 \times 0.05) \times 3.01=-4.07 \\
H_{2}^{\prime}=\frac{\partial F_{D_{1}}}{\partial u_{t_{C}}}=-0.278 \times(30.07+0 \times 3.01) \times 0.05=-0.41
\end{gathered}
$$




$$
\sigma_{F}=\sqrt{\sum\left(H_{i}^{\prime}\right)^{2}}=\sqrt{(-4.07)^{2}+(-0.41)^{2}}=4.09
$$

For the next iteration:

$$
\begin{gathered}
Y_{i}=-\frac{H_{i}^{\prime}}{\sigma_{F}}\left[\beta+\frac{H(Y)}{\sigma_{F}}\right] \\
Y_{1}=-\frac{(-4.07)}{4.09} \times\left[0+\frac{9.26}{4.09}\right]=2.249 \\
Y_{2}=-\frac{(-0.41)}{4.09} \times\left[0+\frac{9.26}{4.09}\right]=0.225
\end{gathered}
$$

The new value for $\beta$ can be calculated using the following equation.

$$
\begin{gathered}
\beta=\sqrt{\sum\left(Y_{i}\right)^{2}} \\
\beta=\sqrt{(2.249)^{2}+(0.225)^{2}}=2.26
\end{gathered}
$$

\begin{tabular}{|c|c|c|c|c|c|c|c|}
\hline Iteration\# & $\mathrm{Y} 1$ (vcir) & $\mathrm{Y} 2(\mathrm{tc})$ & Beta & $\mathrm{H}(\mathrm{y})$ & $\mathrm{H}^{\prime} 1$ & $\mathrm{H}^{\prime} 2$ & $\sigma_{F}$ \\
\hline 1 & 0 & 0 & 0 & 9.26 & -4.07 & -0.41 & 4.09 \\
\hline 2 & 2.249 & 0.225 & 2.26 & -0.02 & -4.08 & -0.50 & 4.11 \\
\hline 3 & 2.239 & 0.274 & 2.26 & 0.00 & -4.09 & -0.50 & 4.12 \\
\hline 4 & 2.238 & 0.273 & 2.25 & 0.00 & -4.09 & -0.50 & 4.12 \\
\hline
\end{tabular}


As previously mentioned for the desired probability of failure $\left(\mathrm{P}_{\mathrm{f}}\right)$ a corresponding $\beta$ value can be calculated as shown in the following table.

\begin{tabular}{|l|l|}
\hline $\begin{array}{l}\text { Probability of Failure, } \\
\text { Pf }\end{array}$ & Reliability Index, \\
\hline $1 \%$ & 2.33 \\
\hline $2 \%$ & 2.06 \\
\hline $3 \%$ & 1.88 \\
\hline $4 \%$ & 1.75 \\
\hline $5 \%$ & 1.64 \\
\hline
\end{tabular}

Therefore, to reach the desired probability of failure the estimated value of $I S D_{a}$ should be optimized using the Excel Solver so that the model converges to the desired reliability index value. In the case of $\beta=2.33$, Excel Solver found a value of $50.31 \mathrm{~m}$ for $I S D_{a}$. The following figure depicts a snapshot of Solver's window for given sample calculations.

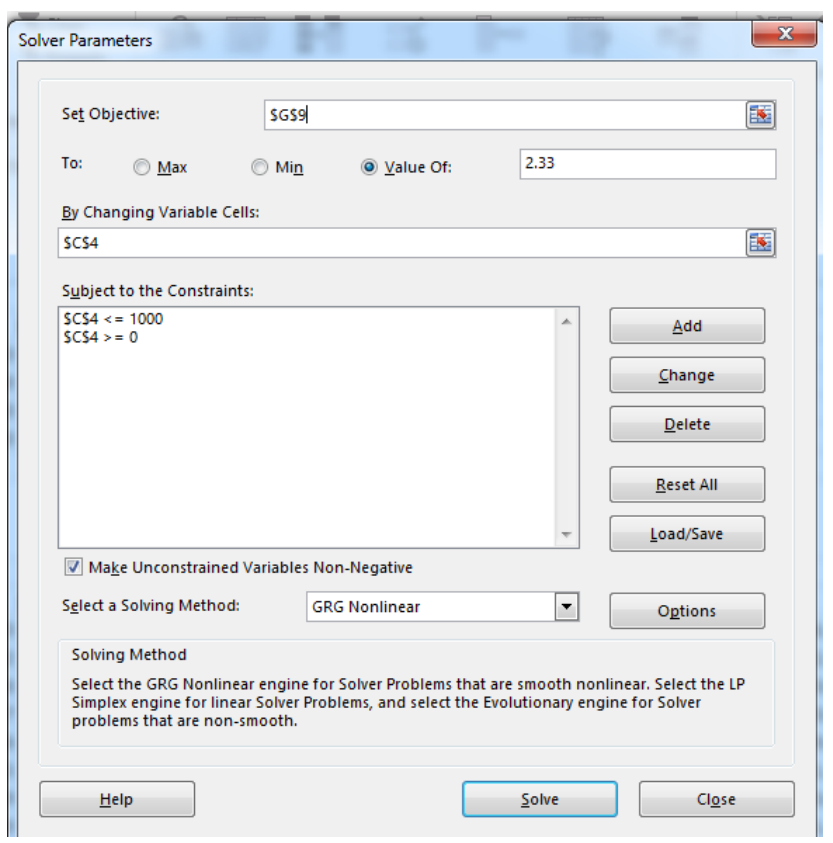




\section{BIBLIOGRAPHY}

AZARKHAIL et al., M. (2012). The Evolution and History of Reliability Engineering: Rise. International Journal of Performability Engineering, Vol. 8, No. 1, January 2012, pp. 35-47. Retrieved from http://paris.utdallas.edu/lJPE/Vol08/Issue01/pp.3547\%20Paper\%203.pdf

CHUNGUANG et al., L. (2000). RELIABILITY ANALYSIS OF URBAN TRANSPORTATION SYSTEM. Retrieved from https://www.iitk.ac.in/nicee/wcee/article/0236.pdf

DENOEL, V. (2017). An introduction to Reliability Analysis. University of Liege, ArGEnCo, MS2F,Departement of Architecture, Geology, Environment and Construction-Solid, Structures and Fluid Mechanics Division -. Retrieved from https://orbi.uliege.be/bitstream/2268/164363/1/An\%20Introduction\%20To\%20Reli ability\%20Analysis\%20DENOEL.pdf

DRDNI. (2007). GEOMETRIC DESIGN OF ROUNDABOUTS Volume 6, Section 2, Part 3 TD16/07, Belfast, Northern Ireland. Departmentfor Regional Development Nothern Ireland. Retrieved from http://www.standardsforhighways.co.uk/ha/standards/dmrb/vol6/section2/td1607. pdf 
Du, X. (2005). First Order and Second Reliability Methods. In Probabilistic Engineering Design. University of Missouri - Rolla. Retrieved from http://web.mst.edu/ dux/repository/me360/ch7.pdf

Easa. (2000). Reliability Approach to Intersection Sight Distance Design. Transportation Research Record Journal of the Transportation Research Board 1701(1):42-52. doi:https://doi.org/10.3141/1701-06

Easa. (2000). Reliability Approach to Intersection Sight Distance Design. Transportation Research Record Journal of the Transportation Research Board 1701(1):42-52. doi:https://doi.org/10.3141/1701-06

Easa. (2017). DESIGN GUIDELINES FOR SYMMETRICAL SINGLE-LANE ROUNDABOUTS. Transportation engineering journal of ASCE 143(10). doi:DOI: 10.1061/JTEPBS.0000081

FAGHRI et al., A. (1988). Reliability and Risk Assessment in the Prediction of Hazards at Rail-Highway Grade Crossings. TRANSPORTATION RESEARCH RECORD 1160. Retrieved from http://onlinepubs.trb.org/Onlinepubs/trr/1988/1160/1160006.pdf

Felipe , E. (1996). Reliability-based designs for highway horizontal curve. Retrieved from https://open.library.ubc.ca/clRcle/collections/ubctheses/831/items/1.0050374

FHWA. (2000). Rounabouts: An informational guide. Retrieved from https://www.fhwa.dot.gov/publications/research/safety/00067/000676.pdf 
GQ. (2013). Road planning and design manual. Chapter 14: Roundabouts, Department of Transport and Main Roads, Queensland, Australia. Retrieved from file://C:/Users/user/Downloads/RPDM_Chapter14.pdf

Greto, K. A. (2016). Reliability analysis of truck escape ramp design.

Hildebrand, A. (2009). Introduction to Probability:Variance, covariance, correlation, moment-generating functions. Retrieved from https://faculty.math.illinois.edu/ hildebr/461/variance.pdf

Hussain et al., A. (2015). Reliability Analysis of Left-Turn Sight Distance at Signalized Intersections. Journal of Transportation Engineering.

Inman, V. W. (2007). Synthesis of Literature Relevant to Roundabout Signalization to Provide Pedestrian Access. Retrieved from https://www.researchgate.net/publication/237431901_Synthesis_of_Literature_R elevant_to_Roundabout_Signalization_to_Provide_Pedestrian_Access

Ismail et al., K. (2009). Risk-based framework for accommodating uncertainty in highway geometric design. Canadian Journal of Civil Engineering, 36(5): 743753. doi:https://doi.org/10.1139/L08-146

Meth, G. (2013). Traffic Circles \& Roundabouts - Expert Article. Retrieved from https://www.robsonforensic.com/articles/traffic-circles-roundabouts-expert-article

Novak et al., J. (2018). How Roundabout Entry Design Parameters Influence Safety. Jornal of the transportation research board. doi:https://doiorg.ezproxy.lib.ryerson.ca/10.1177/0361198118776159 
Rodegerdts et al., L. (2010). Roundabouts: An informational guide. National Cooperative Highway Research Program Report 672. Transportation Research Board. Retrieved from https://nacto.org/docs/usdg/nchrprpt672.pdf

Serrano, A. (2018). ANALYSIS OF PASSING SIGHT DISTANCE USING FIRSTORDER RELIABILITY METHOD.

Smith, G. (1986). Probability and Statistics in Civil Engineering: An Introduction. Nichols Pub.co.

TAC.(2017b). (n.d.). Primer on Roundabouts in Canada. Retrieved from http://www.tacatc.ca/sites/default/files/site/doc/Bookstore/primer_-_january_2017.pdf

Thompson, H. (2009). Safety improvements at roundabouts in Britain. Institute of Transportation Engineers.

WSDOT. (2017). WSDOT Design Manual: Roundabouts, Chapter 1320. Retrieved from http://www.wsdot.wa.gov/publications/manuals/fulltext/M22-01/1320.pdf

WSDOT. (2019). Retrieved from Roundabout benefits:

https://www.wsdot.wa.gov/Safety/roundabouts/benefits.htm 